\title{
MODELING FISCHER-TROPSCH PRODUCT DISTRIBUTION OF A COBALT BASED CATALYST IN DIFFERENT REACTION MEDIA
}

\author{
A Thesis \\ by \\ SHAIK AFZAL \\ Submitted to the Office of Graduate and Professional Studies of \\ Texas A\&M University \\ in partial fulfillment of the requirements for the degree of \\ MASTER OF SCIENCE
}

Chair of Committee, Nimir O. Elbashir

Committee Members, Marcelo Castier Hazem Nounou

Head of Department, M. Nazmul Karim

August 2015

Major Subject: Chemical Engineering

Copyright 2015 Shaik Afzal 


\begin{abstract}
This work discusses the modeling of hydrocarbon product distribution up to carbon number 15 of a cobalt-based catalyst under Fischer-Tropsch (FT) synthesis conditions. The proposed kinetics of the reaction has been adapted from Todic et al. In the first part of the study, a Genetic Algorithm code in MATLAB ${ }^{\circledR}$ was developed to generate parameters of the 19-parameter kinetic model. In the next part of the work, an experimental campaign was conducted in a high pressure FT reactor unit to verify the model predictability of the cobalt catalyst product profile in gas phase. The results in terms of conversion and hydrocarbon product formations were reported. Less than $12 \% \mathrm{CO}$ conversion was maintained in all 7 runs in order to ensure that the reaction was occurring in the kinetic regime. After the peak identification and analysis, the experimental data was input into the developed MATLAB ${ }^{\circ}$ code to estimate model parameters. This model estimates the FT product distribution in the gas phase media with a mean absolute relative residual (MARR) of $48.44 \%$. This is higher than that obtained by Todic et al. The higher error is attributed to the fewer number of experimental runs carried out and due to some assumptions made in product characterization. This work lays the foundation for future work towards investigations of FT product distribution in the presence of a supercritical solvent to bring the reaction media to near critical and supercritical phase conditions.
\end{abstract}




\section{DEDICATION}

Dedicated to my family 


\section{ACKNOWLEDGMENTS}

In the name of God, Most Gracious, Most Merciful.

I would like to thank my committee chair, Dr. Nimir Elbashir for his consistent and unwavering support throughout the course of this research. I thank my committee members, Dr. Hazem Nounou, Dr. Marcelo Castier for their guidance and support during the course of this research.

Thanks also go to my friends and colleagues and the department faculty and staff for making my time at Texas A\&M University at Qatar a great experience. I also want to extend my gratitude to Jan Blank and Rehan Hussain for being there always to answer my questions. Lastly but not the least I want to thank my dad, Ilyas, my mum, Anjum, my sister, Ayesha and my wife, Wafa for their love and support throughout the period of my study. 


\section{NOMENCLATURE}

$\alpha$

c

$\mathrm{n}$

r

$\mathrm{k}$

K

S

$\mathrm{P}_{\mathrm{i}}$

$\mathrm{T}$

A

$\mathrm{R}$

$\Delta \mathrm{E}$

$\Delta \mathrm{H}$

MARR probability of chain growth

constant c, $-\Delta \mathrm{E} / \mathrm{RT}$

nth carbon number

rate of reaction

Arrhenius rate constant

equilibrium constant

fraction of vacant sites at catalyst surface

partial pressure of $i^{\text {th }}$ component

absolute temperature, $\mathrm{K}$

pre-exponential factor in Arrhenius rate equation

universal gas constant, $8.314 \mathrm{~J} / \mathrm{K} / \mathrm{mol}$

activation energy

heat of reaction / adsorption (as applicable)

mean absolute relative residual 


\section{TABLE OF CONTENTS}

Page

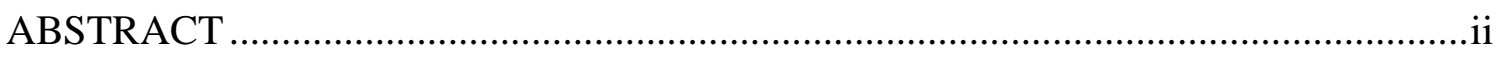

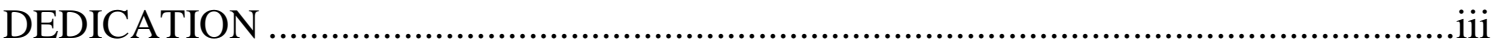

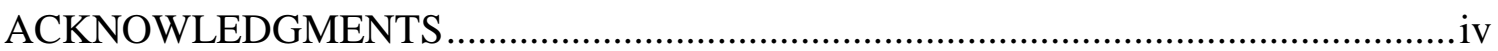

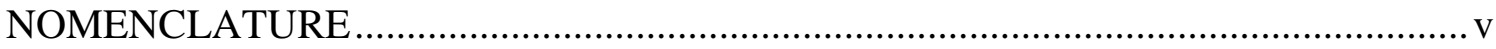

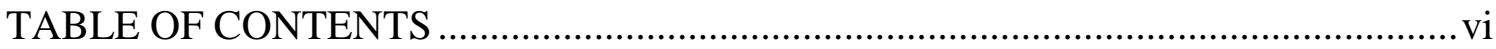

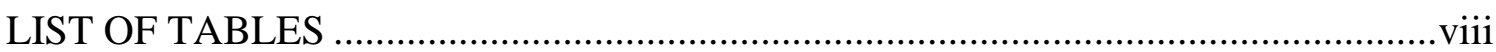

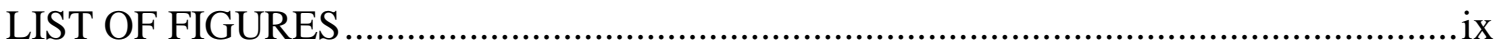

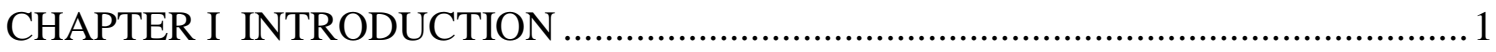

1.1 Fischer Tropsch chemistry and the utilization of supercritical fluids in GTL

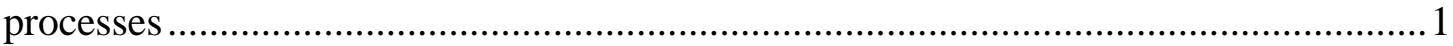

1.2 Background of modeling Fischer-Tropsch reactors ........................................

CHAPTER II RESEARCH OBJECTIVE ........................................................... 15

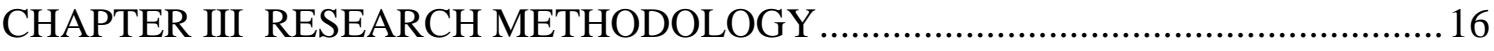

3.1 Development of a kinetic model with focus on product distribution .................... 17

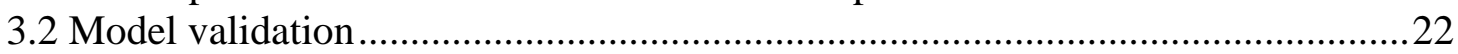

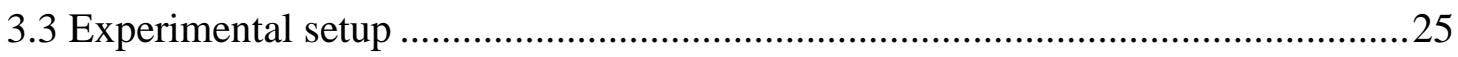

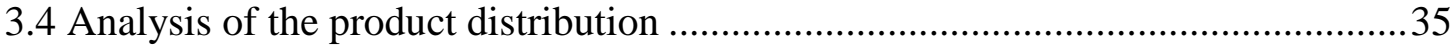

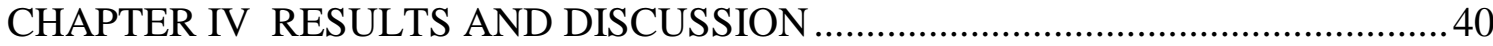

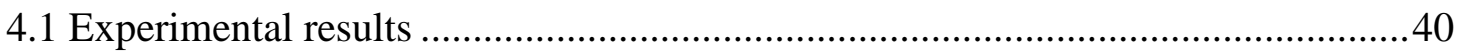

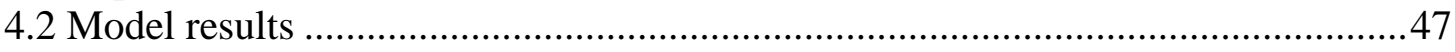

CHAPTER V CONCLUSION \& FUTURE WORK ..............................................53

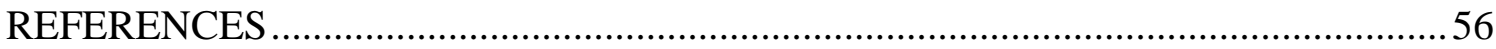

APPENDIX A REACTOR DATA ANALYSIS CALCULATIONS ...........................6 63 
APPENDIX C DATA ANALYSIS RESULTS FOR ALL RUNS

.71 


\section{LIST OF TABLES}

Page

Table 1 - Reaction Pathway of Carbide Mechanism from Todic et al [39].................... 18

Table 2 - Input Range for Model Parameters [39] ....................................................21

Table 3 - Comparison of GA Results with Parameters determined by Todic et al [39]..23

Table 4 - Experimental Conditions planned for Kinetic Study ..................................34

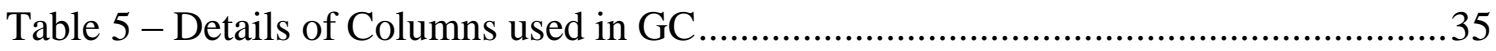

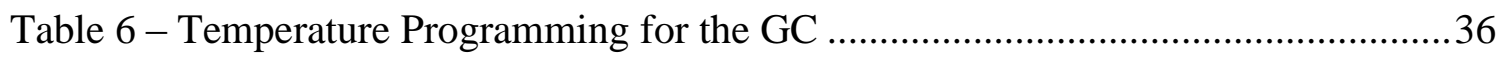

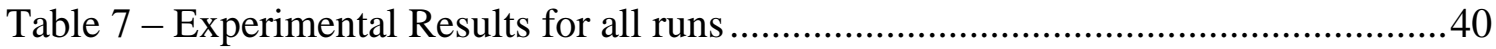

Table 8 - Model Results............................................................................... 48 


\section{LIST OF FIGURES}

Figure 1 - Chain Growth Probability in FT ..........................................................

Figure 2 - Typical ASF Hydrocarbon Product Distribution ......................................4

Figure 3 - Non Ideal FT Product Distribution..........................................................

Figure 4 - Proposed Methodology for Research into FT in SCF Phase ....................... 16

Figure 5 - Validation of Genetic Algorithm Code ............................................25

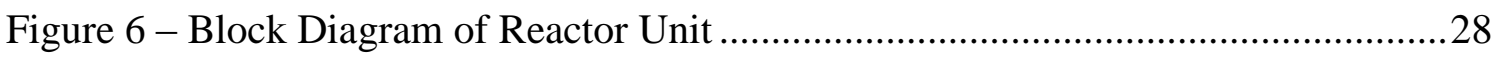

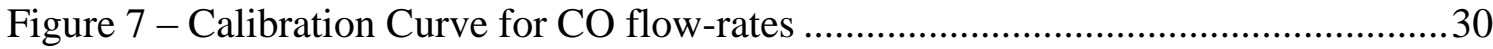

Figure 8 - Calibration Charts for $\mathrm{CO}$, Syngas and $\mathrm{H}_{2}$ Flow Controllers......................... 31

Figure 9 - Column Oven Temperature Program ................................................. 36

Figure 11 - Identification of Olefin Peaks .......................................................... 38

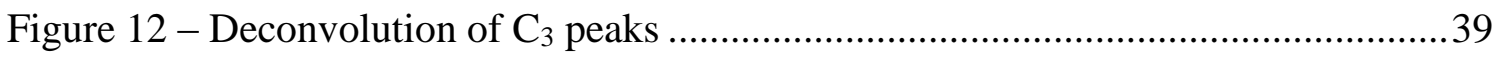

Figure 13 - CO Conversion $\%$ with time-on-stream.............................................43

Figure $14-\mathrm{CO}_{2}$ Selectivity with time-on-stream ...............................................43

Figure $15-\mathrm{CH}_{4}$ Selectivity with time-on-stream ............................................. 44

Figure 16 - Peak Area with Carbon Number for Run No. 3 ......................................45

Figure 17 - Hydrocarbon Formation Rates with Carbon Number for Run No. $3 \ldots \ldots \ldots . . .46$

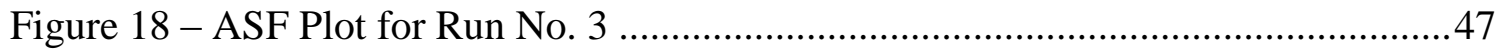

Figure 19 - Olefin-to-Paraffin Ratio with Carbon Number for Run No. 3 ....................47

Figure 20 - Comparison of Experimental and Model Results ....................................50 


\section{CHAPTER I}

\section{INTRODUCTION}

\subsection{Fischer Tropsch chemistry and the utilization of supercritical fluids in GTL processes}

The Fischer-Tropsch synthesis (FT) is the heart of the Gas-to-Liquids (GTL) technology as it is the process by which synthesis gas (or syngas, a mixture of carbon monoxide and hydrogen) can be converted into ultra-clean fuels and value added chemicals [1]. Syngas can be obtained from abundant natural resources such as coal, natural gas, and biomass. Commercially, there are three main FT reactors currently in use by industry for large scale GTL plants, namely fixed bed, slurry bubble bed and the fluidized bed. Shell in its Pearl GTL plant uses the multitubular fixed-bed reactor while Oryx GTL (a joint venture between Qatar Petroleum-SASOL) employs the slurry reactor technology. Both plants are located in Qatar. Each reactor has its own advantages and limitations.

The Fischer-Tropsch reaction is a heterogeneous chemical reaction in which syngas is converted into a range of hydrocarbon products of varying carbon numbers including condensate, middle distillate and long chain hydrocarbon waxes. These waxes may further be cracked to produce molecules of the desired carbon lengths for the production of ultra-clean fuels (gasoline, jet fuels and diesel) besides value-added chemicals and lubricants. FT has gained importance among the scientific and industrial community in the past few decades due to the increased costs of crude oil in global markets. The process is an excellent way for countries to monetize their gas 
reserves and diversify their businesses into the international liquid fuels and chemicals market.

The current research is aimed at studying fixed-bed FT reactors that operate under non-conventional reaction media through the use of supercritical fluid solvents. This unique reaction medium leverages certain advantages of the current commercial technologies while at the same time overcoming several of their major limitations [2]. With diffusivities that are higher than normal liquids and viscosities that are lower than their liquid counterparts, supercritical solvents have gained importance as media for chemical reactions due to their inherent transport properties [3].

The use of supercritical fluids for FT was first reported by Kaoru Fujimoto's group at the University of Tokyo in 1989 [4], many researchers reported higher catalyst activity and better FT performance in the presence of a solvent at the near critical and supercritical phase conditions [5-8]. Several studies have proved that the solvent medium affects the secondary reactions taking place on the catalyst surface in FT and hence plays a role in the chain growth process thereby influencing the overall product distribution [5, 9-12].

In a previous study, our team reported the development of FT fixed bed reactor model based on evaluation of the micro and macro reactor bed performance while simultaneously accounting for the reactor bed heat and mass transfer behaviors [13]. The temperature and concentration profiles of the reactants inside the catalyst pores and throughout the reactor bed have been accounted for [14]. 
The product distribution in FT is of paramount importance as it is the deciding factor for the selection of downstream processing units and plays a big role in the overall economics of the process. There is a general agreement between scientists that FT can be modeled as a polymerization reaction and hence the product distribution can be studied on the basis of the Anderson Schulz Flory (ASF) chain propagation model [15]. The ASF model assumes that a $\mathrm{CH}_{\mathrm{x}}$ monomer resulted from the disassociation of the chemisorbed $\mathrm{CO}$ and $\mathrm{H}_{2}$ on the cobalt catalyst surface propagate to form heavier hydrocarbons or terminate as a hydrocarbon with the same carbon number as shown in Figure 1.

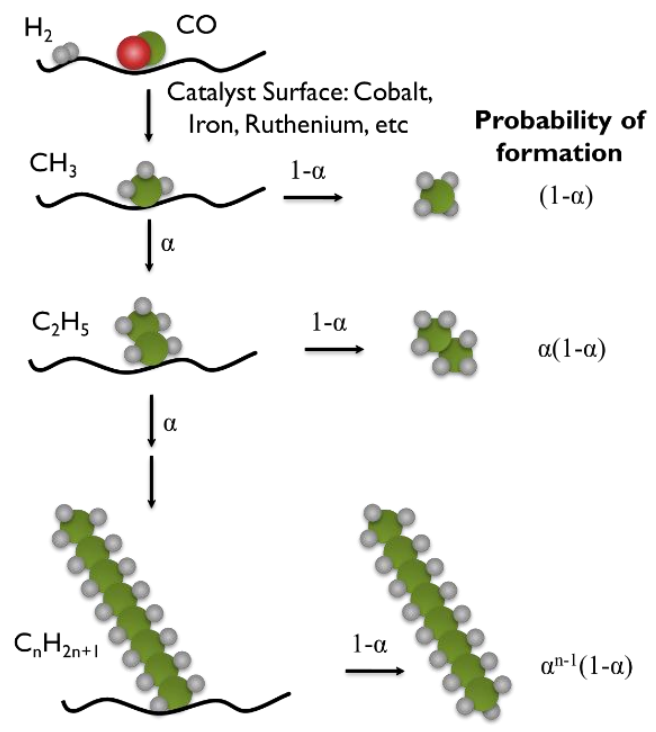

Figure 1 - Chain Growth Probability in FT 
The chain growth probability $\alpha$ in the ASF model is assumed to be independent of the carbon number and temperature. The FT hydrocarbon product profile for various values of $\alpha$ is shown below in Figure 2.

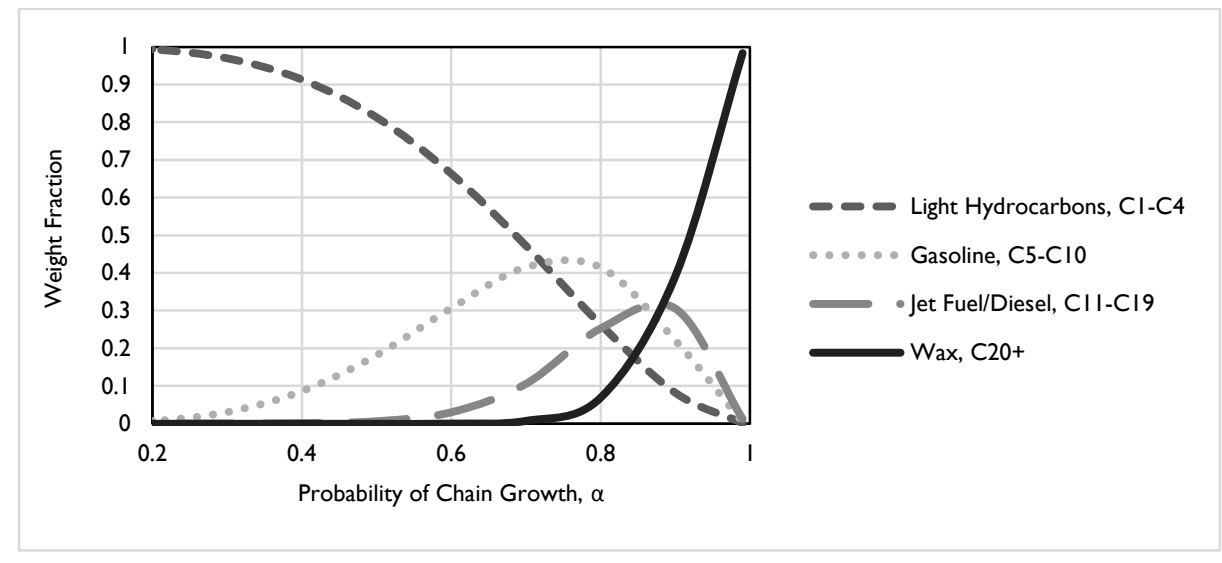

Figure 2 - Typical ASF Hydrocarbon Product Distribution

Several studies reported experimental data of FT product distribution that deviate from the ASF plot $[16,17]$. A number of researchers accounted for this deviation by assuming multiple chain growth values ( $\alpha$-values) [17-19].

The deviation from standard ASF has also been observed in FT reactions in supercritical phase medium [18]. The solvent phase could influence chain growth pathway by suppressing methanation and favoring formation of olefins and long chains, which could result in deviation from ASF plot [18]. 


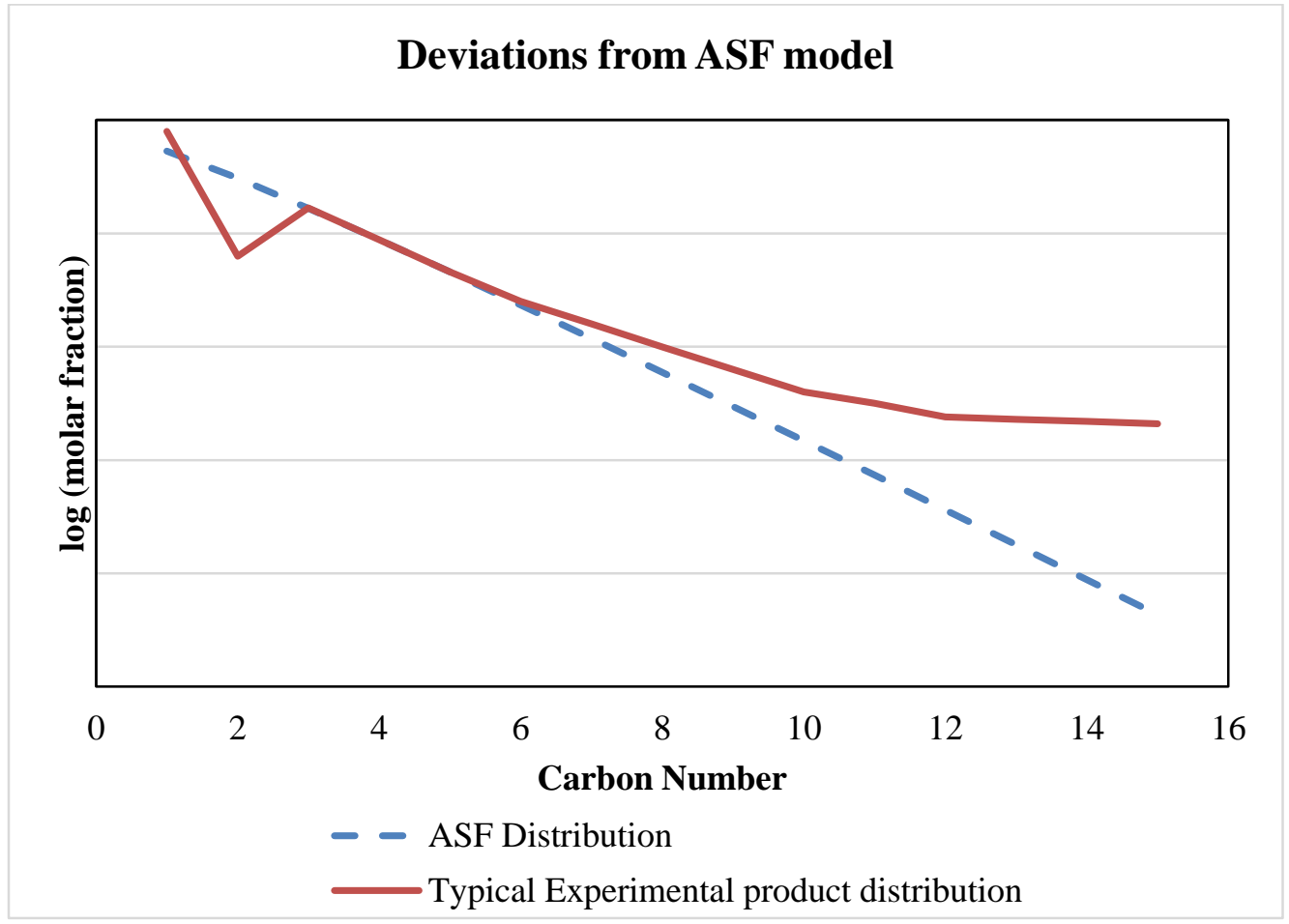

Figure 3 - Non Ideal FT Product Distribution

The aim of the current study is to model the FT hydrocarbon product distribution for both conventional gas phase media and supercritical phase. This shall be the first step towards the ultimate goal of modeling the possible deviations in product distribution from the standard ASF as shown in Figure 3. The next section presents a literature survey of modeling Fischer Tropsch reactors.

\subsection{Background of modeling Fischer-Tropsch reactors}

Reactor modeling can be a very handy tool in the design of commercial reactors, scale-up from bench to pilot scale and then to commercial scale. Additionally, models are useful in predicting the reactor behavior when altering the operating conditions and feed 
composition. Developing a comprehensive model that is capable of predicting the FischerTropsch reaction performance (conversion, selectivity) while simultaneously account for the heat and mass transfer behavior inside the reactor bed is a quite complex mission since this reaction involves complex mechanisms for hundreds of reactions take place at the catalyst surface [20].

Furthermore, FT is a highly exothermic reaction that could cause hot spot formation on catalyst surface especially for the fixed-bed reactors. To control the temperature inside these type of reactors, it is essential to measure or predict the axial and the radial temperature profiles inside catalyst pores and in the bulk phase. The accurate prediction or modeling of these profiles require appropriate accounting of the reaction kinetics and thermodynamics of the FT reaction mixture, which further complicate the modeling development process. The catalyst type and pellet properties (shape, diameter, pore and surface characteristics) are critical parameters in controlling the FT reaction performance and they are the starting point in developing a model for the reaction at the micro-scale level. The comprehensive model for the FT fixed-bed reactor includes the macro-scale level of the process as well to provide quantitative assessments of the following: mass and heat transfer rates between the bulk fluid and the pellet outer surface (external transfer), the inter-particle diffusion of mass and heat inside the tortuous pellet structure (internal transfer), the rate of surface reaction and diffusing back of products and remaining reactants from the catalyst interior pore to the surface of the catalyst pellet and then to the bulk fluid. Producing a detailed reactor model should take into account the aforementioned mass, heat and momentum transfer processes, which are quite challenging 
to quantify simultaneously [21]. As the temperature influences the reaction kinetics and chain growth process directly, tracking temperature changes in the reactor bed is crucial to FT process safety and performance. The temperature profile inside the reactor bed should match the measured or predicted primary and secondary reaction rates and chain termination rates as they are intensely affected by the reactor bed temperature. Likewise the diffusion and other physical properties controlling the reaction rate are strongly dependent on temperature. In conclusion, the complexity of the mathematics associated to the model makes the formulation of the simulation program cumbersome and time consuming.

\subsubsection{Techniques to Develop Fischer Tropsch Fixed Bed Reactor Models}

Various 1-Dimensional (1-D) models have been proposed in literature for fixed bed FT reactors. This section discusses some of these approaches. Wang et al. [22] studied the effects of tube diameter, recycle ratio, pressure and cooling temperature on selectivity, conversion of a $\mathrm{Fe}-\mathrm{Cu}-\mathrm{K}$ based catalyst while modeling the temperature profiles in a jacketed FBR. The catalyst pores were assumed to be filled with wax and the gas film mass transfer was neglected. Separate mass and energy balances were set up for bulk gas phase and catalyst pores. They showed that increase in cooling temperatures increases syngas conversion though suppressing $\mathrm{C}_{5+}$ content. On the other hand their findings showed that increasing the pressure benefits both the $\mathrm{CO}$ conversion as well as $\mathrm{C}_{5+}$ product yield. A promising paper on the selection of reactor type for low temperature FischerTropsch was published by Robert and Thomas [23]. They simulated various FT reactor 
types using 1-D model and simple first order kinetics to provide a comparison in the efficiency and the performance of these different reactors (fixed bed (trickle flow), slurry bubble column, monolith loop (slug flow) and micro structured (film flow regime)). A comprehensive list of equations used in each case was presented. They concluded that slurry bubble column is far better than fixed bed reactors in terms of catalyst requirements and reactor volume in the trickle flow regime [8]. However, the challenges facing slurry reactor is the catalyst separation and loss due to attrition. Monolith loop reactors are a good choice for FT except for the fact that they require huge amounts of recycle, which might not be a commercially viable option. Their findings showed that the micro structured reactor could be the best choice in terms of productivity per unit catalyst volume due to negligible heat and mass transfer resistances. Again the small size makes it potentially costly and difficult to maintain, thus industrially unattractive. A special type of reactors (thermally coupled reactor) for FT and cyclohexane dehydrogenation to benzene was simulated by Rahimpour et al [24]. As FT is an exothermic reaction and cyclohexane dehydrogenation is endothermic, this presents an opportunity for energy integration. Both reactions occur side by side, separately, in a co-current recuperative coupled reactor. They justified using a 1-D model as compared to 2-D by stating that the conversion and yield profiles did not differ in both cases, though the temperature difference in the radial direction can be as high as $12 \mathrm{~K}$. Axial diffusion was neglected owing to high gas velocities. The obtained results showed that the model has predicted conversions quite well ( $0.5 \%$ error), however the model selectivity deviated considerably (up to $24 \%$ error). Alex and Posi [25], used Ergun equation to additionally account for 
the pressure drop along the reactor, the estimated pressure drop was found to be large (4 $\mathrm{MPa}$ ) for a reactor length of $3 \mathrm{~m}$ and catalyst particle diameter of $70 \mu \mathrm{m}$. The ideal gas law was used to calculate physical parameters. The kinetics of FT was described via the alkyl-alkenyl mechanism for the iron-based catalyst. The model simulated the effect of syngas molar feed ratio $\left(\mathrm{H}_{2} / \mathrm{CO}\right)$, pressure and reactor length on conversion and product distribution (paraffin and olefin selectivity). Their model showed that carbon conversion rate increases with increasing pressure, reactor length and syngas feed ratio. The total paraffin selectivity increased with increasing syngas molar feed $\mathrm{H}_{2} / \mathrm{CO}$ ratio and reactor length, but decreased with increasing reactor pressure. On the other hand, olefins selectivity was found to decrease with increasing syngas feed ratio and reactor length, while improving with increasing pressure. Although their model showed encouraging results, it was only based on material balance without accounting for the energy balance (assuming reactor operates isothermally at $270{ }^{\circ} \mathrm{C}$ ).

Brunner et al [26], simulated a 1-D trickle fixed bed reactor by using correlations for radial thermal conductivity and fixed user defined selectivity. It was assumed that $1 \%$ of water was formed in the liquid phase at operating conditions of $40 \mathrm{~atm}$ and $490 \mathrm{~K}$. Their assumptions included constant catalyst activity, uniform porosity in bed and fixed selectivity. The validation of the model was conducted relative to experimental data obtained from SASOL's Arge reactors. Two set of results were obtained for both Fe-based and Co-based catalysts using different kinetic expressions for each. This work also showed the influence of various model building parameters on simulation results. The influence of effective diffusivity on bed length and Prandtl Number on bed temperature was shown. 
The effect of catalyst structuring on the reactor performance was illustrated by Hooshyar et al [27]. They developed a 1-D model for FT fixed bed reactor to study the effects of particle diameter on temperature and concentration profiles inside the reactor bed. In this theoretical study, the focus was on improving reactor performance by structuring which involves cross-flow structure packing. This packing structure forces the gas-liquid mixture in a diagonal path resulting in much more effective radial heat transfer. Their model accounts for internal transport limitations by calculating the catalyst effectiveness factor for a fixed product distribution assumed based on a chain growth probability of $\alpha=0.9$. The cross flow packing helped achieve a much better effective radial heat transfer while reducing the catalyst diffusion length. This was reflected in the modeling results represented by significant increase in conversion for such packing to reach almost $40 \%$.

As explained above, 1-D models suffer from many limitations due to various assumptions. A 2-D model will address the temperature and concentration profiles in the radial direction thus shedding light on hot spot formations, concentration gradients, etc. These results can be used to create better reactor designs for FT. In the area of twodimensional models for FT fixed bed reactors, Marvast et al. [20], Jess and Kern [28] and Rafiq et al. [29] have used similar approach in developing their models. Marvast and his coworkers used Fe-HZSM5 catalyst whereas Jess and Kern and Rafiq et al. used cobaltbased catalyst. The model results from Marvast et al [20], were found to be in a good agreement with experimental data in terms of conversion. Nevertheless, the calculated selectivity deviated considerably from the experimentally measured profile. Rafiq et al. 
[29], used bio syngas $\left(50 \% \mathrm{~N}_{2}, 33 \% \mathrm{H}_{2}\right.$, and $\left.17 \% \mathrm{CO}\right)$ as a feed to FT fixed bed reactor to conduct a simulation for a suitable reactor bed. Their model was found to be in a good agreement with the experimental data. Jess and Kern [28], showed that though the CO conversions in 1-D and 2-D models are almost identical, the 1-D model predicts a higher critical cooling temperature than the 2-D model. This illustrates that more data on heat transfer parameters in the reactor will result in realistic estimation of these parameters.

Sharma et al. [30] developed a 2-D fixed bed reactor model for FT synthesis and extrapolated the model to industrial conditions. They were able to estimate the number of tubes needed in one reactor to produce $30,000 \mathrm{bbl} / \mathrm{day}$ of diesel and naphtha products. The reactor required 20,000 tubes of internal diameter $20.32 \mathrm{~mm}$. They showed that foam structure catalyst had better performance than packed extrudates catalyst but this resulted in higher catalyst and reactor volumes. Liu et al. [21], studied steady state and dynamic state behavior of a fixed bed FT reactor, and the unsteady state mass and energy balance ordinary differential equations for the system were solved [21].

Lee [31], Pratt [32] and Mirolaei [33] used CFD (Computational Fluid Dynamics) modeling to build 3-D models of FT reactors. Their CFD models mainly consist of mass, heat and momentum transport equations. Since CFD is based on fundamental physics and are scale independent they hold the potential to play an important role in scale-up problems [34]. The CFD models become particularly useful in studying extreme conditions such as high temperature and pressure, where it would be costly and hazardous to make actual measurements at such conditions [34]. The main advantage of CFD is that it needs no physical modifications, it can be used to predict systems performance before the actual 
installation of the system, thus saving time and cost required for modifying the system each time a change is made [35].

Though CFD models generate great amount of results with 3-D contour plots, which provide good insight into the model, they suffer from many limitations. CFD is highly limited by the computing power and software being used. The personnel operating the CFD software should be aware of the pitfalls of using the simulation software. Complex CFD simulations are usually time consuming, making CFD a less favorable option especially for industrial corporations which desire quick results. If models possess some symmetry features, one can use them to significantly reduce the amount of computation involved.

Lee [31] used carbide mechanism and lumped kinetics from the Langmuir Hinshelwood Hougen Watson model to simulate a 2-D heterogeneous fixed bed reactor on Co-based catalyst. The model has been used to generate several catalyst performance parameters such as conversion, product distribution and temperature profile. What was interesting in this work is that their model was capable to generate a non-ASF product distribution (a carbon number dependent $\alpha$ value) and fitted it with remarkable agreement to the experimental results by Elbashir and Roberts [18].

\subsubsection{Simulation of FT Reactor Beds Operate Under Near Critical and Supercritical Conditions}

Given the challenges faced in FT reactor modeling, the problem is compounded by the fact that the current research is aimed at operating conditions that are in near critical 
and supercritical regions. The transport properties in this region vary significantly in a short span of operating conditions and hence, the selection of an Equation of State (EOS) is a challenge. Mogalicherla and Elbashir [36] developed kinetic models for FT in supercritical fluids. $\mathrm{CO}$ conversion and $\mathrm{CH}_{4}$ yield could be estimated from the isothermal plug flow reactor models. The $\mathrm{CO}$ conversion and $\mathrm{CH}_{4}$ yield profiles with respect to temperature and pressure were compared for fugacity and partial pressure models. It was concluded that fugacity better explains the non-ideal behavior of the system than partial pressures and hence reaction rate expressions were modified accordingly. Mogalicherla et al [37], studied variations in diffusional flux versus conversion for gas phase and supercritical FT. Though the CO diffusional flux is higher in gases, with time the catalyst pores are filled with wax thus reducing the $\mathrm{CO}$ concentration at active sites considerably. The effect is not so pronounced in supercritical phase FT where the effectiveness factor drop is not as intense as in gas phase. Fugacity profiles of $\mathrm{CO}$ and $\mathrm{H}_{2}$ in catalyst pores were generated. The previous work by Mogalicherla et al [37], is a good precedent to carry on work on modeling supercritical FT fixed bed reactors. In the process of the SCF-FT technology moving on its path to potential commercialization in the future, a reliable reactor model is quite essential. The objective is to build a sophisticated model that can account for simultaneous heat and mass transfer profiles inside catalyst pores as well as the bulk phase, in the reactor. This will enable in supporting reactor design, scale up of reactors as well as energy integration.

Modeling a fixed bed reactor operating under the supercritical phase conditions adds additional puzzle to the already complex reaction system. This reaction requires 
better understanding and identification of the reaction mixture phase behavior. Moreover, it has been shown that the supercritical phase reaction media could influence the chain growth pathway and the overall product distribution via their influence on the secondary reactions that take place on catalyst surface $[12,38]$. Thus, detailed product distribution profile and rates of reactant consumption under the specified reaction conditions should be incorporated in the model utilizing the appropriate EOS that is capable of describing the thermo-physical characteristics and the phase behavior of the non-ideal reaction media. The current work deals only with hydrocarbon product distribution of FT in gas phase which will be the foundation stone to study the same in super critical solvent assisted Fischer-Tropsch synthesis. 


\section{CHAPTER II}

\section{RESEARCH OBJECTIVE}

As explained in Chapter 1, the product distribution in Fischer-Tropsch is one of the governing factors for the selection of downstream processing units which plays a big role in the overall economics of the project. Some investigators have focused on selectivity models that aim to explain the non-ASF behavior by proposing a $2-\alpha$ model $[18,19]$, in which the first $\alpha$ accounts for the light hydrocarbons growth and the other one for the heavy hydrocarbons.

Todic et al [39] have developed a detailed mechanistic model and tried to account for the non-ideal product distribution in Fischer-Tropsch in a slurry bed reactor. In the present work, their model was used as a starting point to develop a MATLAB $®$ code for the kinetic model that is capable of predicting FT product distribution of a cobalt catalyst in fixed bed reactor. Experimental data from an advanced high-pressure Fischer Tropsch laboratory scale reactor was used as input to the model to estimate model parameters. Hence, the objective of this work is to develop a MATLAB $®$ code and use experimental gas phase FT data to estimate model parameters. This will be the starting step for a long term research objective of studying the FT reaction in non-conventional reaction media. 


\section{CHAPTER III}

\section{RESEARCH METHODOLOGY}

In order to study the subject area systematically, our research group has carved out a strategy which is shown in Figure 4 below. In the first part, an existing FT kinetic model with focus on product distribution will be studied. Experimental results conducted in the more familiar gas phase medium will be used to generate parameters of the kinetic model. In the second phase of the work, experimental data from FT-SCF phase will be used to generate parameters of the same kinetic model. Based on the comparison of the parameters generated in both reactor media, changes can be suggested in the FT mechanism in SCF phase.

The current work mainly concerns with the first part of the above sequence, which is, to use an existing kinetic model and generate the model parameters using experimental data from FT reactor in gas phase. This chapter explains the methodology that has been used to accomplish this task.

Use an existing kinetic model and generate parameters using experimental results from Gas Phase FT
Use the validated model with experimental data input from SCF phase
Suggest changes in mechanism of FT in SCF phase

Figure 4 - Proposed Methodology for Research into FT in SCF Phase 


\subsection{Development of a kinetic model with focus on product distribution}

Todic et al. [39] developed a comprehensive micro-kinetic model based on carbide mechanism that predicts FT product distribution over a cobalt-based catalyst up to carbon number 15. This model explains the non-ASF product distribution using a carbon number dependent olefin formation rate ( $\mathrm{e}^{\mathrm{nc}}$ term, see Eq. 2, 4 below). Constant $\mathrm{c}$ is related to weak Van der Waals interaction ( $\mathrm{c}=-\Delta \mathrm{E} / \mathrm{RT}$ ) where $\Delta \mathrm{E}$ is the contribution in the increase of desorption energy per every $\mathrm{CH}_{2}$ group [39]. The rate equations for the olefins and paraffins used in the model are listed below (Eq. 1-4).

$$
\begin{gathered}
\mathrm{r}_{\mathrm{CH}_{4}}=\mathrm{k}_{5 \mathrm{~m}} \mathrm{~K}_{7}^{0.5} \mathrm{P}_{\mathrm{H}_{2}}^{1.5} \alpha_{1}[\mathrm{~S}] \\
\mathrm{r}_{\mathrm{C}_{2} \mathrm{H}_{4}}=\mathrm{k}_{6 \mathrm{e}} \mathrm{e}^{2 \mathrm{c}} \sqrt{\mathrm{K}_{7} \mathrm{P}_{\mathrm{H}_{2}}} \alpha_{1} \alpha_{2}[\mathrm{~S}] \\
\mathrm{r}_{\mathrm{C}_{\mathrm{n}} \mathrm{H}_{2 \mathrm{n}+2}}=\mathrm{k}_{5} \mathrm{~K}_{7}^{0.5} \mathrm{P}_{\mathrm{H}_{2}}^{1.5} \alpha_{1} \alpha_{2} \prod_{\mathrm{i}=3}^{\mathrm{n}} \alpha_{\mathrm{i}}[\mathrm{S}] \\
\mathrm{r}_{\mathrm{C}_{\mathrm{n}} \mathrm{H}_{2 \mathrm{n}}}=\mathrm{k}_{6} \mathrm{e}^{\mathrm{nc}} \sqrt{\mathrm{K}_{7} \mathrm{P}_{\mathrm{H}_{2}}} \alpha_{1} \alpha_{2} \prod_{\mathrm{i}=3}^{\mathrm{n}} \alpha_{\mathrm{i}}[\mathrm{S}]
\end{gathered}
$$

These rate equations are obtained after writing up all the individual rate expressions at each mechanistic step and working up the algebra involved. The reaction steps that lead to these rate equations is listed in Table 1 on the next page. The mathematical derivation for the above equations is available in supplementary information by Todic et al [39]. 
Table 1 - Reaction Pathway of Carbide Mechanism from Todic et al [39]

\begin{tabular}{|c|c|c|c|}
\hline No. & Elementary Reaction & $\begin{array}{l}\text { Kinetic / } \\
\text { Equilibrium } \\
\text { constants } \\
\text { used in the } \\
\text { model }\end{array}$ & Comments \\
\hline 1 & $\mathrm{CO}+\mathrm{C}_{\mathrm{n}} \mathrm{H}_{2 \mathrm{n}+1}-\mathrm{S} \rightarrow \mathrm{C}_{\mathrm{n}} \mathrm{H}_{2 \mathrm{n}+1^{-}}-\mathrm{S}-\mathrm{CO}$ & $\mathrm{k}_{1}$ & $\begin{array}{c}\text { Initiation Step. CO } \\
\text { adsorption onto } \\
\text { bonded H-S site. } \\
\text { Followed by } \\
\text { subsequent bonding of } \\
\text { CO on alkyl bonded } \\
\text { sites }\end{array}$ \\
\hline 2 & $\begin{array}{l}\mathrm{C}_{\mathrm{n}} \mathrm{H}_{2 \mathrm{n}+1}-\mathrm{S}-\mathrm{CO}+\mathrm{H}_{2} \leftarrow \rightarrow \mathrm{C}_{\mathrm{n}} \mathrm{H}_{2 \mathrm{n}+1}-\mathrm{S}-\mathrm{C} \\
+\mathrm{H}_{2} \mathrm{O}\end{array}$ & $\mathrm{K}_{2}$ & $\begin{array}{l}\text { Elimination of oxygen } \\
\text { by production of water }\end{array}$ \\
\hline 3 & $\mathrm{C}_{\mathrm{n}} \mathrm{H}_{2 \mathrm{n}+1^{-}} \mathrm{S}-\mathrm{C}+\mathrm{H}_{2} \leftarrow \rightarrow \mathrm{C}_{\mathrm{n}} \mathrm{H}_{2 \mathrm{n}+1^{-}}-\mathrm{S}-\mathrm{CH}_{2}$ & $\mathrm{~K}_{3}$ & $\begin{array}{l}\text { Hydrogenation of } \\
\text { bonded carbide }\end{array}$ \\
\hline 4 & $\mathrm{C}_{\mathrm{n}} \mathrm{H}_{2 \mathrm{n}+1}-\mathrm{S}-\mathrm{CH}_{2} \leftarrow \mathrm{C}_{\mathrm{n}} \mathrm{H}_{2 \mathrm{n}+1}-\mathrm{CH}_{2}-\mathrm{S}$ & $\mathrm{K}_{4}$ & $\begin{array}{l}\text { Chain propagation by } \\
\text { rearrangement }\end{array}$ \\
\hline 5 & $\begin{array}{l}\mathrm{CH}_{3}-\mathrm{S}+\mathrm{H}_{2} \rightarrow \mathrm{CH}_{4}+\mathrm{H}-\mathrm{S} \\
\mathrm{C}_{\mathrm{n}} \mathrm{H}_{2 \mathrm{n}+1}-\mathrm{S}+\mathrm{H}_{2} \rightarrow \mathrm{C}_{\mathrm{n}} \mathrm{H}_{2 \mathrm{n}+2}+\mathrm{H}-\mathrm{S}\end{array}$ & $\begin{array}{c}\mathrm{k}_{5 \mathrm{~m}} \\
\mathrm{k}_{5}\end{array}$ & $\begin{array}{c}\text { Separate rate } \\
\text { expressions for } \\
\text { methane formation } \\
\text { and other paraffin } \\
\text { formation }\end{array}$ \\
\hline 6 & $\begin{array}{l}\mathrm{C}_{2} \mathrm{H}_{5}-\mathrm{S} \rightarrow \mathrm{C}_{2} \mathrm{H}_{4}+\mathrm{H}-\mathrm{S} \\
\mathrm{C}_{n} \mathrm{H}_{2 n+1-}-\mathrm{S} \rightarrow \mathrm{C}_{n} \mathrm{H}_{2 n}+\mathrm{H}-\mathrm{S}\end{array}$ & $\begin{array}{l}\mathrm{k}_{6 \mathrm{e}} \\
\mathrm{k}_{6 \mathrm{n}}\end{array}$ & $\begin{array}{c}\text { Separate rate } \\
\text { expressions for } \\
\text { ethylene formation } \\
\text { and other olefin } \\
\text { formation }\end{array}$ \\
\hline 7 & $\mathrm{H}_{2}+2 \mathrm{~S} \leftarrow \rightarrow 2 \mathrm{H}-\mathrm{S}$ & $\mathrm{K}_{7}$ & $\begin{array}{l}\text { Hydrogen Adsorption } \\
\text { - the precursor to all } \\
\text { above steps }\end{array}$ \\
\hline
\end{tabular}

Note: $\mathrm{K}$ refers to Equilibrium constant of the corresponding reaction and $\mathrm{k}$ refers to the Arrhenius constant of the corresponding reaction and the corresponding equations are given in Eq. 5 and 6. 


$$
\begin{aligned}
& \mathrm{k}_{\mathrm{i}}(\mathrm{T})=\mathrm{A}_{\mathrm{i}} \mathrm{e}^{\frac{-\mathrm{E}_{\mathrm{a}, \mathrm{i}}}{\mathrm{RT}}} \\
& \mathrm{K}_{\mathrm{i}}(\mathrm{T})=\mathrm{A}_{\mathrm{i}} \mathrm{e}^{\frac{-\Delta \mathrm{H}_{\mathrm{i}}}{\mathrm{RT}}}
\end{aligned}
$$

The equilibrium constant of the hydrogen adsorption step is $\mathrm{K}_{7}$. In the next step, $\mathrm{CO}$ bonds to an adsorbed Hydrogen site. The rate constant of this adsorption step is $\mathrm{k}_{1}$. From Arrhenius equations, $A_{1}$ and $E_{a, 1}$ correspond to this first step. Similarly, $K_{2}$ is the equilibrium adsorption step of the addition of hydrogen molecule to the adsorbed. The next step of Hydrogen addition to the carbide molecule is an equilibrium step with an equilibrium constant, $\mathrm{K}_{3}$. The constant for the chain rearrangement step or chain growth step is $\mathrm{K}_{4}$. The rate constants for methanation, paraffin formation, olefin formation and ethylene formation are $\mathrm{k}_{5 \mathrm{~m}}, \mathrm{k}_{5}, \mathrm{k}_{6,0}$ and $\mathrm{k}_{6, \mathrm{e}}$ respectively. In the olefin formation rate equations, if $\Delta \mathrm{E}$ is the desorption energy per $\mathrm{CH}_{2}$ group, then $\mathrm{c}=-\Delta \mathrm{E} /(\mathrm{RT})$. This constant, c affects the olefin desorption rate subsequently affecting olefin formation rate. The derivation of the rate equations and reported values of these constants in literature can be found in the work of Todic et al [39].

In the current study, a MATLAB $®$ code was written to estimate the kinetic model parameters. The optimization of this model was done using a Genetic Algorithm (GA). GA was chosen for optimization as many kinetic studies in literature including FischerTropsch kinetic models have successfully used GA to estimate kinetic model parameters $[40,41]$. As demonstrated by Costa and Filho [42] in the optimization of a crystallization process, GA proved to be more efficient and could converge to a solution with lesser error than that obtained through successive quadratic programming (SQP). However, GAs 
suffer from the problem that they are time consuming which restricts their utility in real time applications. Kinetic modeling is a one-time process and hence this is not a restriction applicable to this study.

Chang et al [40] used GA to estimate unknown kinetic parameters of an FT kinetic model derived from Langmuir-Hinshelwood-Hougen-Watson approach. Park and Froment [41] demonstrated the use of GA to access the global minimum and showed that low crossover probability with relatively high mutation probability was needed for a good performance of GA. In both these studies, Levenberg-Marquardt (LM) optimizer was used which takes GA results as initial values and performs further optimization. However, LM optimization has not been performed in this current study as it is an add-on optimization that can be added to the existing GA code to make a hybrid optimization tool.

One of the limitations of GA is that they are inefficient with constrained problems [43]. Since the optimization of the current kinetic model does not involve constraints, this was not a problem. No constraints were considered as essentially, genetic algorithms do not need an initial guess to start the optimization. However, a range for each parameter was supplied to the Genetic Algorithm to speed up optimization. It was found that without the range, the optimization becomes very time consuming. These ranges for each parameter were taken from literature [39]. 
Table 2 - Input Range for Model Parameters [39]

\begin{tabular}{|c|c|c|}
\hline Parameter & Description & Range supplied to GA \\
\hline $\mathrm{A}_{1}-\mathrm{A}_{7}, \mathrm{~A}_{5 \mathrm{~m}}, \mathrm{~A}_{6 \mathrm{e}}$ & $\begin{array}{l}\text { A (Pre-exponential factor } \\
\text { in kinetic rate expression) }\end{array}$ & $10^{-20}$ to $10^{20}$ \\
\hline$\Delta \mathrm{E}_{1}$ & $\begin{array}{l}\text { Activation Energy of } \\
\text { Initiation step }\end{array}$ & $50 \mathrm{~kJ} / \mathrm{mol}$ to $150 \mathrm{~kJ} / \mathrm{mol}$ \\
\hline$\Delta \mathrm{E}_{5}, \Delta \mathrm{E}_{5 \mathrm{~m}}$ & $\begin{array}{l}\text { Activation Energy of } \\
\text { Methane and Paraffin } \\
\text { formation step }\end{array}$ & $70 \mathrm{~kJ} / \mathrm{mol}$ to $120 \mathrm{~kJ} / \mathrm{mol}$ \\
\hline$\Delta \mathrm{E}_{6}, \Delta \mathrm{E}_{6 \mathrm{e}}$ & $\begin{array}{l}\text { Activation Energy of } \\
\text { Ethylene and Olefin } \\
\text { formation step }\end{array}$ & $80 \mathrm{~kJ} / \mathrm{mol}$ to $150 \mathrm{~kJ} / \mathrm{mol}$ \\
\hline$\Delta \mathrm{H}_{2}, \Delta \mathrm{H}_{3}, \Delta \mathrm{H}_{4}$ & $\begin{array}{l}\text { Heat of reaction of water } \\
\text { formation step, carbide } \\
\text { hydrogenation step and } \\
\text { chain propagation by } \\
\text { rearrangement step }\end{array}$ & $-50 \mathrm{~kJ} / \mathrm{mol}$ to $50 \mathrm{~kJ} / \mathrm{mol}$ \\
\hline$\Delta \mathrm{H}_{7}$ & $\begin{array}{l}\text { Heat of Adsorption of } \\
\text { hydrogen on vacant site }\end{array}$ & $\begin{array}{c}-100 \mathrm{~kJ} / \mathrm{mol} \text { to }-10 \\
\mathrm{~kJ} / \mathrm{mol}\end{array}$ \\
\hline$\Delta \mathrm{E}$ & $\begin{array}{l}\text { Incremental increase in } \\
\text { desorption energy per } \\
\mathrm{CH}_{2} \text { molecule }\end{array}$ & $\begin{array}{c}0 \mathrm{~kJ} / \mathrm{mol} \mathrm{CH}_{2} \text { to } 10 \\
\mathrm{~kJ} / \mathrm{mol} \mathrm{CH}_{2}\end{array}$ \\
\hline
\end{tabular}

\subsubsection{Genetic Algorithm}

Genetic algorithm is an optimization technique that is based on the theory of evolution. The concept is based on the idea that a better solution can be obtained if we somehow combine good parts of the solution set and eliminate the poor parts of the solution set, the same way nature does by combining the DNA of living organisms. Genetic algorithms have been used to solve various engineering problems [44] as well as for parameter estimation of kinetic models [41]. A dedicated toolbox is also available in $M A T L A B \circledR$ for genetic algorithm which provides an easy user interface to perform optimization. 


\subsection{Model validation}

In order to validate the genetic algorithm code, rate values for each hydrocarbon number were generated using parameters from Todic et al. [39]. These values were input into the MATLAB ${ }^{\circledR}$ code to generate the parameters and check model consistency. The model has 19 parameters that are to be estimated. It takes around 30 minutes with around 30,000 generations in the Genetic Algorithm module in MATLAB® to converge to a set of results with an MARR (Mean absolute relative residual) of less than $1 \%$. Mean Absolute Relative Residual (MARR) is the objective function used. MARR is also used to assess model accuracy and is defined as below:

$$
\text { Objective Function, MARR }=\sum_{i=1}^{n_{\text {resp }}} \sum_{j=1}^{n_{\exp }}\left|\frac{r_{i, j}^{\text {exp }}-r_{i, j}^{c a l}}{r_{i, j}^{\exp }}\right| \times \frac{1}{n_{\text {resp }} n_{\exp }} \times 100 \%
$$

Eqn. 7 above gives the objective function used in the optimization process. In this equation, $\mathrm{n}_{\text {resp }}$ refers to the number of rates calculated for each run. In the model used here, the modeling is done till carbon number 15 . Hence, 15 paraffin rates are calculated and 14 olefin rates are computed. Hence $\mathrm{n}_{\text {resp }}=29$. The number of experimental sets is represented by $n_{\text {exp }}$, which is 7 .

The error is low owing to the fact that a model's calculated values were used as input to the model. As the input was based on a mathematical model of equations, the GA finds it easier to converge with a low value of error. An experimental data set would 
consist of errors due to experimental uncertainties resulting in a higher \% error. A comparison of the model parameters used to calculate the rate values and the values generated by the MATLAB® code is shown in Table 3.

Table 3 - Comparison of GA Results with Parameters determined by Todic et al [39]

\begin{tabular}{|c|c|c|c|}
\hline Parameter & Units & $\begin{array}{c}\text { Estimated Value from Genetic } \\
\text { Algorithm }\end{array}$ & $\begin{array}{c}\text { Value obtained by } \\
\text { Todic et al [39] }\end{array}$ \\
\hline A1 & $\mathrm{mol} / \mathrm{g}_{\mathrm{cat}} / \mathrm{h} / \mathrm{MPa}$ & $1.82 \mathrm{E}+06$ & $1.83 \mathrm{E}+10$ \\
\hline $\bar{A} 2$ & - & 620.59 & 5.8 \\
\hline A3 & $\mathrm{MPa}^{-1}$ & 15.73 & 24.4 \\
\hline A4 & - & 995.89 & 2.9 \\
\hline A5 & $\mathrm{mol} / \mathrm{g}_{\mathrm{cat}} / \mathrm{h} / \mathrm{MPa}$ & $2.58 \mathrm{E}+05$ & $4.49 \mathrm{E}+05$ \\
\hline $\mathrm{A} 5, \mathrm{~m}$ & $\mathrm{~mol} / \mathrm{g}_{\mathrm{cat}} / \mathrm{h} / \mathrm{MPa}$ & $7.89 \mathrm{E}+06$ & $8.43 \mathrm{E}+05$ \\
\hline A6,0 & $\mathrm{mol} / \mathrm{g}_{\mathrm{cat}} / \mathrm{h}$ & $6.33 \mathrm{E}+07$ & $7.47 \mathrm{E}+08$ \\
\hline A6,e & $\mathrm{mol} / \mathrm{g}_{\mathrm{cat}} / \mathrm{h}$ & $1.86 \mathrm{E}+06$ & $7.03 \mathrm{E}+08$ \\
\hline A7 & $\mathrm{MPa}^{-1}$ & $9.08 \mathrm{E}+07$ & $1.00 \mathrm{E}-03$ \\
\hline E1 & $\mathrm{kJ} / \mathrm{mol}$ & 66.66 & 100.4 \\
\hline E5 & $\mathrm{kJ} / \mathrm{mol}$ & 74.22 & 72.4 \\
\hline E5.m & $\mathrm{kJ} / \mathrm{mol}$ & 76.31 & 63 \\
\hline E6,0 & $\mathrm{kJ} / \mathrm{mol}$ & 91.09 & 97.2 \\
\hline E6,e & $\mathrm{kJ} / \mathrm{mol}$ & 88.51 & 108.8 \\
\hline
\end{tabular}


Table 3 (Continued)

\begin{tabular}{|c|c|c|c|}
\hline$\Delta \mathrm{H} 2$ & $\mathrm{~kJ} / \mathrm{mol}$ & 26.54 & 8.68 \\
\hline$\Delta \mathrm{H} 3$ & $\mathrm{~kJ} / \mathrm{mol}$ & 15.09 & 9.44 \\
\hline$\Delta \mathrm{H} 4$ & $\mathrm{~kJ} / \mathrm{mol}$ & 21.23 & 7.9 \\
\hline$\Delta \mathrm{H} 7$ & $\mathrm{~kJ} / \mathrm{mol}$ & -10.09 & -25 \\
\hline$\Delta \mathrm{E}$ & $\mathrm{kJ} / \mathrm{mol} / \mathrm{CH}_{2}$ & 1.13 & 1.12 \\
\hline
\end{tabular}

The heats of adsorption and the activation energies generated are physically meaningful. However a closer look at the comparison of parameters reveals a large difference in $\mathrm{A}_{7}$, the pre-exponential factor of the hydrogen adsorption step. The large variation in the value of $A_{7}$ can be attributed to the nature of the mathematical model equations. The Genetic Algorithm aims to minimize the objective function which is the normalization of the difference between the experimental and the calculated values of the rate equation. As shown in Eqns. 1-4, 6 and 8, the term $\mathrm{K}_{7}\left(=\mathrm{A}_{7} * \exp \left(-\mathrm{E}_{\mathrm{a}} / \mathrm{RT}\right)\right)$ appears in both the numerator and denominator of the hydrocarbon rate expressions. So, the sensitivity of term is minimized irrespective of the value of $A_{7}$ which could cause the large difference of its reported value in this study and the one reported by Todic et al [39].

$$
[\mathrm{S}]=\frac{1}{1+\sqrt{\mathrm{K}_{7} \mathrm{P}_{\mathrm{H}_{2}}}+\sqrt{\mathrm{K}_{7} \mathrm{P}_{\mathrm{H}_{2}}} \times\left(1+\frac{1}{\mathrm{~K}_{4}}+\frac{1}{\mathrm{~K}_{3} \mathrm{~K}_{4} \mathrm{P}_{\mathrm{H}_{2}}}+\frac{\mathrm{P}_{\mathrm{H}_{2} \mathrm{O}}}{\mathrm{K}_{2} \mathrm{~K}_{3} \mathrm{~K}_{4} \mathrm{P}_{\mathrm{H}_{2}}^{2}}\right) \times\left(\alpha_{1}+\alpha_{1} \alpha_{2}+\alpha_{1} \alpha_{2} \times \sum_{\mathrm{i}=3}^{\mathrm{n}} \prod_{\mathrm{j}=3}^{\mathrm{i}} \alpha_{\mathrm{j}}\right)}
$$


The input rate values are compared with rates estimated by the model and are plotted as shown in Figure 5. This validation step helps in testing the performance of the Genetic Algorithm code written and number of generations required to attain a satisfactory solution. It may be noted here that the purpose of this validation check step is to ascertain the mathematical performance of the model with regards to fitting. This step helped to identify errors in the code and fine tune the model based on the equations. Therefore, a sensitivity analysis was not performed for each individual parameter.
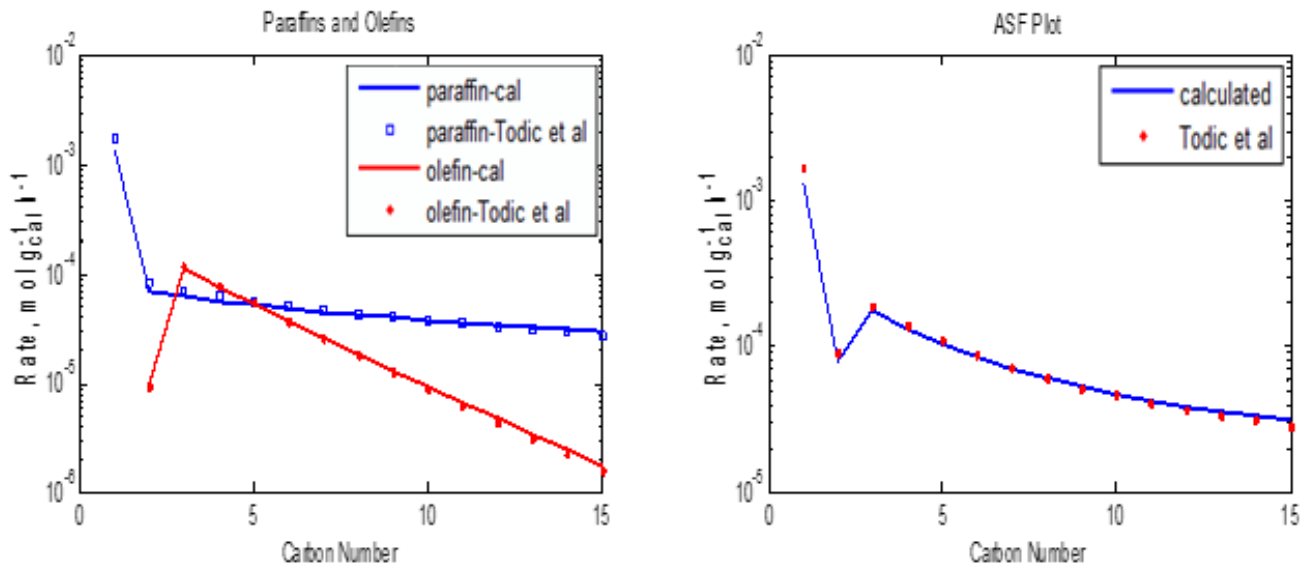

Figure 5 - Validation of Genetic Algorithm Code

\subsection{Experimental setup}

The laboratory scale Fischer-Tropsch reactor designed and commissioned at Texas A\&M at Qatar is currently been used as an important part of the multi-scale investigation on the performance of FT reactors in near critical and supercritical regions. This unit has 
been designed for unattended operation and has various safety features in place like pressure relief valves, automatic shutdown connected to gas sensors, interlocks in control system, etc. shows a schematic diagram of the feed gas and liquid delivery section, reactor section and the product collection and separation sections.

Each of the feed gases (Syngas, $\mathrm{CO}, \mathrm{H}_{2}$ and $\mathrm{Ar}$ ) passes through a purification section for removal of COS, moisture, oxygen and transition metal carbonyls. After passing through the Mass Flow Controllers and Emergency Shutdown valves, all the reactant gases combine at a mixing point. If the reactor is operating in supercritical solvent phase, the solvent is vaporized in a vessel before mixing with the feed gases. The gas mixture passes through a static mixer tube which ensures uniform gas composition. The gas mixture enters the reactor bed which is fitted with thermocouples to monitor the reactor bed temperature profile. The reactor pressure is maintained by a back-pressure valve that serves as a pressure regulator in the reactor outlet. The reactor effluent enters the hot trap vessel. The hot trap is operated at $\sim 135{ }^{\circ} \mathrm{C}$ to separate the high molecular weight waxes $\left(\mathrm{C}_{40+}\right)$ in semi-solid form from the remaining hydrocarbons. Only the heavy waxes settle down and the remaining gas is sent to a custom built Shimadzu GC-2014 Gas Chromatograph (GC) system for product characterization. The GC system is able to characterize the FT product from $\mathrm{C}_{1}-\mathrm{C}_{15}$. Argon which is an inert gas is used as an internal standard by which the peak areas of other compounds are quantified in the GC output results. After the GC system, the gas mixture then passes to the cold trap vessel where a low temperature of $4{ }^{\circ} \mathrm{C}$ is maintained to condense all remaining hydrocarbons. The liquid level in the cold trap is maintained by a level control valve. The liquid samples 
are manually injected into a GC-MS system to further characterize higher hydrocarbons up to carbon number 34. The individual sections are described in further detail in subsequent sections. 


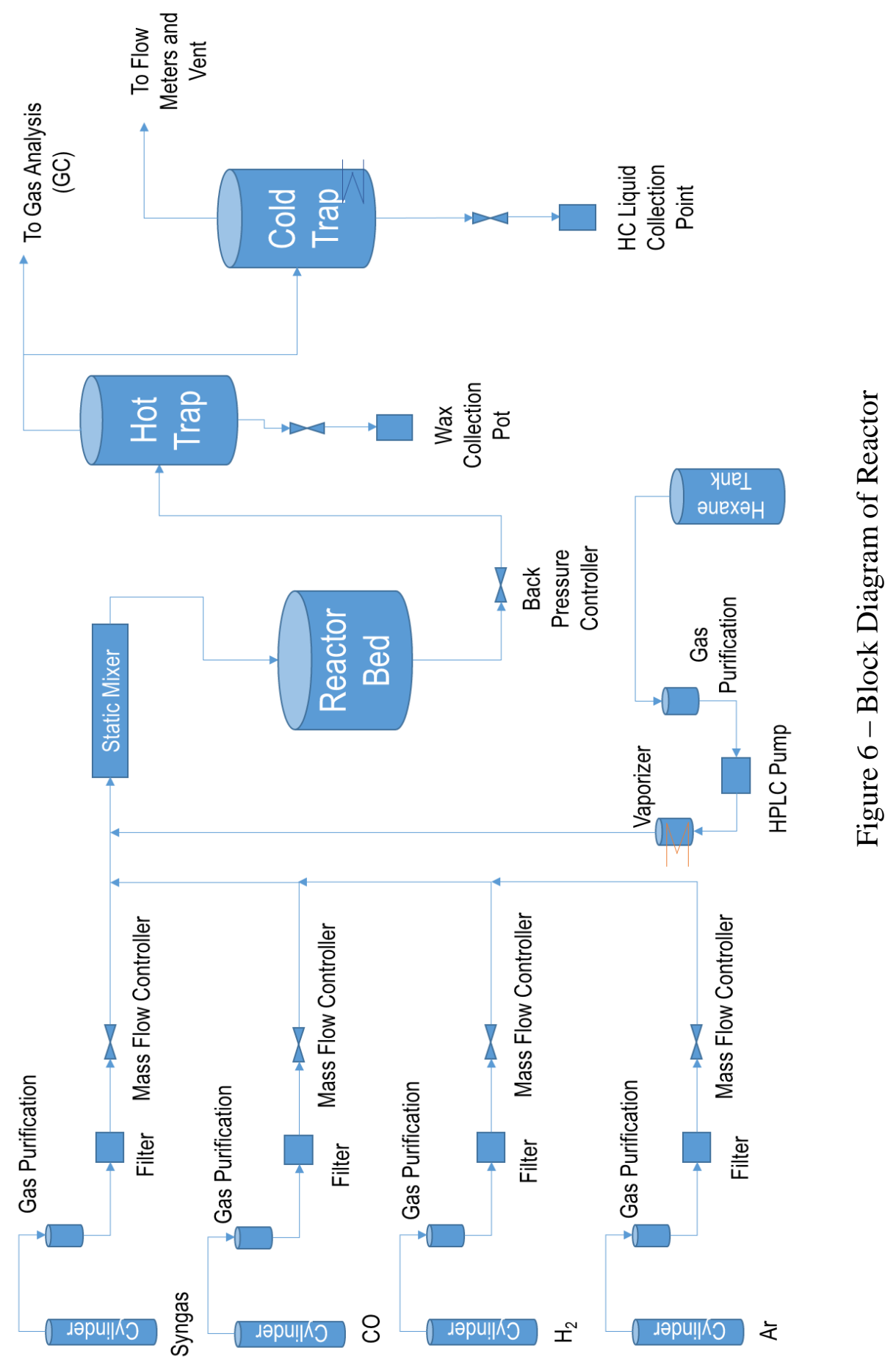




\subsubsection{Feed section}

The feed section controls the flow rates of gases and liquids flowing into the FT reactor. The gas feed consist of dedicated lines for hydrogen $\left(\mathrm{H}_{2}\right)$, syngas (a mixture of $\mathrm{CO}$ and $\mathrm{H}_{2}$ ), argon $(\mathrm{Ar})$ and carbon monoxide $(\mathrm{CO})$. A typical gas line starts at the gas cylinder. Passing through the cylinder's pressure regulator and flow restriction, the gas enters the purification column. There is a provision for purge line, upstream of the purification column to purge the lines during initial unit start-up. After purification, the gas passes through a filter, an emergency shutdown valve (ESDV), forward pressure regulator $(\mathrm{PV})$, mass flow controller $(\mathrm{MFC})$ and eventually enters the mixing point through a non-return valve (NRV). A pressure relief valve (PSV) installed before the MFC to prevent over pressurization of the system. The relief pressure is set at $135 \mathrm{bar}$. The feed lines of all gases are similar except for $\mathrm{CO}$ where a pressure booster and a buffer vessel are used to optimize CO usage. A part of the Ar is taken to the wax collector and the Liquid product tank. This has been done to facilitate purging, when required. The Ar line to Wax collector has been heat traced to increase wax temperature and enhance its mobility and flow properties.

The solvent hexane feed system consists of solvent storage, purification column, 6-way valve, high-pressure HPLC pump and vaporization vessel. A plastic container serves as the hexane tank. A $\mathrm{N}_{2}$ connection and a vent provision are provided to maintain an inert atmosphere in the tank. The hexane from the tank flows through the purification column into a 6-way valve port which serves to inject tracer chemicals into the system. A HPLC pump transfers the hexane into a vaporizer column through NRV and a PSV. The 
vaporizer heats and vaporizes the solvent feed before it mixes with the gaseous feed. The combined gas + solvent feed enter a static mixer to ensure uniform mixing before the feed enters the reactor. Starting from the vaporization vessel, all lines up to the cold trap are heat insulated. A PSV is provided at the reactor inlet.

The flow meters shown in Figure 6 were calibrated with the corresponding response in the gas chromatograph. As Argon is used as the carrier gas, the ratio of the peak area of the reactant gas and the peak area of Ar was used to calibrate the mass flow meters. From the calibration curve, it becomes easy to compute actual flow of the gas at normal conditions from the peak areas which are obtained from the results in the GC. The calibration curve used for $\mathrm{CO}$ is shown in Figure 7.

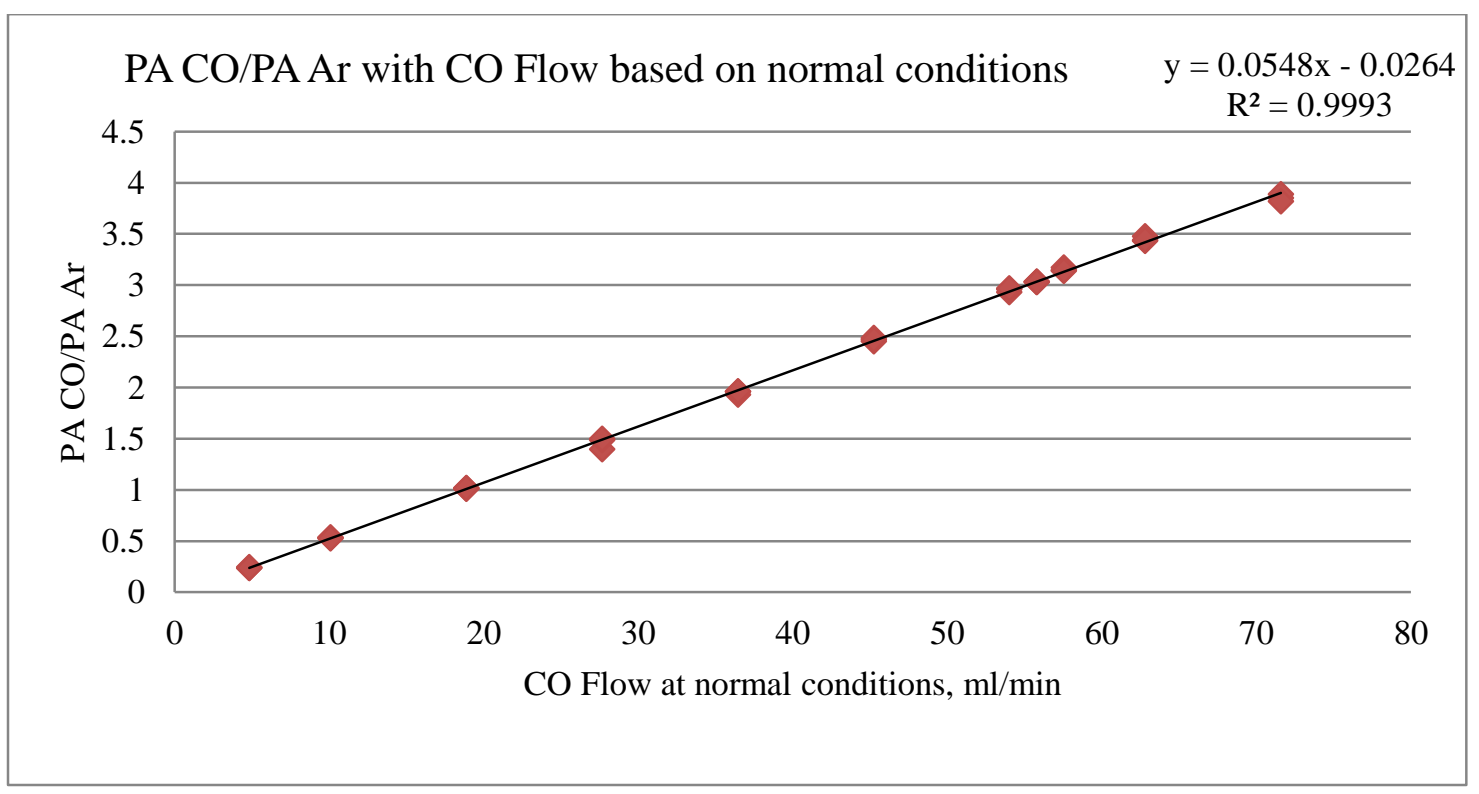

Figure 7 - Calibration Curve for CO flow-rates 
Apart from this, the mass flow-controllers of each reactant gas were calibrated based on a counter installed in the vent of the cold trap. Every $5 \mathrm{~mL}$ of gas increase count by 1 and this was displayed on the control screen on the computer. By varying the set point of the flow-controller and calculating actual flow at standard conditions, 3 graphs were plotted for the calibration of syngas, $\mathrm{CO}$ and $\mathrm{H}_{2}$ flow meters. This made calculations simpler by directly converting set point to flow controller to actual standard flow rates of each individual gas. The calibration charts for the flow meters are shown below.
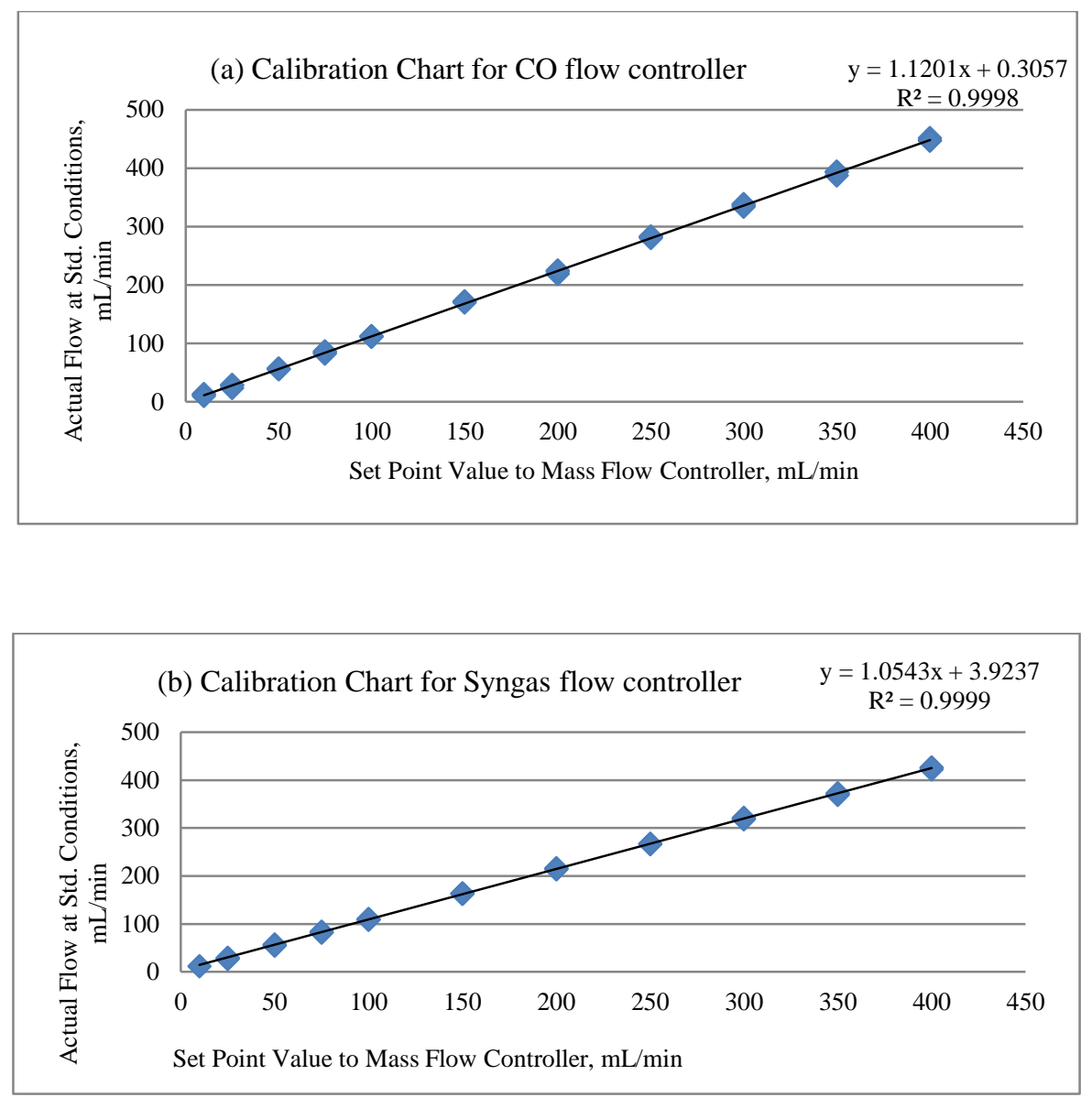

Figure 8 - Calibration Charts for $\mathrm{CO}$, Syngas and $\mathrm{H}_{2}$ Flow Controllers 


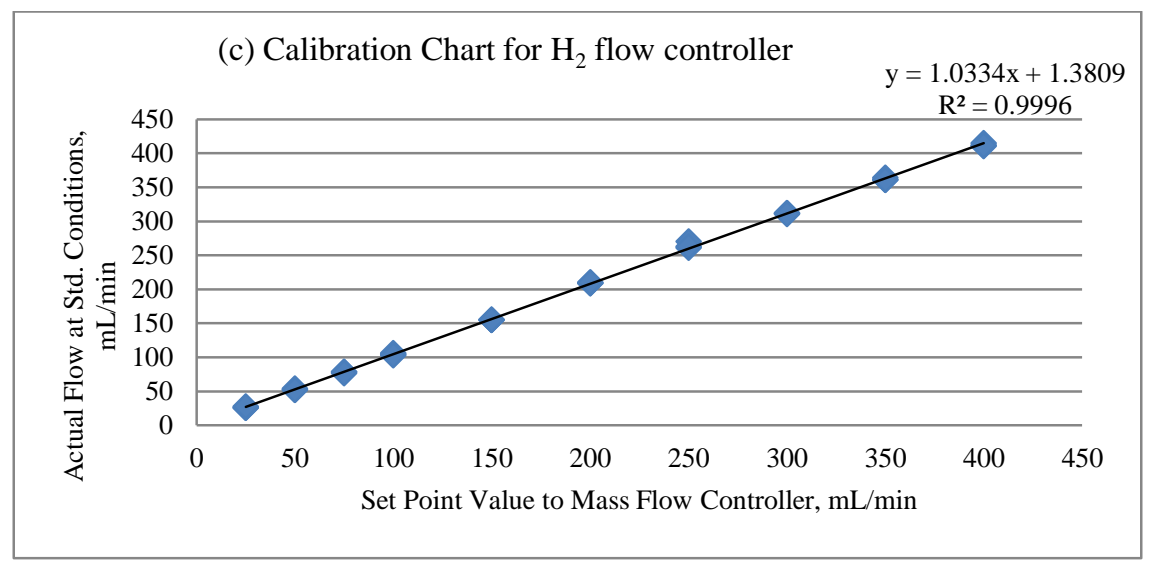

Figure 8 (Continued)

\subsubsection{Reactor}

The mixed feed enters the fixed bed where it contacts the FT catalyst. The fixedbed reactor was loaded with $0.25 \mathrm{~g}$ of $15 \mathrm{wt} \% \mathrm{Co} / \mathrm{Al}_{2} \mathrm{O}_{3}$ catalyst which was provided by Professor Dragomir Bukur's research team at Texas A\&M University at Qatar. Three thermocouples are provided in the bed axially for better temperature monitoring and control of the catalyst bed. The fixed bed can withstand up to 150 bar pressure and 400 ${ }^{\circ} \mathrm{C}$. The pressure in the reactor is maintained by a back pressure regulator (BPR). The reactor tube is made of Stainless Steel 316 and has an overall length of 16" with the heated length being 12 '. Hence, the net volume in the heated zone is approx. $73 \mathrm{cc}$. The reactor internal diameter is $0.688^{\prime \prime}$ and outer diameter is 1 "'. The thermowell installed in the reactor bed are of 0.25 ' size. The reactor is sealed tightly with single nut tightening. The catalyst support is located approx. at $12 \mathrm{~cm}$ from the bottom of the reactor. 


\subsubsection{Separation and product analysis}

The FT product stream after reaction enters the hot trap through the BPR. The line from the reactor to the hot trap is heat traced to prevent any condensation in the line going to the GC as this may disrupt flow consistency. The wax product from the FT settles down in the hot trap, passes through an air-actuated manual valve and gets collected in the wax collector. The Ar utility connection and a vent provision enable purging of the wax collector, when necessary. The vapor from the hot trap passes by a pressure transmitter (PT) and a thermocouple and enters an air actuated 8-way flow selecting valve to be characterized in the GC. All lines are normally returned. After this valve the flow is directed towards a cold trap. The flow selected towards the GC is directed through a 1/16" tube. The outlet from the GC is returned to the rig through an NRV and joins the line towards a cold trap. A cooling water circuit cools down the remaining condensing vapor entering the cold trap. The liquid product passes through a level control valve and settles in the liquid collection vessel. An Ar utility connection and purge provision is provided to the collection vessel. The liquid product has been collected for further analysis.

The vapor from the cold trap returns to the 8-way switch valve for analysis. The unselected flow is directed towards the flow meter. A PSV provided upstream of the switch valve helps prevent over-pressurized vapor from reaching the GC and downstream equipment. The vapor outlet passes through a 3-way valve for purge and a PT to reach the flow meter (FQI). A water column connection to the vapor line helps prevent high pressure in the FQI. This is because of the low operating pressure of the FQI element. The outlet from the FQI is safely disposed off through the fume hood. A vent pot collects all the 
liquid or vapor discharged through any relief valves. The vapor is disposed through the fume hood and the liquid is drained at regular intervals.

The set of experimental data points is shown in Table 4 with the objective of obtaining meaningful FT kinetic data over a variety of operating conditions in terms of gas hourly space velocity, $\mathrm{H}_{2} / \mathrm{CO}$ feed ratio, partial pressures, and temperature. These conditions have been selected to determine the kinetic parameters and to operate the fixed bed reactor as a differential reactor operating at low conversions, thus minimizing the heat and mass transfer limitations.

Table 4 - Experimental Conditions planned for Kinetic Study

\begin{tabular}{|c|c|c|c|c|c|}
\hline $\begin{array}{l}\text { Run } \\
\text { No. }\end{array}$ & $\begin{array}{c}\text { Syngas Flow }\left(\mathbf{C O}+\mathbf{H}_{2}\right) \text {, } \\
\text { NmL/min } \\
\left(\text { at } 0{ }^{\circ} \mathrm{C}, 1013 \mathrm{kPA}\right)\end{array}$ & $\begin{array}{r}\mathrm{H}_{2} / \mathrm{CO} \\
\text { Ratio } \\
\text { (molar) }\end{array}$ & $\begin{array}{c}\text { Temperature, } \\
{ }^{\circ} \mathbf{C}\end{array}$ & $\begin{array}{l}\text { Pco, } \\
\text { bar }\end{array}$ & $\begin{array}{l}\mathbf{P}_{\mathrm{H} 2}, \\
\text { bar }\end{array}$ \\
\hline 1 & 100 & 2 & 210 & 7.38 & 14.76 \\
\hline 2 & 50 & 2 & 210 & 6.26 & 12.51 \\
\hline 3 & 50 & 2 & 220 & 5.57 & 11.14 \\
\hline 4 & 56.85 & 1.28 & 220 & 7.74 & 9.88 \\
\hline 5 & 36.84 & 0.65 & 220 & 10.31 & 6.71 \\
\hline 6 & 54.43 & 0.63 & 220 & 10.32 & 6.53 \\
\hline 7 & 50 & 2 & 230 & 5.89 & 11.77 \\
\hline
\end{tabular}




\subsection{Analysis of the product distribution}

The product analysis from the custom built Shimadzu GC-2014 Gas Chromatograph for each experimental run was done to identify hydrocarbon peaks. The details on the calculations can be found in Appendix A. The gas chromatograph consists of 3 separate channels - 2 TCD (Thermal Conductivity Detector) channels and 1 FID (Flame Ionization Detector) channel. The first TCD column separates $\mathrm{H}_{2}, \mathrm{Ar}$ (carrier gas), $\mathrm{CO}$ and $\mathrm{CO}_{2}$. The second TCD column exclusively contains the $\mathrm{H}_{2}$ peak. This was done to improve the accuracy of $\mathrm{H}_{2}$ detection. The third channel which is the FID column is capable of separating the hydrocarbon products from $C_{1}$ up to $C_{15}$. Table 5 and Table 6 give the details on the column and Figure 9 shows the column oven temperature program used in the GC.

Table 5 - Details of Columns used in GC

\begin{tabular}{|c|c|}
\hline Column & Specification \\
\hline TCD-1 (for $\left.\mathrm{CH}_{4}, \mathrm{CO}\right)$ & Rt-MS-5A 0.53 mm (ID), 30 m length \\
\hline TCD-1 (for $\mathrm{CO}_{2}, \mathrm{C}_{2}$ compounds) & Rt-Q PLOT 0.53 mm (ID), 30 m length \\
\hline Fixed in second GC oven & Rtx-1 $0.53 \mathrm{~mm}$ (ID), 60 m length \\
\hline TCD-2 (for $\left.\mathrm{H}_{2}\right)$ & Rt-MS-5A $0.53 \mathrm{~mm}$ (ID), 30 m length \\
\hline
\end{tabular}


Table 6 - Temperature Programming for the GC

\begin{tabular}{|c|c|c|c|}
\hline Step & Rate $\left({ }^{\circ} \mathrm{C} / \mathrm{min}\right)$ & Temperature $\left({ }^{\circ} \mathrm{C}\right)$ & Hold Time (min) \\
\hline 0 & - & 50.0 & 6.00 \\
\hline 1 & 8.00 & 90.0 & 0.00 \\
\hline 2 & 30.00 & 240.0 & 134.00 \\
\hline
\end{tabular}

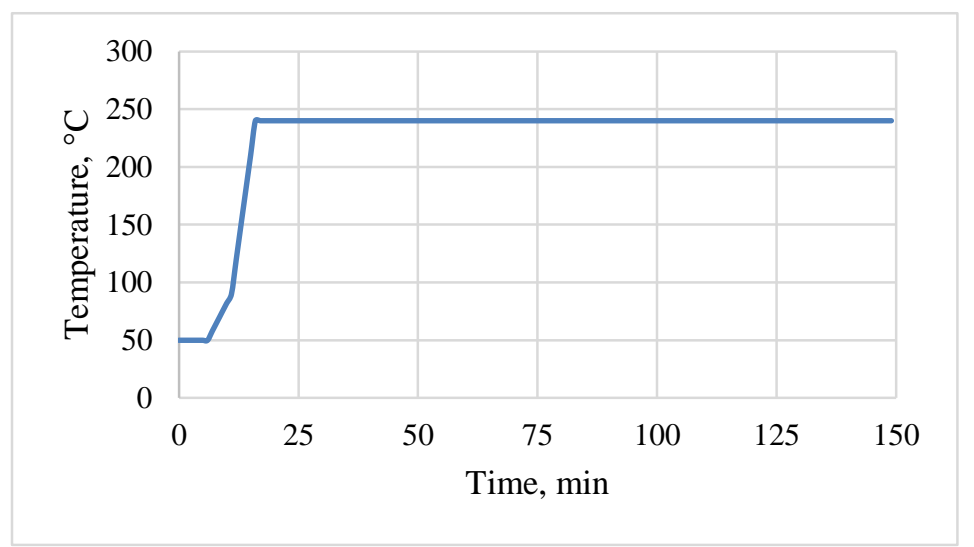

Figure 9 - Column Oven Temperature Program

\subsubsection{Identification of Alkanes / Alkenes}

The identification of olefin and paraffin peaks for lower carbon numbers up to carbon number 4 was done using a calibration gas. A known sample of a mixture of $\mathrm{C}_{1}$, $\mathrm{C}_{2}, \mathrm{C}_{3}$ olefin and paraffin and $\mathrm{C}_{4}$ isomers, paraffin and olefins was injected into the GC. Based on the retention time of individual compounds, it was possible to identify them.

For the identification of hydrocarbons of higher carbon numbers, the following approach has been used: two GC peaks were overlapped which corresponded to reaction conditions of highest molar $\mathrm{H}_{2} / \mathrm{CO}$ ratio (2) and lowest molar $\mathrm{H}_{2} / \mathrm{CO}$ ratio (0.63). From the reaction chemistry of Fisher-Tropsch, it can be summarized and this has been proven 
experimentally too [45] that a high $\mathrm{H}_{2}$ content results in double-bond saturation leading to formation of predominantly paraffins. On the other hand, $\mathrm{H}_{2}$ deficiency results in the unsaturation and after chain termination results in formation of a larger number of olefins as compared to the previous case. This concept has been used in this analysis to identify the olefin and paraffin peaks up to carbon number 15. In Figure 10, the dotted line corresponds to the low $\mathrm{H}_{2} / \mathrm{CO}$ condition of 0.63 and the solid line corresponds to the high $\mathrm{H}_{2} / \mathrm{CO}$ ratio of 2 .

The following scheme was used to identify the peaks:

- The peak which has a larger FID response in $\mathrm{H}_{2}$ deficient conditions is an olefin (Eg. Peak No. 2 is a $\mathrm{C}_{4}$ olefin which was also confirmed by the calibration gas)

- The peak which has a larger peak area in $\mathrm{H}_{2}$ rich conditions is a paraffin (Eg. Peak No. 1,3,6 are $\mathrm{C}_{4}$ paraffins which was again confirmed by the calibration gas)

- Peaks overlapping perfectly in shape and size were regarded as paraffins (Eg. Peak No. 4, 5 were categorized under paraffins. Upto carbon number 4, this could be verified by the calibration gas test, however for higher carbon numbers, these peaks have been categorized under paraffins which become insignificant in FID response at higher carbon numbers) 


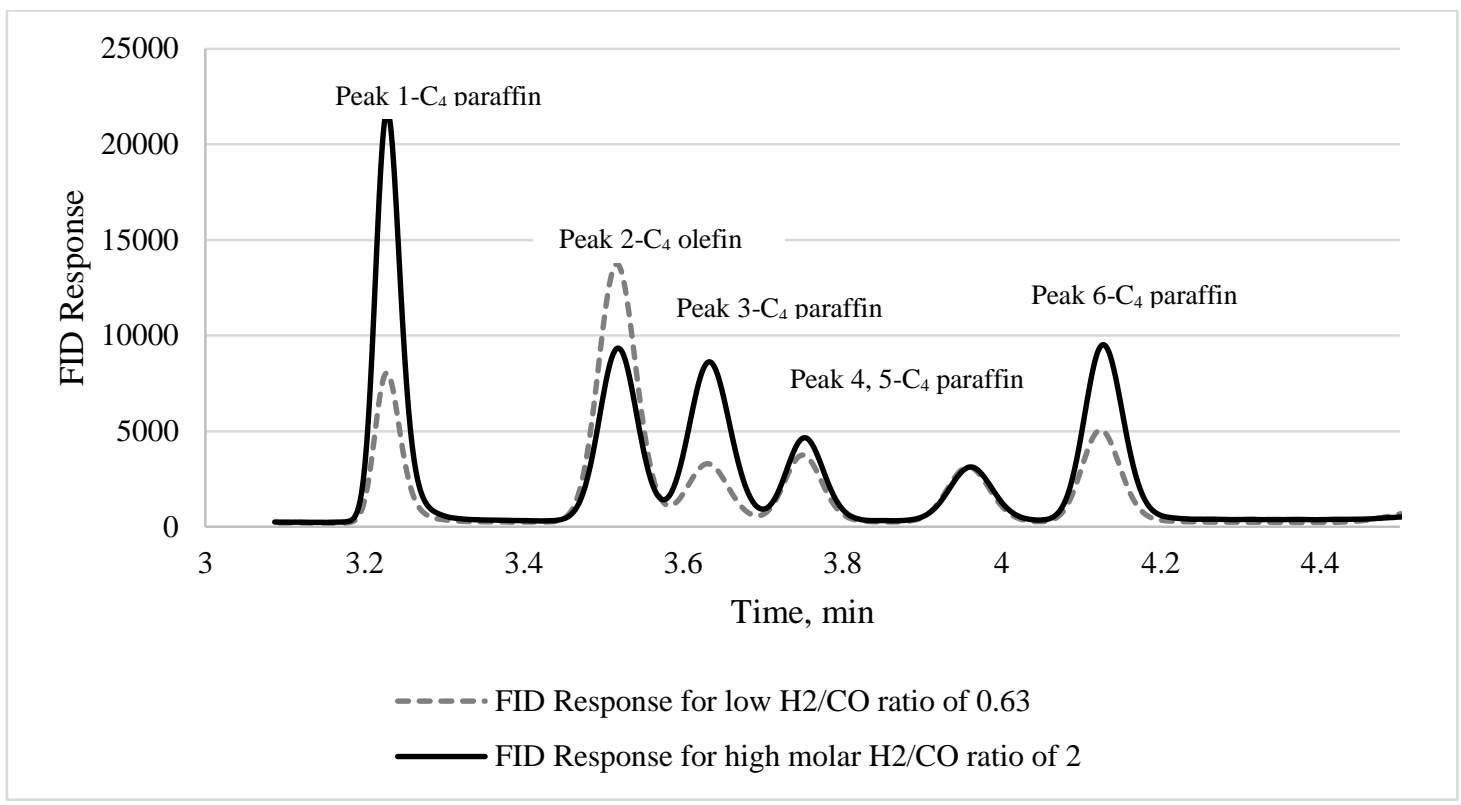

Figure 10 - Identification of Olefin Peaks

\subsubsection{Deconvolution of $\mathrm{C}_{3}$ peaks}

Since the propylene and propane peaks have retention times close to each other, they merge to form a composite curve as shown by the solid line in Figure 11. Hence, a MATLAB code [46] was used for peak-splitting. The resultant peaks (dotted lines) were normalized to the areas obtained and these values were used in the product distribution analysis. The composite curve was resolved into 2 Gaussian peaks, the first one corresponding to propylene and the next to propane. This is due to the fact that in the calibration step it was observed from the GC response that up to carbon number 4 , the alkene always precedes the alkane. 


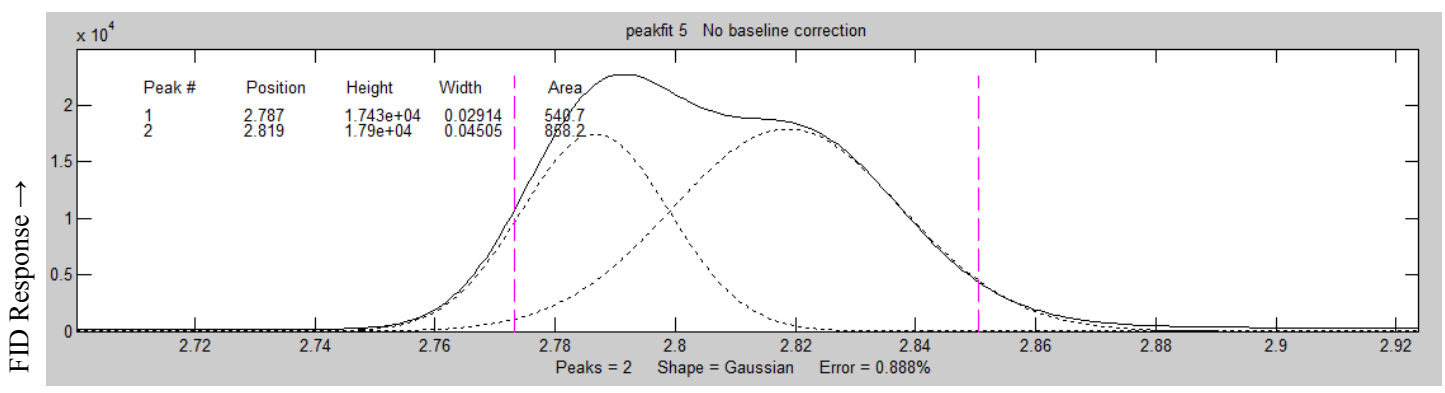

Time, $\min \rightarrow$

Figure 11 - Deconvolution of $\mathrm{C}_{3}$ peaks 


\section{CHAPTER IV}

\section{RESULTS AND DISCUSSION}

This chapter discusses the experimental results obtained from the Reactor. The experimental results are discussed first in Section 4.1. After working up the raw data obtained from the reactor to the form required by the MATLAB program, the data was fed to the MATLAB code to estimate parameters. This is discussed in detail in Section 4.2.

\subsection{Experimental results}

The reaction was carried out for a total time-on-stream (TOS) of 380 hours. Sufficient time was allowed in each run for the unit to reach steady state which was decided based on steady state behavior of $\mathrm{CO}$ conversion \% graphs qualitatively. The $\mathrm{CO}$ conversion $\%$ data with TOS is shown in Figure 12. The CO consumption rate graph is shown in Figure A1 in Appendix A. Seven set of conditions were maintained in the reactor as shown in Table 7 below.

Table 7 - Experimental Results for all runs

\begin{tabular}{|c|c|c|c|c|c|c|}
\hline $\begin{array}{l}\text { Run } \\
\text { No. }\end{array}$ & $\begin{array}{c}\text { Syngas Flow } \\
\left(\mathrm{CO}+\mathrm{H}_{2}\right), \\
\text { NmL/min* }\end{array}$ & $\begin{array}{c}\mathrm{H}_{2} / \mathrm{CO} \\
\text { Ratio } \\
\text { (molar) }\end{array}$ & $\begin{array}{c}\text { Temperature, } \\
{ }^{\circ} \mathbf{C}\end{array}$ & $\begin{array}{l}\text { Pco, } \\
\text { bar }\end{array}$ & $\begin{array}{l}\text { PH2, }_{\text {bar }} \\
\text { be }\end{array}$ & $\begin{array}{c}\text { Conversion, } \\
\%\end{array}$ \\
\hline 1 & $100 \pm 0.73$ & 2 & 210 & 7.38 & 14.76 & $3.07 \pm 0.30$ \\
\hline 2 & $50 \pm 1.3$ & 2 & 210 & 6.26 & 12.51 & $5.42 \pm 1.43$ \\
\hline
\end{tabular}


Table 7 (Continued)

\begin{tabular}{|c|c|c|c|c|c|c|}
\hline $\begin{array}{l}\text { Run } \\
\text { No. }\end{array}$ & $\begin{array}{l}\text { Syngas Flow } \\
\left(\mathrm{CO}+\mathrm{H}_{2}\right) \text {, } \\
\text { NmL/min* }\end{array}$ & $\begin{array}{c}\mathrm{H}_{2} / \mathrm{CO} \\
\text { Ratio } \\
\text { (molar) }\end{array}$ & $\begin{array}{c}\text { Temperature, } \\
{ }^{\circ} \mathrm{C}\end{array}$ & $\begin{array}{l}\text { Pco, } \\
\text { bar }\end{array}$ & $\begin{array}{l}\mathbf{P H}_{\mathrm{H}}, \\
\text { bar }\end{array}$ & $\begin{array}{c}\text { Conversion, } \\
\%\end{array}$ \\
\hline 3 & $50 \pm 1.3$ & 2 & 220 & 5.57 & 11.14 & $7.97 \pm 0.24$ \\
\hline 4 & $56.85 \pm 1.68$ & 1.28 & 220 & 7.74 & 9.88 & $2.76 \pm 0.27$ \\
\hline 5 & $36.84 \pm 1.68$ & 0.65 & 220 & 10.31 & 6.71 & $5.25 \pm 0.28$ \\
\hline 6 & $54.43 \pm 1.68$ & 0.63 & 220 & 10.32 & 6.53 & $2.57 \pm 0.29$ \\
\hline 7 & $50 \pm 1.3$ & 2 & 230 & 5.89 & 11.77 & $10.99 \pm 0.41$ \\
\hline
\end{tabular}

*Uncertainty in values has been calculated for corresponding flow-meter used in each case as syngas flow-rate is the sum of individual mass flow-rates of $\mathrm{CO}$ and $\mathrm{H}_{2}$ flow-rates in runs 4-6. The $\mathrm{CO}$ and $\mathrm{H}_{2}$ flow-controllers have been individually calibrated using a volume counter in the vent of cold trap.

The Argon flow was adjusted to maintain constant syngas partial pressure of 25 bar in the reactor for different runs. As shown in Figure 12 (b), a reduction in the syngas flow-rate from $100 \mathrm{Nml} / \mathrm{min}$ to $50 \mathrm{Nml} / \mathrm{min}$ between run 1 and run 2 caused the $\mathrm{CO}$ conversion to increase from $3.07 \pm 0.30 \%$ to $5.42 \pm 1.43 \%$, although there was no corresponding increase in $\mathrm{CO}$ consumption rate. This is an expected behavior as the catalyst activity is constant, the moles of $\mathrm{CO}$ reacted remains constant but the conversion $\%$ changes. 
An increase in the reactor bed temperature by $10{ }^{\circ} \mathrm{C}$ (to $220^{\circ} \mathrm{C}$ ) in run 3 while keeping the flow-rate constant, resulted in an increase in activity. Consequently, the CO conversion rose to $7.97 \pm 0.24 \%$. The conversion from the next run (run 4) was lower due to the low $\mathrm{H}_{2} / \mathrm{CO}$ inlet ratio (i.e. lower partial pressure of $\mathrm{H}_{2}$ ). In run 5, the syngas flow-rate was reduced and the $\mathrm{H}_{2} / \mathrm{CO}$ ratio was adjusted to 0.65 . The conversion and activity were found to increase due to lower flow-rates and higher partial pressure of $\mathrm{CO}$. In run 6 , keeping the partial pressures of $\mathrm{CO}$ and $\mathrm{H}_{2}$ constant, the syngas flowrate was increased from 36.84 to $54.43 \mathrm{Nml} / \mathrm{min}$. This resulted in a lower conversion and $\mathrm{CO}$ activity. Finally, the last run (run 7) was at $230^{\circ} \mathrm{C}$ and hence resulted in the highest $\mathrm{CO}$ activity among all runs. The $\mathrm{CO}$ conversion in all runs was maintained at low levels, with all the runs being below $12 \%$. This provided the meaningful kinetic data required for input to the MATLAB® code. 


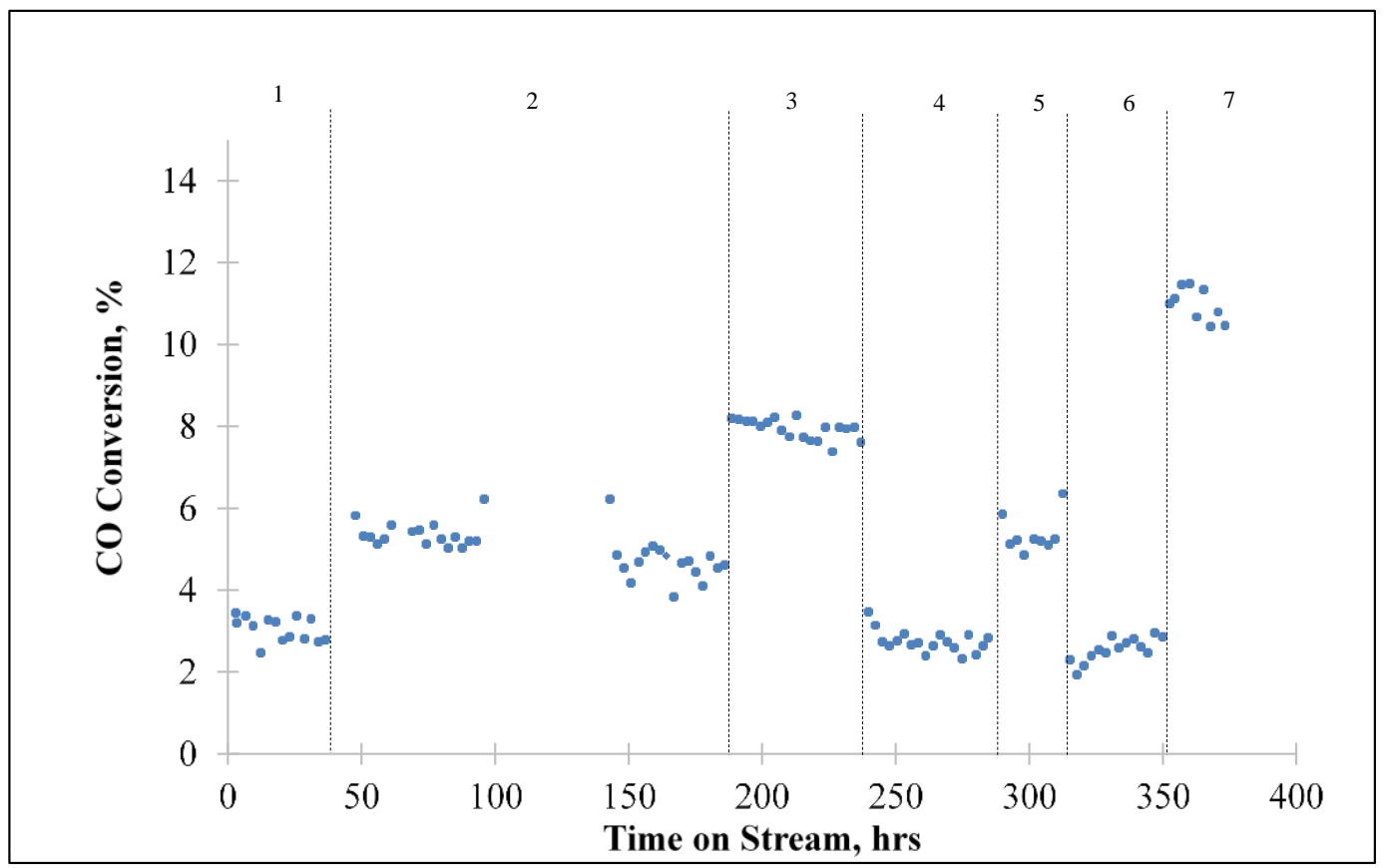

Figure 12 - CO Conversion $\%$ with time-on-stream

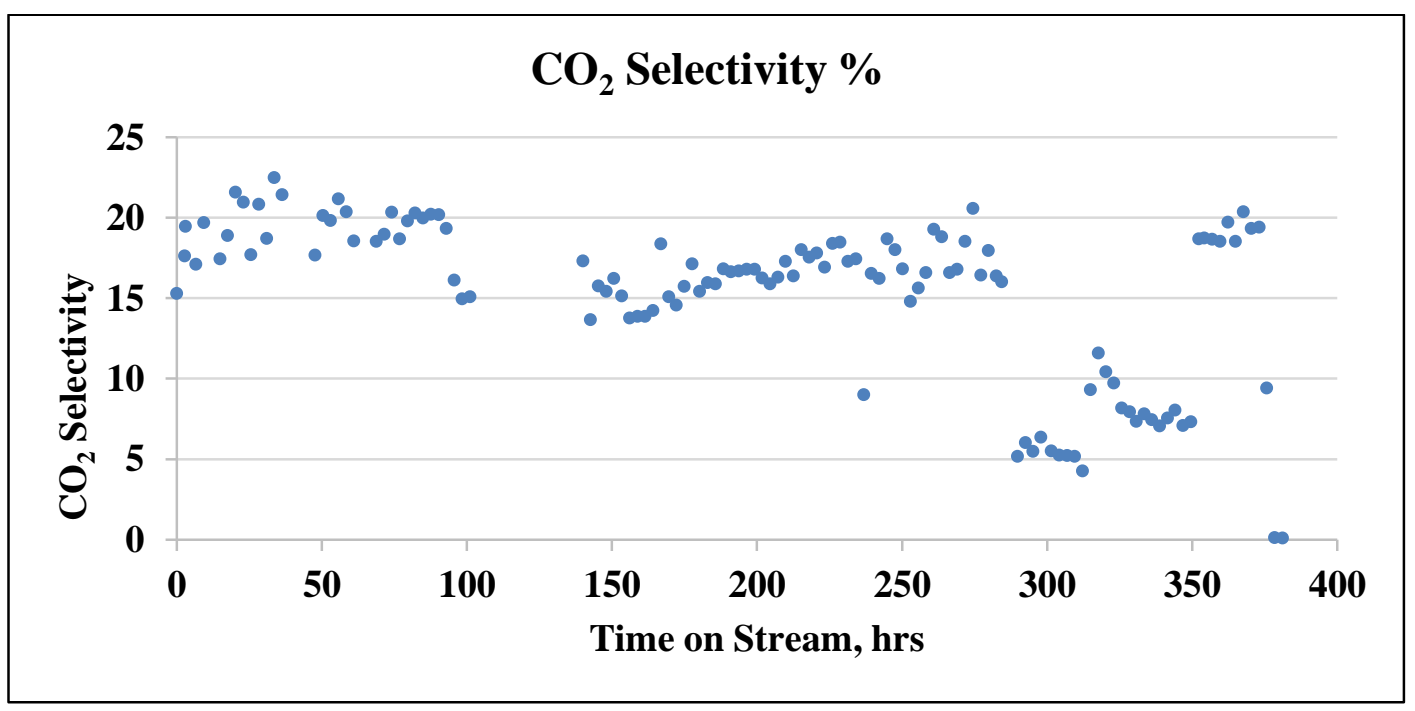

Figure $13-\mathrm{CO}_{2}$ Selectivity with time-on-stream 


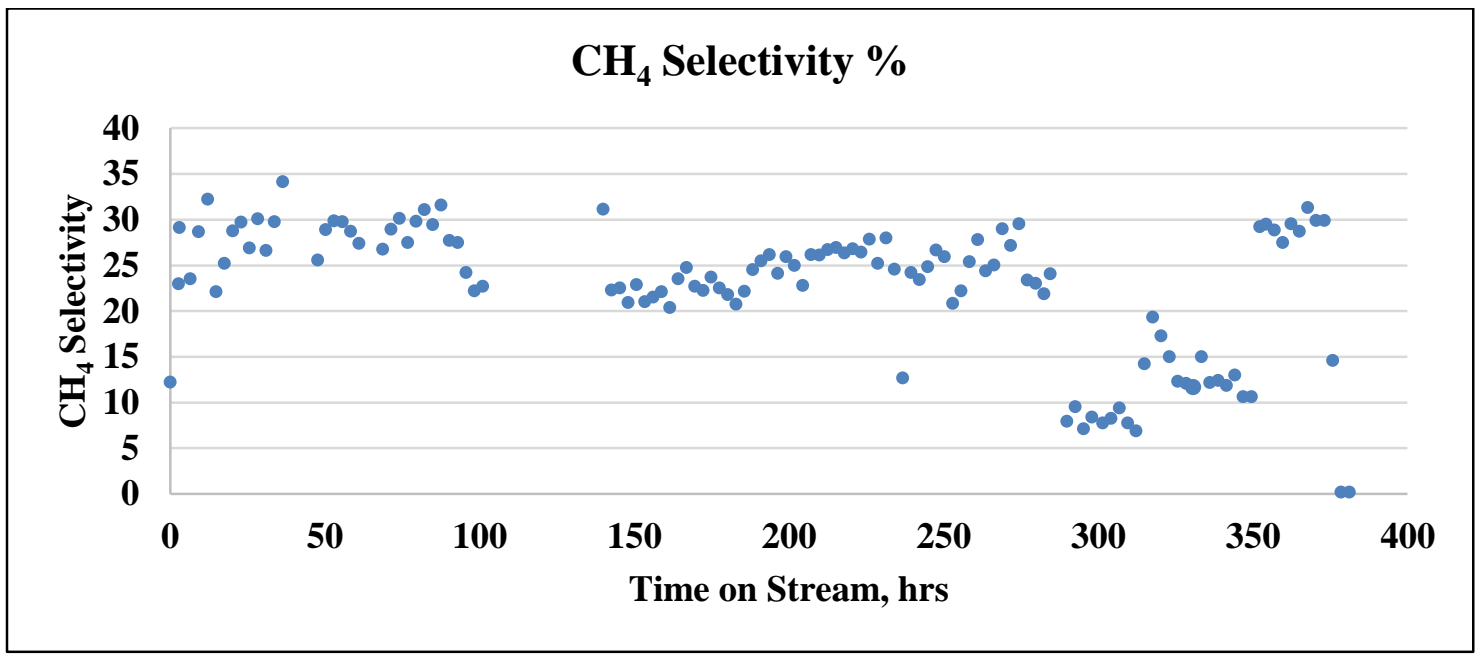

Figure $14-\mathrm{CH}_{4}$ Selectivity with time-on-stream

Figure 13 and Figure 14 show the $\mathrm{CO}_{2}$ selectivity and $\mathrm{CH}_{4}$ selectivity, respectively, with Time-on-Stream (TOS). Both $\mathrm{CO}_{2}$ and $\mathrm{CH}_{4}$ are undesirable products in FT as they reduce the production of long chain hydrocarbons. $\mathrm{CO}_{2}$ selectivity was quite high and varied between 15 to $20 \%$ for all runs except Runs No. 5 and 6 where the reading was in the range of 5-10\%. For Runs No. 5 and 6 , the $\mathrm{H}_{2} / \mathrm{CO}$ molar ratio was kept low at 0.64 (average).

Methane selectivity varied between $20-30 \%$ for all runs except Run No. 5 and 6 where in the range of $8-12 \%$. The low $\mathrm{H}_{2} / \mathrm{CO}$ ratio results in hydrogen deficient conditions which leads to a higher chain growth probability resulting in lesser methane formation rates. Moreover, the high methane selectivity could be a result of the catalyst which has been synthesized locally and is not a commercial catalyst where these parameters are an integral part of catalyst design. 
The result of analysis is given in detail for each run in Appendix B. The product profile graphs for the third run $\left(50 \mathrm{NmL} /\right.$ min syngas, $\left.\mathrm{H}_{2} / \mathrm{CO}=2: 1,220^{\circ} \mathrm{C}\right)$ are shown below. In Figure 15, the total sum of peak areas with carbon numbers is shown. The peak area for carbon number 6 is unusally higher than 5 and 7 . This is attributed to the use of hexane $\left(\mathrm{C}_{6}\right)$ for the use of cleaning and flushing of lines in the reactor system. Hence, in the product analysis, $\mathrm{C}_{6}$ paraffin and olefin formation rates have been estimated by averaging the $\mathrm{C}_{5}$ and $\mathrm{C}_{7}$ formation rates.

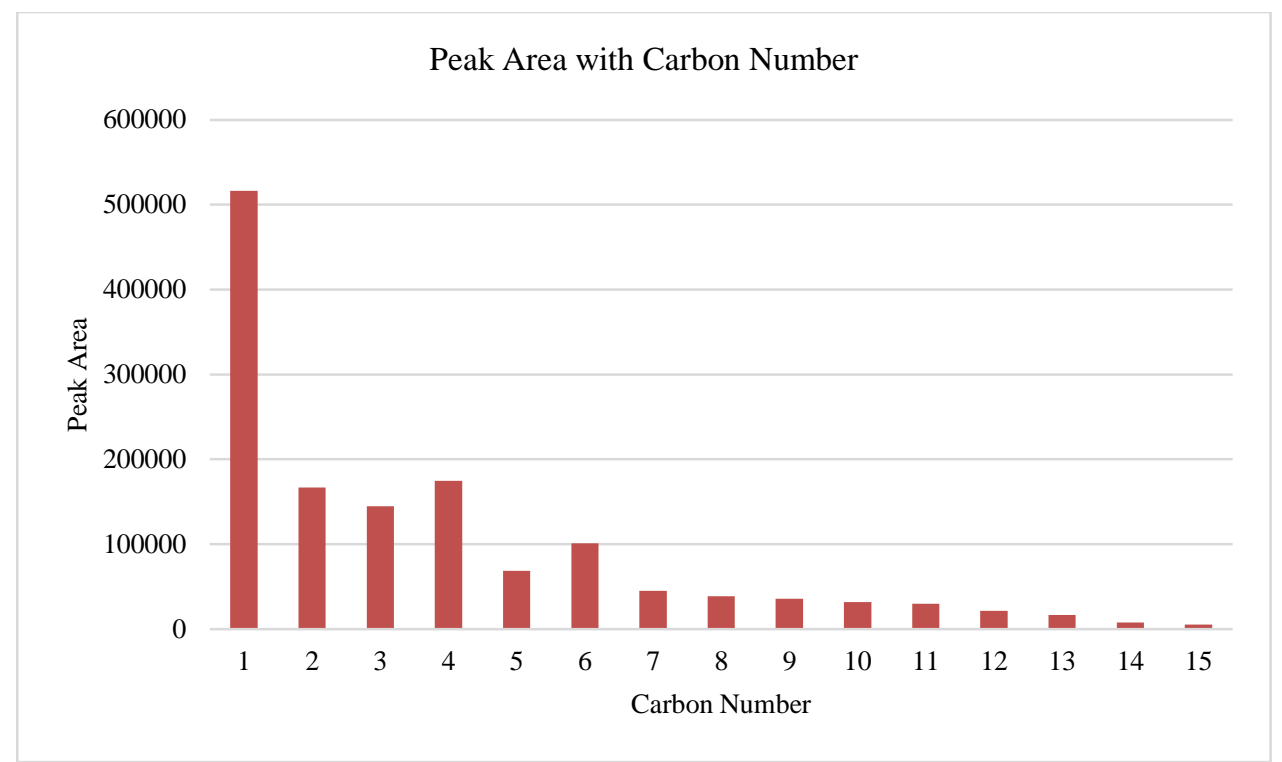

Figure 15 - Peak Area with Carbon Number for Run No. 3

The hydrocarbon formation rates including olefin and paraffin rates for Run No. 3 are shown in Figure 16. As shown in the graph, the olefin formation rates drop at a higher rate for higher carbon numbers. This is due to the expected non-ideal ASF distributions. Theories put forward in literature to explain this behavior are discussed in section 1.1. 


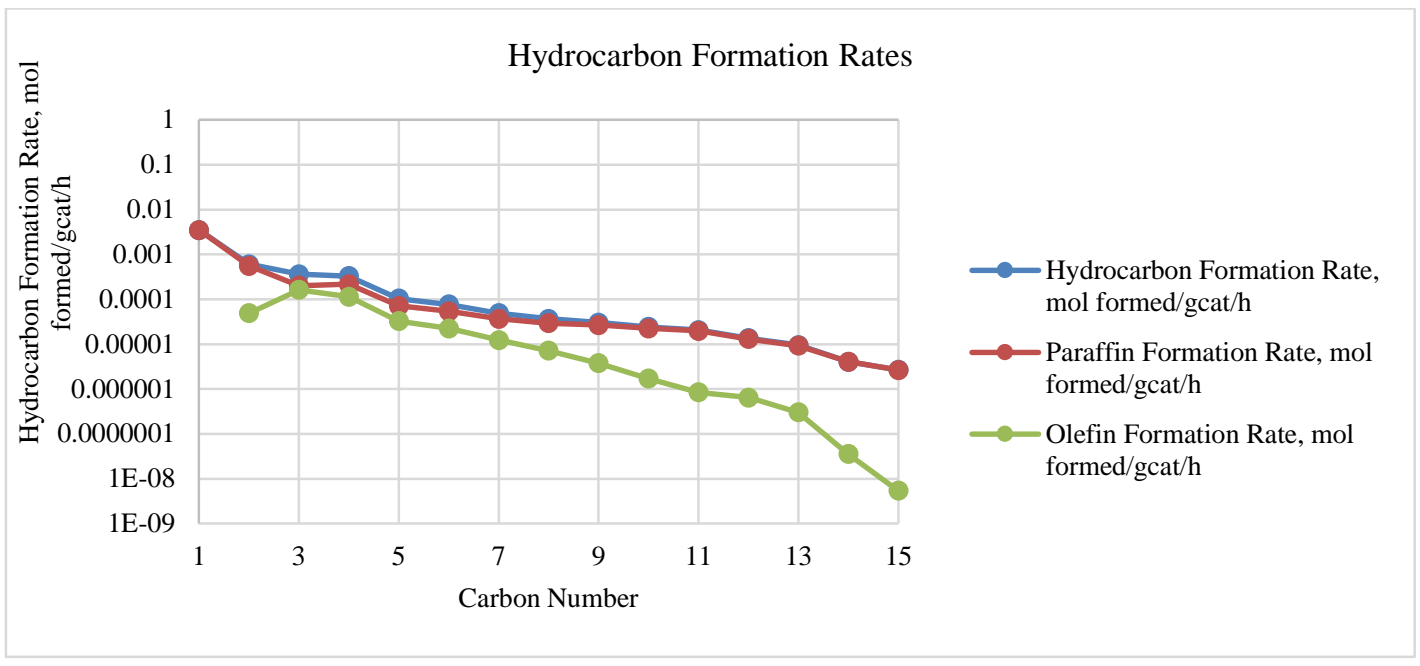

Figure 16 - Hydrocarbon Formation Rates with Carbon Number for Run No. 3

The ASF plot for Run No. 3 has been shown in Figure 17. As expected for FischerTropsch product profiles, the graph of $\ln \left(\mathrm{W}_{\mathrm{n}} / \mathrm{n}\right)$ with $\mathrm{n}$ is a straight line with negative slope. The ASF equation is as follows:

$$
\frac{\mathrm{W}_{\mathrm{n}}}{\mathrm{n}}=(1-\alpha) \times \alpha^{\mathrm{n}-1}
$$

The olefin-to-paraffin ratio versus carbon number is shown in Figure 18. 


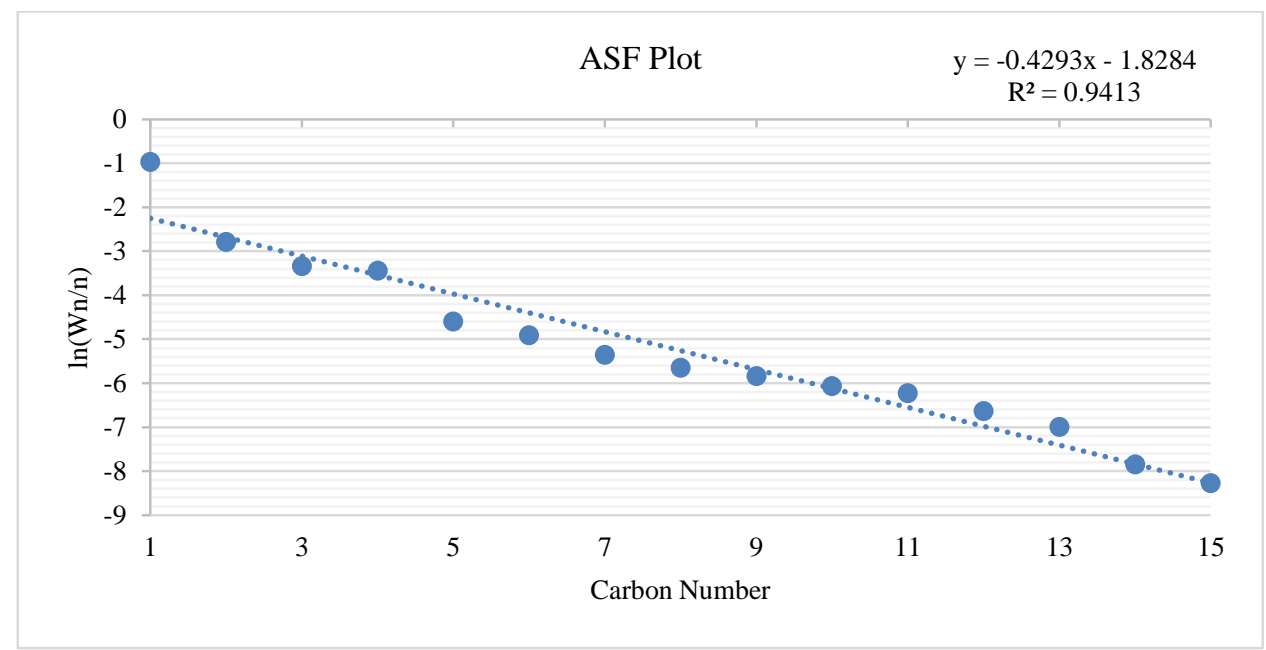

Figure 17 - ASF Plot for Run No. 3

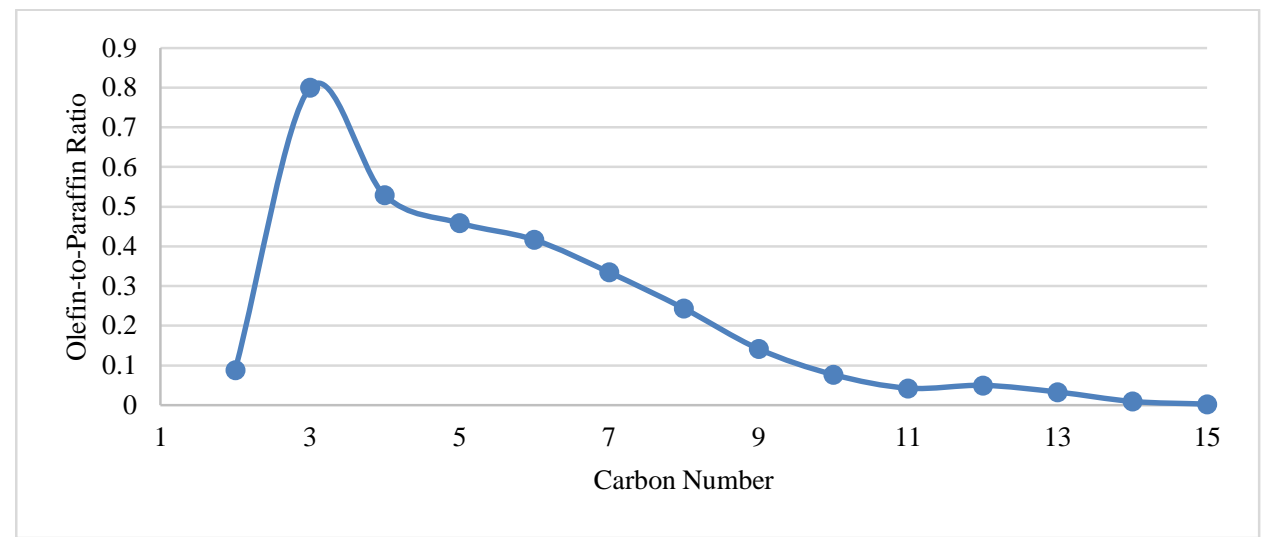

Figure 18 - Olefin-to-Paraffin Ratio with Carbon Number for Run No. 3

\subsection{Model results}

The data obtained from the reactor was fed into the GA program. The values for the parameters obtained are given in Table 8 . The convergence of the parameters has been discussed in Appendix B. 
Table 8 - Model Results

\begin{tabular}{|c|c|c|}
\hline Parameter & Value & Units \\
\hline A1 & $1.87 \mathrm{E}+04$ & $\mathrm{~mol} / \mathrm{gcat} / \mathrm{h} / \mathrm{MPa}$ \\
\hline A2 & $4.02 \mathrm{E}+04$ & - \\
\hline A3 & $4.15 \mathrm{E}-03$ & $\mathrm{MPa}^{-1}$ \\
\hline A4 & $3.48 \mathrm{E}+01$ & - \\
\hline A5 & $9.71 \mathrm{E}+05$ & $\mathrm{~mol} / \mathrm{gcat} / \mathrm{h} / \mathrm{MPa}$ \\
\hline $\mathrm{A} 5, \mathrm{~m}$ & $1.55 \mathrm{E}+08$ & $\mathrm{~mol} / \mathrm{gcat} / \mathrm{h} / \mathrm{MPa}$ \\
\hline A6,0 & $9.74 \mathrm{E}+09$ & $\mathrm{~mol} / \mathrm{gcat} / \mathrm{h}$ \\
\hline A6,e & $6.47 \mathrm{E}+07$ & $\mathrm{~mol} / \mathrm{gcat} / \mathrm{h}$ \\
\hline A7 & $9.74 \mathrm{E}+09$ & $\mathrm{MPa}^{-1}$ \\
\hline E1 & 50.69 & $\mathrm{~kJ} / \mathrm{mol}$ \\
\hline E5 & 76.31 & $\mathrm{~kJ} / \mathrm{mol}$ \\
\hline E5.m & 83.57 & $\mathrm{~kJ} / \mathrm{mol}$ \\
\hline E6,0 & 89.23 & $\mathrm{~kJ} / \mathrm{mol}$ \\
\hline E6,e & 80.00 & $\mathrm{~kJ} / \mathrm{mol}$ \\
\hline$\Delta \mathrm{H} 2$ & 22.01 & $\mathrm{~kJ} / \mathrm{mol}$ \\
\hline$\Delta \mathrm{H} 3$ & 15.57 & $\mathrm{~kJ} / \mathrm{mol}$ \\
\hline$\Delta \mathrm{H} 4$ & 8.64 & $\mathrm{~kJ} / \mathrm{mol}$ \\
\hline$\Delta \mathrm{H} 7$ & -16.70 & $\mathrm{~kJ} / \mathrm{mol}$ \\
\hline$\Delta \mathrm{E}$ & 2.91 & $\mathrm{~kJ} / \mathrm{mol} / \mathrm{CH}_{2}$ \\
\hline
\end{tabular}


The model parameters listed above are intrinsic constants. Hence, they are expected to give a good fit of the experimental data and also satisfy physico-chemical laws. The activation energies should be positive as they are expected to obey Arrhenius temperature dependency. Heat of adsorption is always negative due to thermodynamic nature of adsorption process. In the adsorption process, there is a loss of entropy as molecules go from gaseous to an adsorbed phase. From the equation, $\Delta \mathrm{G}=\Delta \mathrm{H}-\mathrm{T} \Delta \mathrm{S}$, we infer that when $\Delta \mathrm{S}$ (entropy) is negative, $\Delta \mathrm{H}$ (enthalpy change) should be negative to give a negative value for $\Delta \mathrm{G}$ (change in Gibbs free energy). The heat of hydrogen adsorption, $\Delta \mathrm{H}_{7}$ has a negative value of $-16.7 \mathrm{~kJ} / \mathrm{mol}$ similar to the reported value of $15 \mathrm{~kJ} / \mathrm{mol}$ for cobalt catalysts [47].

The activation energy for CO (E1) was estimated to be $50.69 \mathrm{~kJ} / \mathrm{mol}$, lower than reported value of $80.7 \mathrm{~kJ} / \mathrm{mol}$ by Pannell et al [48]. The paraffin formation activation energy, $E_{5}=76.31 \mathrm{~kJ} / \mathrm{mol}$ is comparable to the value of $74 \mathrm{~kJ} / \mathrm{mol}$ reported by Chang et al [40]. Activation energies for olefin formation rates ( 89.23 and $89 \mathrm{~kJ} / \mathrm{mol})$ are slightly lower than those reported by Todic et al [39]. A comparison of the experimental and model results for hydrocarbon formation rates and ASF plot is given in Figure 19. 

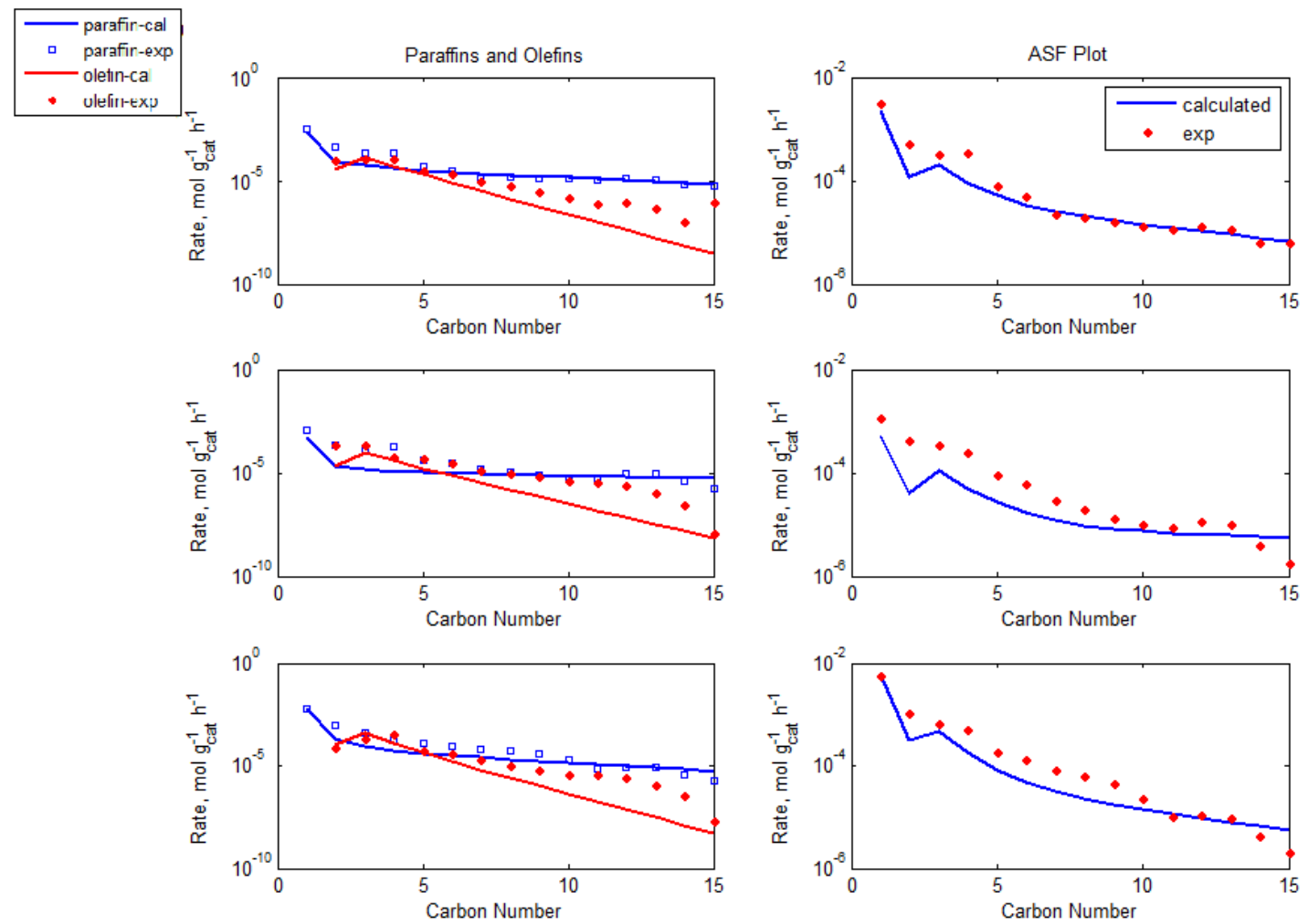

Figure 19 - Comparison of Experimental and Model Results

As shown in Figure 19, the predictability of the paraffin formation fit was fairly good but the olefin formation rates needs improvement. Mean Absolute Relative Residual (MARR) has been calculated to assess model accuracy.

$$
\text { MARR }=\sum_{i=1}^{n_{\text {resp }}} \sum_{j=1}^{n_{\text {exp }}}\left|\frac{r_{i, j}^{\text {exp }}-r_{i, j}^{c a l}}{r_{i, j}^{e x p}}\right| \times \frac{1}{n_{\text {resp }} n_{\text {exp }}} \times 100 \%
$$


In the above equation, $\mathrm{n}_{\text {resp }}$ refers to the number of rates calculated for each run. In the model used here, the modeling is done till carbon number 15 . Hence, 15 paraffin rates are calculated and 14 olefin rates are computed. Hence $\mathrm{n}_{\text {resp }}=29$. The number of experimental sets is represented by $n_{\exp }$, which is 7 . The MARR for the model is comparatively higher at $48.44 \%$, than that reported by Todic et al $(26.6 \%)$. The attribution of this difference has been discussed in the section below.

\subsubsection{Probable reasons for error}

Though the model provides a reasonably good fit for paraffins, the error in estimation of olefin formation rate is high. This discrepancy is attributed to two main reasons as described below.

The genetic algorithm code used in the model estimates 19 parameters. Though just one set of experimental data can also be used to obtain a solution set, the solution set becomes more meaningful if the input data spans a wide range of input conditions. In this study, 7 conditions have been used to generate the experimental data and each condition gives 29 data points, which are hydrocarbon formation rates upto $\mathrm{C}_{15}$ of both paraffins and olefins. Hence, the total number of data points for the entire experiment is 203. More experiments planned could not be conducted due to logistical reasons. The number of data points in the current experimental work is comparatively lesser than the number of data points used by other researchers on models of similar complexity. Todic et al [39] used 696 data points and Chang et al [40] used 504 data points on similar kinetic models for prediction of FT product distribution. 
Additionally, the number of experimental conditions is lesser than the number of parameters (19). This could be one probable reason for the error in olefin prediction rates.

Secondly, as described in Section 3.4.1, a methodology has been used to identify olefins and paraffins in higher carbon number range. Though the technique is based on engineering judgment and has a theoretical basis, ideally, the product analysis should include a simultaneous MS (Mass Spectroscopy) and GC (Gas Chromatograph) analysis. This might have resulted in missing some olefin peaks in the higher carbon number range which might have led to the under-prediction of olefins as shown in Figure 19.

Another source for experimental error could arise due to small sample loop volume in the GC which means that too little was injected into the GC to "see" the smaller peaks in the FID response. Experimental and simulation studies done by Gao et al [49] suggest that one of the reasons for the deviations observed frequently in experimental studies for higher hydrocarbon number product formation rates are due to the inherent complex nature of product characterization of FT. They concluded that maintaining low syngas conversion level, higher temperature and lower pressure of hot trap could minimize this source of experimental error. 


\section{CHAPTER V}

\section{CONCLUSION \& FUTURE WORK}

This study represents a step forward towards the understanding of product distribution in Fischer-Tropsch synthesis. As discussed in Chapter 3, this is a part of a bigger research initiative that is aimed at understanding Fischer-Tropsch in nonconventional reaction media like supercritical hydrocarbon solvents. A set of 7 experimental runs have been carried out and the experimental results have been input to a carbide mechanism model in MATLAB to estimate the parameters in the model.

Considering the experimental results, it was observed that the hydrocarbon product profile obtained was similar to the ones found in literature with high methane content and decreasing yield of hydrocarbons with increasing carbon number. The main experimental findings are listed below:

- $\mathrm{CO}$ conversion $\%$ increased with increase in reactor bed temperature. This is an expected behavior for exothermic reactions like FT due to temperature dependency in Arrhenius rate equation and is also corroborated by experimental work carried out on cobalt-based FT by Yao et al [50].

- When the syngas flow-rate was reduced to half without changing the $\mathrm{H}_{2} / \mathrm{CO}$ ratio, the $\mathrm{CO}$ conversion \% increased but there was no change in $\mathrm{CO}$ conversion rate which denotes that catalyst activity is constant. This observation has also been supported by CFD simulations and experimental findings by Miroliaei et al [33]. 
- $\mathrm{CO}_{2}$ selectivity was high and varied between $15 \%$ and $20 \%$ for most of the experimental runs, except when the $\mathrm{H}_{2} / \mathrm{CO}$ ratio was low in which case it was $5-10 \%$. Methane selectivity had similar trend and it varied between $20-30 \%$ for all runs and in the low $\mathrm{H}_{2} / \mathrm{CO}$ ratio runs, the selectivity was $8-12 \%$. Hence both, the selectivity of $\mathrm{CH}_{4}$ and $\mathrm{CO}_{2}$ dropped significantly at low $\mathrm{H}_{2} / \mathrm{CO}$ ratios.

- As hexane was used for flushing the lines on the reactor system, $\mathrm{C}_{6}$ peak response was abnormally high. The $\mathrm{C}_{6}$ formation rate was hence estimated by averaging out $\mathrm{C}_{5}$ and $\mathrm{C}_{7}$ formation rates.

Summarizing the modeling results, the MARR (mean absolute relative residual) for the fitted model is comparatively high at $48.44 \%$. As evident from Figure 19, the paraffin fit is better than olefin fit and this is attributed to the lesser number of data points available for fitting and the probable mis-identification of some olefin peaks for higher hydrocarbons. However, the model is able to predict the hydrocarbon formation rate trends fairly well for cobalt catalyst based FT.

The next stage in this work is to carry out more experimental sets to overcome some limitations of the current fitted model. This provides the necessary framework for further studies of Fischer-Tropsch in supercritical hydrocarbon solvents. Data generated experiments in the supercritical solvent phase will be compared with results from gasphase reaction which could give insight into the mechanism of FT in non-conventional reaction media. The result of these studies could enable us to suggest modifications 
in the existing model to account for the effect of the supercritical solvent on the system.

This work will be linked with the research team's effort to develop a master FT reactor model that is suitable both for conventional (gas-phase) in nonconventional (supercritical solvent) reaction media. Based on the outcome of these studies, modifications to existing kinetic models can be suggested thereby accounting for the effect of the supercritical solvent on the system. The overall goal will be to model the whole reactor bed and optimize the supercritical FT process with a view to potential scale-up and commercialization of this technology. 


\section{REFERENCES}

[1] Tropsch, F.F.H., The synthesis of petroleum at atmospheric pressures from gasification products of coal. Brennstoff-Chemie 1926. 17: p. 97-104.

[2] Elbashir, N.O., D.B. Bukur, E. Durham, and C.B. Roberts, Advancement of Fischer-Tropsch synthesis via utilization of supercritical fluid reaction media. AIChE J., 2010. 56: p. 997-1015.

[3] Savage, P.E., S. Gopalan, T.I. Mizan, C.J. Martino, and E.E. Brock, Reactions at supercritical conditions: Applications and fundamentals. AIChE Journal, 1995. 41(7): p. 1723-1778.

[4] Yokota, K. and K. Fujimoto, Supercritical phase Fischer-Tropsch synthesis reaction. Fuel, 1989. 68: p. 255-6.

[5] Huang, X. and C.B. Roberts, Selective Fischer-Tropsch synthesis over an A12O3 supported cobalt catalyst in supercritical hexane. Fuel Process. Technol., 2003. 83: p. 81-99.

[6] Bukur, D.B., X. Lang, A. Akgerman, and Z. Feng, Effect of process conditions on olefin selectivity during conventional and supercritical Fischer-Tropsch synthesis. Ind. Eng. Chem. Res., 1997. 36: p. 2580-2587.

[7] Li, X., X. Liu, Z.-W. Liu, K. Asami, and K. Fujimoto, Supercritical phase process for direct synthesis of middle iso-paraffins from modified Fischer-Tropsch reaction. Catal. Today, 2005. 106: p. 154-160. 
[8] Liu, X., W. Linghu, X. Li, K. Asami, and K. Fujimoto, Effects of solvent on Fischer-Tropsch synthesis. Applied Catalysis A: General, 2006. 303(2): p. 251257.

[9] Yokota, K. and K. Fujimoto, Supercritical-phase Fischer-Tropsch synthesis reaction. 2. The effective diffusion of reactant and products in the supercriticalphase reaction. Ind. Eng. Chem. Res., 1991. 30: p. 95-100.

[10] Huang, X., N.O. Elbashir, and C.B. Roberts, Supercritical Solvent Effects on Hydrocarbon Product Distributions from Fischer-Tropsch Synthesis over an Alumina-Supported Cobalt Catalyst. Ind. Eng. Chem. Res., 2004. 43: p. 63696381.

[11] Tsubaki, N., K. Yoshii, and K. Fujimoto, Anti-ASF Distribution of FischerTropsch Hydrocarbons in Supercritical-Phase Reactions. J. Catal., 2002. 207: p. $371-375$.

[12] Elbashir, N.O., Fundamentals and Design of the Supercritical Fluids Fischer Tropsch. 2013: LAP LAMBERT Academic Publishing, Saarbrücken, Germany

[13] Rehan Hussain, J.H.B., Branislav Todic, Nimir O. Elbashir and Dragomir Bukur, Development of Gas-to-Liquid Technologies from Micro- to Macro-scale, Excellence and Impact of Research at Texas A\&M University at Qatar. 2013.

[14] Bani Nasser, L.A., Simulation of Fischer-Tropsch Fixed-Bed Reactor in Different Reaction Media, in Master of Science Thesis 2013. 2013, Texas A\&M University (available online). 
[15] Flory, P.J., Molecular Size Distribution in Linear Condensation Polymers1. Journal of the American Chemical Society, 1936. 58(10): p. 1877-1885.

[16] Puskas, I. and R.S. Hurlbut, Comments about the causes of deviations from the Anderson-Schulz-Flory distribution of the Fischer-Tropsch reaction products. Catalysis Today, 2003. 84(1-2): p. 99-109.

[17] Snel, R., Deviations of Fischer-Tropsch products from an Anderson-Schulz-Flory distribution. Catalysis Letters, 1988. 1(10): p. 327-330.

[18] Elbashir, N.O. and C.B. Roberts, Enhanced Incorporation of $\alpha$-Olefins in the Fischer-Tropsch Synthesis Chain-Growth Process over an Alumina-Supported Cobalt Catalyst in Near-Critical and Supercritical Hexane Media. Ind. Eng. Chem. Res., 2005. 44: p. 505-521.

[19] Donnelly, T.J. and C.N. Satterfield, Product distributions of the Fischer-Tropsch synthesis on precipitated iron catalysts. Applied Catalysis, 1989. 52(1): p. 93-114.

[20] Marvast, M.A., M. Sohrabi, S. Zarrinpashne, and G. Baghmisheh, Fischer-Tropsch synthesis: Modeling and performance study for Fe-HZSM5 bifunctional catalyst. Chemical Engineering \& Technology, 2005. 28(1): p. 78-86.

[21] Liu, Q.S., Z.X. Zhang, and J.L. Zhou, Steady-state and dynamic behavior of fixedbed catalytic reactor for Fischer-Tropsch synthesis - II. Steady-state and dynamic simulation results. Journal of Natural Gas Chemistry, 1999. 8(3): p. 238-247.

[22] Wang, Y.-N., Y.-Y. Xu, Y.-W. Li, Y.-L. Zhao, and B.-J. Zhang, Heterogeneous modeling for fixed-bed Fischer-Tropsch synthesis: Reactor model and its applications. Chemical Engineering Science, 2003. 58(3-6): p. 867-875. 
[23] Guettel, R. and T. Turek, Comparison of different reactor types for low temperature Fischer-Tropsch synthesis: A simulation study. Chemical Engineering Science, 2009. 64(5): p. 955-964.

[24] Rahimpour, M.R., M.H. Khademi, and A.M. Bahmanpour, A comparison of conventional and optimized thermally coupled reactors for Fischer-Tropsch synthesis in GTL technology. Chemical Engineering Science, 2010. 65(23): p. 6206-6214.

[25] Moutsoglou, A. and P.P. Sunkara, Fischer-Tropsch Synthesis in a Fixed Bed Reactor. Energy \& Fuels, 2011. 25(5): p. 2242-2257.

[26] Brunner, K.M., J.C. Duncan, L.D. Harrison, K.E. Pratt, R.P.S. Peguin, C.H. Bartholomew, and W.C. Hecker, A Trickle Fixed-Bed Recycle Reactor Model for the Fischer-Tropsch Synthesis. International Journal of Chemical Reactor Engineering, 2012. 10(1).

[27] Hooshyar, N., D. Vervloet, F. Kapteijn, P.J. Hamersma, R.F. Mudde, and J.R. van Ommen, Intensifying the Fischer-Tropsch Synthesis by reactor structuring - A model study. Chemical Engineering Journal, 2012. 207-208: p. 865-870.

[28] Jess, A. and C. Kern, Modeling of Multi-Tubular Reactors for Fischer-Tropsch Synthesis. Chemical Engineering \& Technology, 2009. 32(8): p. 1164-1175.

[29] Rafiq, M.H., H.A. Jakobsen, R. Schmid, and J.E. Hustad, Experimental studies and modeling of a fixed bed reactor for Fischer-Tropsch synthesis using biosyngas. Fuel Processing Technology, 2011.92(5): p. 893-907. 
[30] Sharma, A., R. Philippe, F. Luck, and D. Schweich, A simple and realistic fixed bed model for investigating Fischer-Tropsch catalyst activity at lab-scale and extrapolating to industrial conditions. Chemical Engineering Science, 2011. 66(24): p. 6358-6366.

[31] Lee, T.S. and J.N. Chung, Mathematical Modeling and Numerical Simulation of a Fischer-Tropsch Packed Bed Reactor and Its Thermal Management for Liquid Hydrocarbon Fuel Production using Biomass Syngas. Energy \& Fuels, 2012. 26(2): p. 1363-1379.

[32] Pratt, J.W., A Fischer-Tropsch Synthesis Reactor Model Framework for Liquid Biofuels Production, in SANDIA REPORT. 2012, Sandia National Laboratories.

[33] Miroliaei, A.R., F. Shahraki, H. Atashi, and R. Karimzadeh, Comparison of CFD results and experimental data in a fixed bed Fischer-Tropsch synthesis reactor. Journal of Industrial and Engineering Chemistry, 2012. 18(6): p. 1912-1920.

[34] Xia, B. and D.-W. Sun, Applications of computational fluid dynamics (cfd) in the food industry: a review. Computers and Electronics in Agriculture, 2002. 34(13): p. 5-24.

[35] P. Kaushal, S.H., Concept of Computational Fluid Dynamics (CFD) and its Applications in Food Processing Equipment Design. Food Processing \& Technology, 2011.3.

[36] Mogalicherla, A.K. and N.O. Elbashir, Development of a Kinetic Model for Supercritical Fluids Fischer-Tropsch Synthesis. Energy \& Fuels, 2011. 25(3): p. 878-889. 
[37] Mogalicherla, A.K., E.E. Elmalik, and N.O. Elbashir, Enhancement in the intraparticle diffusion in the supercritical phase Fischer-Tropsch synthesis. Chemical Engineering and Processing: Process Intensification, 2012. 62: p. 5968.

[38] Elbashir, N.O.M., Utilization of supercritical fluids in the Fischer-Tropsch synthesis over cobalt-based catalytic systems. 2004. p. 308 pp.

[39] Todic, B., T. Bhatelia, G.F. Froment, W. Ma, G. Jacobs, B.H. Davis, and D.B. Bukur, Kinetic Model of Fischer-Tropsch Synthesis in a Slurry Reactor on CoRe/A12O3Catalyst. Industrial \& Engineering Chemistry Research, 2013. 52(2): p. 669-679.

[40] Chang, J., L. Bai, B. Teng, R. Zhang, J. Yang, Y. Xu, H. Xiang, and Y. Li, Kinetic modeling of Fischer-Tropsch synthesis over catalyst in slurry phase reactor. Chemical Engineering Science, 2007. 62(18-20): p. 4983-4991.

[41] Park, T.-Y. and G.F. Froment, A hybrid genetic algorithm for the estimation of parameters in detailed kinetic models. Computers \& Chemical Engineering, 1998. 22, Supplement 1(0): p. S103-S110.

[42] Costa, C.B.B. and R. Maciel Filho, Evaluation of optimisation techniques and control variable formulations for a batch cooling crystallization process. Chemical Engineering Science, 2005. 60(19): p. 5312-5322.

[43] Constrained minimization using GA. Available from: http://www.mathworks.com/help/gads/constrained-minimization-using-ga.html. 
[44] Silva, C.M. and E.C. Biscaia, Multi-Objective parameter estimation problems: an improved strategy. Inverse Problems in Science and Engineering, 2004. 12(3): p. 297-316.

[45] Yates, I.C. and C.N. Satterfield, The hydrocarbon selectivity of cobalt FischerTropsch catalysts. 1991. p. Medium: X; Size: Pages: (38 p).

[46] O'Haver, T. http://www.mathworks.com/matlabcentral/fileexchange/23611-peakfitter. Available from: http://www.mathworks.com/matlabcentral/fileexchange/23611-peak-fitter.

[47] Ojeda, M., R. Nabar, A.U. Nilekar, A. Ishikawa, M. Mavrikakis, and E. Iglesia, CO activation pathways and the mechanism of Fischer-Tropsch synthesis. Journal of Catalysis, 2010. 272(2): p. 287-297.

[48] Pannell, R.B., C.L. Kibby, and T.P. Kobylinski, A Steady-State Study of FischerTropsch Product Distributions Over Cobalt, Iron and Ruthenium, in Studies in Surface Science and Catalysis. 1981. p. 447-459.

[49] Gao, J., B. Wu, L. Zhou, Y. Yang, X. Hao, J. Xu, Y. Xu, and Y. Li, Irregularities in Product Distribution of Fischer-Tropsch Synthesis Due to Experimental Artifact. Industrial \& Engineering Chemistry Research, 2012. 51(36): p. 1161811628.

[50] Yao, Y., X. Liu, D. Hildebrandt, and D. Glasser, The effect of CO2 on a cobaltbased catalyst for low temperature Fischer-Tropsch synthesis. Chemical Engineering Journal, 2012. 193-194(0): p. 318-327. 


\section{APPENDIX A}

\section{REACTOR DATA ANALYSIS CALCULATIONS}

This section describes the calculations in brief used to study raw data obtained from the reactor. The reactor was run for 380 hours with sufficient time given for each run to ensure steady state operation for each of the conditions listed in Table A1 below. Based on transient data, 7 representative data points were chosen to carry out analysis from 127 sets of available data points. The calculation sheets for Run No. 5 are shown in Tables A2, $\mathrm{A} 3$ and $\mathrm{A} 4$.

Table A1 - Reactor Conditions

\begin{tabular}{|c|c|c|c|c|c|}
\hline $\begin{array}{l}\text { Run } \\
\text { No. }\end{array}$ & $\begin{array}{c}\text { Syngas Flow } \\
\left(\mathrm{CO}+\mathrm{H}_{2}\right), \\
\text { NmL/min }\end{array}$ & $\begin{array}{c}\mathrm{H}_{2} / \mathrm{CO} \\
\text { Ratio } \\
\text { (molar) }\end{array}$ & $\begin{array}{c}\text { Temperature, } \\
{ }^{\circ} \mathbf{C}\end{array}$ & $\begin{array}{l}\text { Pco, } \\
\text { bar }\end{array}$ & $\begin{array}{l}\mathbf{P}_{\mathrm{H}}, \\
\text { bar }\end{array}$ \\
\hline 1 & $100 \pm 0.73$ & 2 & 210 & 7.38 & 14.76 \\
\hline 2 & $50 \pm 1.3$ & 2 & 210 & 6.26 & 12.51 \\
\hline 3 & $50 \pm 1.3$ & 2 & 220 & 5.57 & 11.14 \\
\hline 4 & $56.85 \pm 1.68$ & 1.28 & 220 & 7.74 & 9.88 \\
\hline 5 & $36.84 \pm 1.68$ & 0.65 & 220 & 10.31 & 6.71 \\
\hline 6 & $54.43 \pm 1.68$ & 0.63 & 220 & 10.32 & 6.53 \\
\hline 7 & $50 \pm 1.3$ & 2 & 230 & 5.89 & 11.77 \\
\hline
\end{tabular}


The first step is data acquisition for the TCD channel. This channel gives information on $\mathrm{CO}$ and $\mathrm{CH}_{4}$. As shown in Table A2, the input flow-rates into the reactor are tabulated. The Peak Areas in the outlet of the reactor as measured by the Gas Chromatograph is also tabulated. All the values in light green shade are to be input by the user. The Excel Sheet calculated all values in light violet shade. Based on calibration curves, the amounts of individual compounds leaving the reactor are calculated. From this data, $\mathrm{CO}$ conversion, $\mathrm{CO}$ consumption rate, $\mathrm{CO}_{2}$ Selectivity and $\mathrm{CH}_{4}$ Selectivity can be calculated. This completes the analysis on data obtained from TCD. The calculated CO consumption rates for all the runs is shown in Figure A1.

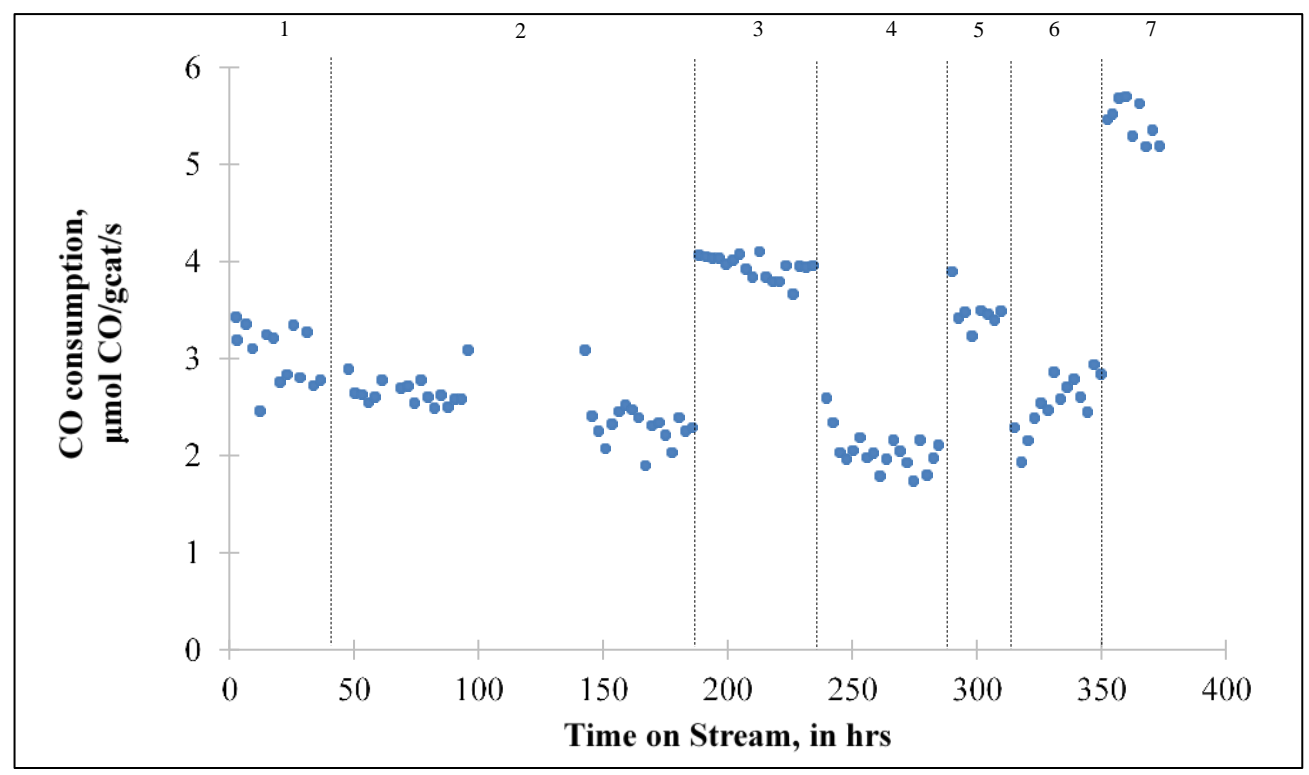

Figure A1 - CO consumption rates with time-on-stream 
Table A2 - Typical TCD Calculation Sheet

\begin{tabular}{|c|c|c|c|}
\hline & \multirow[b]{2}{*}{ sample 95} & TOS, hrs & 295.225 \\
\hline & & Reactor T, C & 220 \\
\hline & & & 25 \\
\hline \multirow{10}{*}{ Inlet } & \multirow{4}{*}{$\begin{array}{l}\text { SP Values input to respective FICs on } \\
\text { the screen }\end{array}$} & Qsyngas, $\mathrm{mL} / \mathrm{min}$ & 0 \\
\hline & & $\mathrm{QCO}, \mathrm{mL} / \mathrm{min}$ & 19.65 \\
\hline & & $\mathrm{QH}_{2}, \mathrm{~mL} / \mathrm{min}$ & 9.85 \\
\hline & & Qargon, $\mathrm{mL} / \mathrm{min}$ & 10 \\
\hline & & $\mathrm{PA} \mathrm{H}_{2}$ (TCD 1) & 490.8 \\
\hline & & $\mathrm{PA} \mathrm{Ar}$ & 36599.8 \\
\hline & & $\mathrm{PACH}_{4}$ & 202.7 \\
\hline & & $\mathrm{PACO}$ & 61411.4 \\
\hline & & $\mathrm{PACO} \mathrm{CO}_{2}$ & 256.3 \\
\hline & & $\mathrm{PA} \mathrm{H}_{2}(\mathrm{TCD} 2)$ & 114984.3 \\
\hline \multirow{4}{*}{ Inlet } & \multirow{4}{*}{$\begin{array}{l}\text { Normal Values at } 0 \mathrm{C}, 1013 \mathrm{kPA} \text {, } \\
\text { Entering through individual FICs }\end{array}$} & Qsyngas, nmL/min & 0 \\
\hline & & $\mathrm{QCO}, \mathrm{nmL} / \mathrm{min}$ & 22.3157 \\
\hline & & $\mathrm{QH}_{2}, \mathrm{nmL} / \mathrm{min}$ & 14.5208 \\
\hline & & Qargon, $\mathrm{nmL} / \mathrm{min}$ & 10 \\
\hline \multirow{15}{*}{ Outlet } & \multirow{2}{*}{$\begin{array}{l}\text { Normal Values at } 0 \mathrm{C}, 1013 \mathrm{kPA} \text {, in } \\
\mathrm{GC} \text {, calculated from peak areas and } \\
\text { calibration charts }\end{array}$} & $\mathrm{QCO}, \mathrm{nmL} / \mathrm{min}$ & 21.1448 \\
\hline & & $\begin{array}{c}\mathrm{QH}_{2}, \mathrm{nmL} / \mathrm{min}-\mathrm{BASED} \text { ON } \\
\mathrm{TCD} 2\end{array}$ & 9.7674 \\
\hline & \multicolumn{2}{|c|}{$\mathrm{CO}$ consumption, $\mathrm{nml} / \mathrm{min}$} & 1.1709 \\
\hline & \multicolumn{2}{|c|}{$\mathrm{CO}$ consumption, $\mu \mathrm{mol} \mathrm{CO}$ reacted $/ \mathrm{gcat} / \mathrm{s}$} & 0.2177 \\
\hline & \multicolumn{2}{|c|}{ CO Conversion $\%$} & 5.2469 \\
\hline & \multicolumn{2}{|c|}{$\mathrm{CH}_{4}$ formation, $\mathrm{nml} / \mathrm{min}$} & 0.0836 \\
\hline & \multicolumn{2}{|c|}{$\mathrm{CH}_{4}$ selectivity $\%$} & 7.1381 \\
\hline & \multicolumn{2}{|c|}{$\mathrm{H}_{2}$ Consumption, $\mathrm{nml} / \mathrm{min}$} & 4.7534 \\
\hline & \multicolumn{2}{|c|}{$\mathrm{H}_{2}$ consumption, $\mu \mathrm{mol} \mathrm{H} \mathrm{H}_{2}$ reacted/gcat/s } & 3.5345 \\
\hline & \multicolumn{2}{|c|}{$\mathrm{H}_{2}$ Conversion $\%$} & 32.7349 \\
\hline & \multicolumn{2}{|c|}{ Syngas Conversion $\%$} & 16.0826 \\
\hline & \multicolumn{2}{|c|}{$\mathrm{CH}_{4}$ Formation Rate, $\mu \mathrm{mol} \mathrm{CH} 4$ formed/gcat/s } & 0.0621 \\
\hline & \multicolumn{2}{|c|}{$\mathrm{CO}_{2}$ formation, $\mathrm{nml} / \mathrm{min}$} & 0.0641 \\
\hline & \multicolumn{2}{|c|}{$\mathrm{CO}_{2}$ Formation Rate, $\mu \mathrm{mol} \mathrm{CH} 4$ formed/gcat/s } & 0.0477 \\
\hline & \multicolumn{2}{|c|}{$\mathrm{CO}_{2}$ selectivity $\%$} & 5.4761 \\
\hline
\end{tabular}


The FID channel gives information on the hydrocarbon products obtained from the Fischer-Tropsch reaction. Table A3 shows the raw data obtained from the FID channel. Based on the calibration gas test and the methodology explained in Section 3.4.1, the peaks are identified as olefins or paraffins and listed in a tabular form. In the FID channel, relative peak areas are proportional to weight fraction ratios. $\mathrm{CH}_{4}$ peak appears both in TCD and the FID channel. Hence, the $\mathrm{CH}_{4}$ formation rate obtained from TCD channel is used as a base to calculate other hydrocarbon formation rates. It may be noted here that peak area ratios of 2 compounds in TCD channel are proportional to their molar fractions and the peak area ratios obtained from FID channel are proportional to their weight fractions. This concept has been used while calculating individual hydrocarbon formation rates as shown in Table A4. 
Table A3 - FID Data

\begin{tabular}{|c|c|c|c|c|c|c|c|c|}
\hline Sample 95 & & & & & & & & \\
\hline Peak\# & Ret.Time & Area & Area\% & Compound & Type & \begin{tabular}{|l|} 
Isomers \\
\end{tabular} & Linear Paraffin & Olefins \\
\hline 1 & 2.378 & 223929.1 & \begin{tabular}{|l|}
17.0497 \\
\end{tabular} & $\mathrm{CH} 4$ & normal & 0 & 223929.1 & 0 \\
\hline 2 & 2.472 & 39704.9 & 3.0231 & $\mathrm{C} 2$ & olefin & 0 & 0 & 39704.9 \\
\hline 3 & 2.52 & 81523 & 6.2071 & $\mathrm{C} 2$ & normal & 0 & 81523 & 0 \\
\hline 4 & 2.79 & 128347.7 & 9.7723 & $\mathrm{C} 3$ & olefin & 0 & 0 & 128347.7 \\
\hline 5 & 3.055 & 56.7 & 0.0043 & $\mathrm{C} 4$ & isomer & 56.7 & 0 & 0 \\
\hline 6 & 3.231 & 29699.8 & 2.2613 & $\mathrm{C} 4$ & isomer & 29699.8 & 0 & 0 \\
\hline 7 & 3.52 & 39585.4 & 3.014 & $\mathrm{C} 4$ & olefin & 0 & 0 & 39585.4 \\
\hline 8 & 3.635 & 13279.7 & 1.0111 & $\mathrm{C} 4$ & normal & 0 & 13279.7 & 0 \\
\hline 9 & 3.754 & 13236.8 & 1.0078 & $\mathrm{C} 4$ & olefin & 0 & 0 & 13236.8 \\
\hline 10 & 3.962 & 11445.2 & 0.8714 & $\mathrm{C} 4$ & olefin & 0 & 0 & 11445.2 \\
\hline 11 & 4.129 & 25922.7 & 1.9737 & $\mathrm{C} 4$ & isomer & \begin{tabular}{|l|}
25922.7 \\
\end{tabular} & 0 & 0 \\
\hline 12 & 4.524 & 2205.4 & 0.1679 & $\mathrm{C} 4$ & olefin & \begin{tabular}{|l|}
0 \\
\end{tabular} & 0 & 2205.4 \\
\hline 13 & 4.802 & 3359.8 & \begin{tabular}{|l|}
0.2558 \\
\end{tabular} & C5 & isomer & 3359.8 & 0 & 0 \\
\hline 14 & 4.884 & 3269 & \begin{tabular}{|l|}
0.2489 \\
\end{tabular} & C5 & olefin & 0 & 0 & 3269 \\
\hline 15 & 5.032 & 1045.8 & 0.0796 & $\mathrm{C} 5$ & olefin & 0 & 0 & 1045.8 \\
\hline 16 & 5.259 & 22393 & 1.705 & $\mathrm{C} 5$ & olefin & 0 & 0 & 22393 \\
\hline 17 & 5.436 & 951.4 & 0.0724 & $\mathrm{C} 5$ & isomer & 951.4 & 0 & 0 \\
\hline 18 & 5.561 & 9192 & 0.6999 & C5 & normal & 0 & 9192 & 0 \\
\hline 19 & 5.749 & 7450.9 & 0.5673 & $\mathrm{C} 5$ & isomer & 7450.9 & 0 & 0 \\
\hline 20 & 5.987 & 5509.1 & \begin{tabular}{|l|}
0.4195 \\
\end{tabular} & $\mathrm{C5}$ & isomer & 5509.1 & 0 & 0 \\
\hline 21 & 6.142 & 1551.1 & 0.1181 & $\mathrm{C} 5$ & isomer & 1551.1 & 0 & 0 \\
\hline 22 & 6.857 & 11126.4 & 0.8472 & C6 & isomer & 11126.4 & 0 & 0 \\
\hline 23 & 7.416 & 1669.2 & 0.1271 & C6 & isomer & \begin{tabular}{|l|}
1669.2 \\
\end{tabular} & 0 & 0 \\
\hline 24 & 7.817 & 1413.5 & \begin{tabular}{|l}
0.1076 \\
\end{tabular} & C6 & isomer & 1413.5 & 0 & 0 \\
\hline 25 & 8.045 & 1116.9 & 0.085 & C6 & isomer & 1116.9 & 0 & 0 \\
\hline 26 & 8.387 & 1097.7 & 0.0836 & C6 & isomer & 1097.7 & 0 & 0 \\
\hline 27 & 8.561 & 16829.6 & 1.2814 & C6 & olefin & 0 & 0 & 16829.6 \\
\hline 28 & 8.996 & 106288 & 8.0927 & C6 & normal & 0 & 106288 & 0 \\
\hline 29 & 9.142 & 4616.1 & 0.3515 & C6 & isomer & 4616.1 & 0 & 0 \\
\hline 30 & 9.547 & 3596.1 & 0.2738 & C6 & isomer & \begin{tabular}{|l|}
3596.1 \\
\end{tabular} & 0 & 0 \\
\hline 31 & 10.215 & 1841.4 & 0.1402 & C6 & olefin & 0 & 0 & 1841.4 \\
\hline 32 & 10.546 & 819.4 & 0.0624 & C6 & isomer & 819.4 & 0 & 0 \\
\hline 33 & 10.829 & 870.9 & 0.0663 & C7 & isomer & 870.9 & 0 & 0 \\
\hline 34 & 11.044 & 394.3 & 0.03 & C7 & isomer & 394.3 & 0 & 0 \\
\hline 35 & 11.635 & 860 & 0.0655 & $\mathrm{C} 7$ & isomer & 860 & 0 & 0 \\
\hline 36 & 12.033 & 537.1 & 0.0409 & C7 & isomer & 537.1 & 0 & 0 \\
\hline 37 & 12.509 & 12747 & 0.9705 & C7 & olefin & 0 & 0 & 12747 \\
\hline 38 & 12.937 & 7003.6 & \begin{tabular}{|l|}
0.5332 \\
\end{tabular} & $\mathrm{C} 7$ & normal & 0 & 7003.6 & 0 \\
\hline 39 & 13.089 & 3794.1 & 0.2889 & C7 & isomer & \begin{tabular}{|l|}
3794.1 \\
\end{tabular} & 0 & 0 \\
\hline 40 & 13.43 & 2202.3 & 0.1677 & C7 & isomer & 2202.3 & 0 & 0 \\
\hline 41 & 16.042 & 10823.2 & 0.8241 & $\mathrm{C} 8$ & olefin & 0 & 0 & 10823.2 \\
\hline 42 & 16.413 & 7154.3 & 0.5447 & $\mathrm{C} 8$ & normal & 0 & 7154.3 & 0 \\
\hline 43 & 16.496 & 2911.5 & 0.2217 & $\mathrm{C} 8$ & isomer & 2911.5 & 0 & 0 \\
\hline 44 & 16.824 & 2056.5 & \begin{tabular}{|l}
0.1566 \\
\end{tabular} & $\mathrm{C} 8$ & isomer & 2056.5 & 0 & 0 \\
\hline 45 & 19.336 & 8936.5 & 0.6804 & C9 & olefin & 0 & 0 & 8936.5 \\
\hline 46 & 19.707 & 10698.5 & 0.8146 & C9 & normal & 0 & 10698.5 & 0 \\
\hline 47 & 20.097 & 2213.4 & 0.1685 & C9 & isomer & 2213.4 & 0 & 0 \\
\hline 48 & 22.564 & 6893.6 & 0.5249 & $\mathrm{C} 10$ & olefin & 0 & 0 & 6893.6 \\
\hline 49 & 22.718 & 485.6 & 0.037 & $\mathrm{C} 10$ & isomer & 485.6 & 0 & 0 \\
\hline 50 & 22.919 & 13053 & 0.9938 & $\mathrm{C} 10$ & normal & 0 & 13053 & 0 \\
\hline 51 & 23.303 & 2211.6 & 0.1684 & $\mathrm{C} 10$ & isomer & 2211.6 & 0 & 0 \\
\hline 52 & 25.342 & 553.7 & \begin{tabular}{|l|}
0.0422 \\
\end{tabular} & $\mathrm{C} 11$ & isomer & 553.7 & 0 & 0 \\
\hline 53 & 25.643 & 3141.9 & 0.2392 & C11 & olefin & 0 & 0 & 3141.9 \\
\hline 54 & 25.734 & 297.3 & 0.0226 & C11 & isomer & 297.3 & 0 & 0 \\
\hline 55 & 25.966 & 15400.5 & 1.1726 & $\mathrm{C} 11$ & normal & 0 & 15400.5 & 0 \\
\hline 56 & 26.34 & 1977.6 & \begin{tabular}{|l|l|}
0.1506 \\
\end{tabular} & C11 & isomer & 1977.6 & 0 & 0 \\
\hline 57 & 28.078 & 979.8 & \begin{tabular}{|l|}
0.0746 \\
\end{tabular} & $\mathrm{C} 12$ & isomer & 979.8 & 0 & 0 \\
\hline 58 & 28.582 & 2197.8 & \begin{tabular}{|l|l|}
0.1673 \\
\end{tabular} & $\mathrm{C} 12$ & olefin & 0 & 0 & 2197.8 \\
\hline 59 & 28.845 & 18222.3 & \begin{tabular}{|l|}
1.3874 \\
\end{tabular} & $\mathrm{C} 12$ & normal & 0 & 18222.3 & 0 \\
\hline 60 & 29.226 & 1682.8 & 0.1281 & $\mathrm{C} 12$ & isomer & 1682.8 & 0 & 0 \\
\hline 61 & 30.796 & 252 & 0.0192 & C13 & isomer & 252 & 0 & 0 \\
\hline 62 & 31.34 & 776.1 & 0.0591 & $\mathrm{C} 13$ & olefin & 0 & 0 & 776.1 \\
\hline 63 & 31.553 & 16221.1 & 1.2351 & C13 & normal & 0 & 16221.1 & 0 \\
\hline 64 & 31.942 & 287.3 & 0.0219 & C13 & isomer & 287.3 & 0 & 0 \\
\hline 65 & 32.186 & 1513.5 & 0.1152 & C13 & isomer & 1513.5 & 0 & 0 \\
\hline 66 & 33.89 & 15.3 & 0.0012 & $\mathrm{C} 14$ & olefin & 0 & 0 & 15.3 \\
\hline 67 & 34.075 & 6881.3 & 0.5239 & $\mathrm{C} 14$ & normal & 0 & 6881.3 & 0 \\
\hline 68 & 34.44 & 337.3 & 0.0257 & $\mathrm{C} 14$ & isomer & 337.3 & 0 & 0 \\
\hline 69 & 36.263 & 50.4 & 0.0038 & $\mathrm{C} 15$ & olefin & 0 & 0 & 50.4 \\
\hline 70 & 36.452 & 4531.6 & 0.345 & $\mathrm{C} 15$ & normal & 0 & 4531.6 & 0 \\
\hline
\end{tabular}




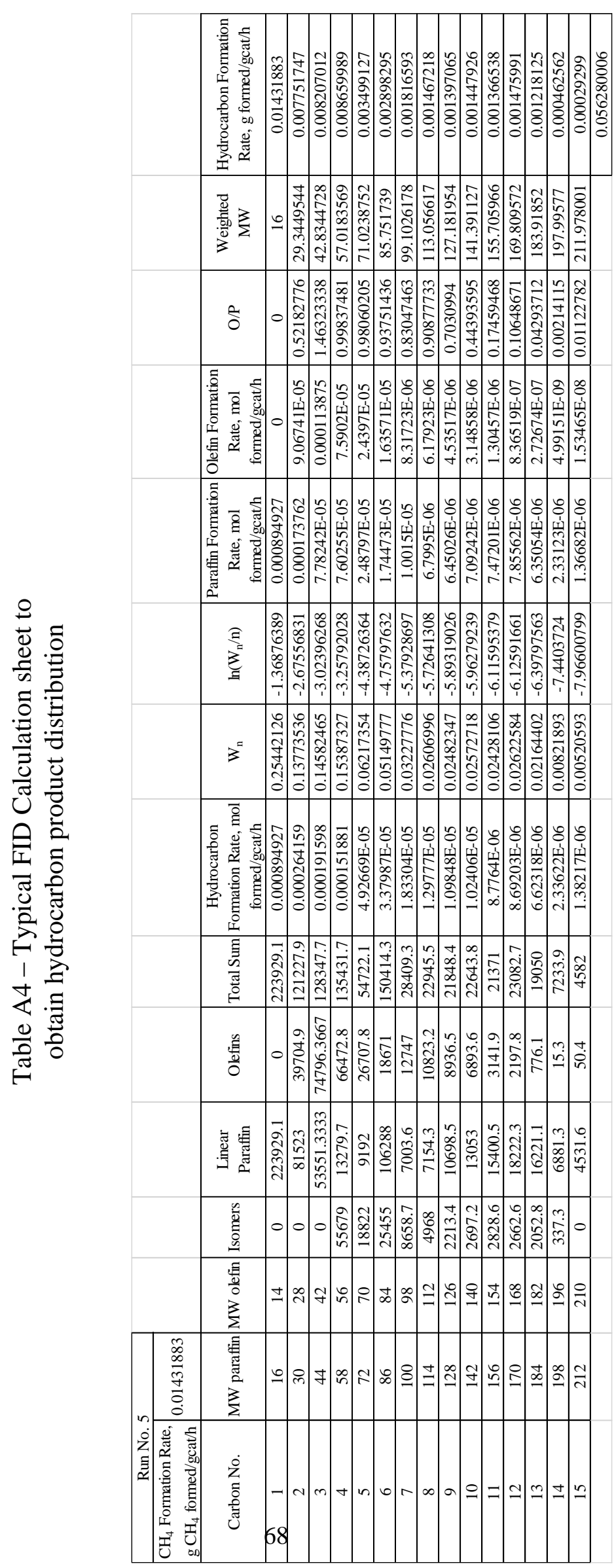




\section{APPENDIX B}

\section{CONVERGENCE OF GENETIC ALGORITHM RESULTS}

As mentioned in chapter 3 on the research methodology followed, genetic algorithm is the optimization tool used for estimating the parameters of the kinetic model. Unlike traditional search algorithms, the GA does not search for solutions in the state space. GAs work in solution space and build new, hopefully better solutions based on existing ones.

In the current optimization study, to ascertain the convergence of all 19 parameters to a stable value, each parameter is plotted with generation and is shown in Figure B1. The plot was made for 50,000 generations and an f-count of 1,000,000. As is evident, the population stabilizes with time and converges to a concordant value. 

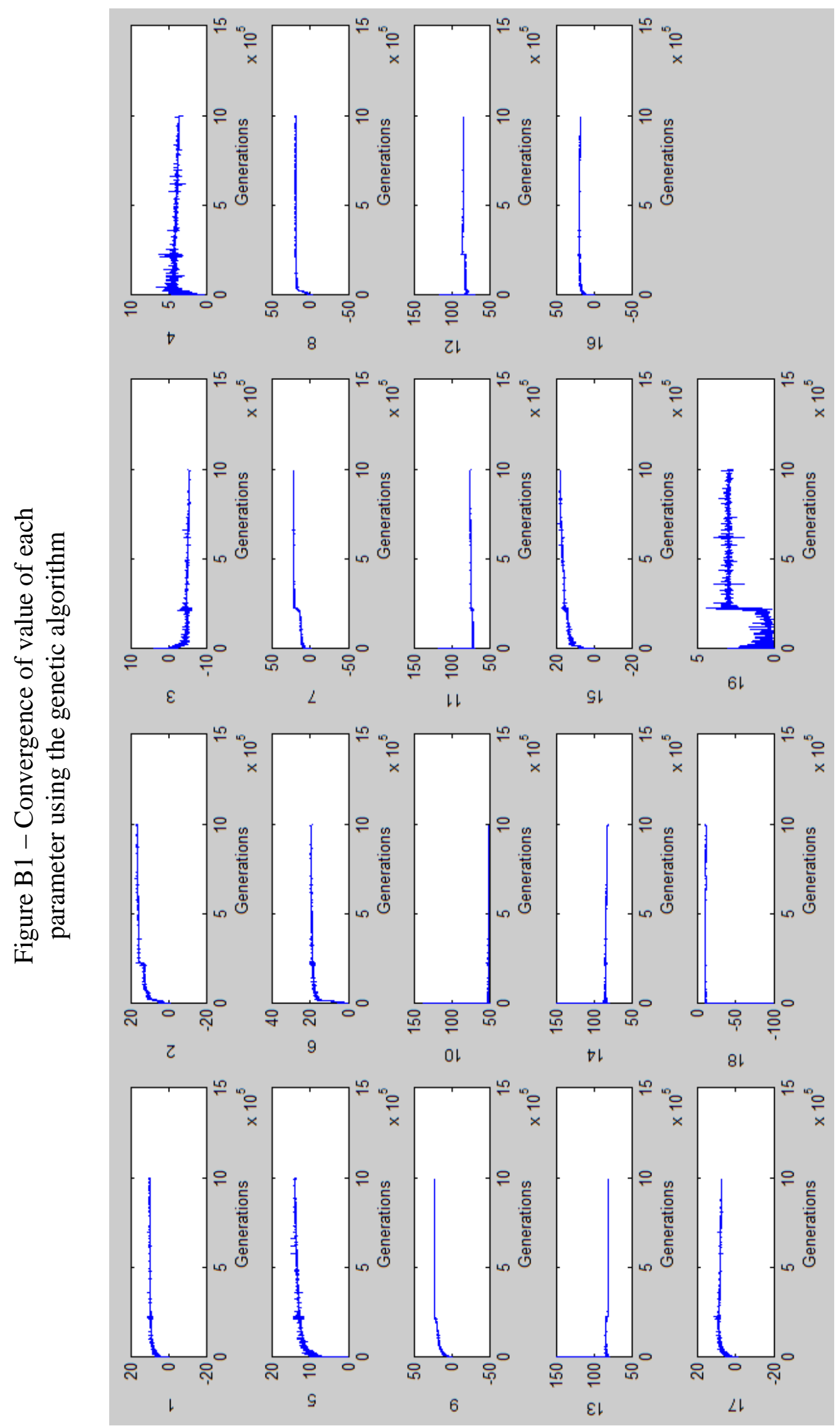


\section{APPENDIX C}

\section{DATA ANALYSIS RESULTS FOR ALL RUNS}

This section contains the graphs obtained as a result of the data analysis for all the runs.

The following graphs are shown below for each experimental run:

- Peak Area for each carbon number obtained from GC

- ASF Plot for product distribution

- Paraffin, olefin and total Hydrocarbon formation rates for each carbon number

- Olefin to paraffin ratio for each carbon number

\section{Run No. 1}

Syngas Flow $100 \mathrm{NmL} / \mathrm{min}, \mathrm{H}_{2} / \mathrm{CO}$ ratio $2: 1$, Bed Temperature $210{ }^{\circ} \mathrm{C}, \mathrm{CO}$ Conversion $3.07 \%$

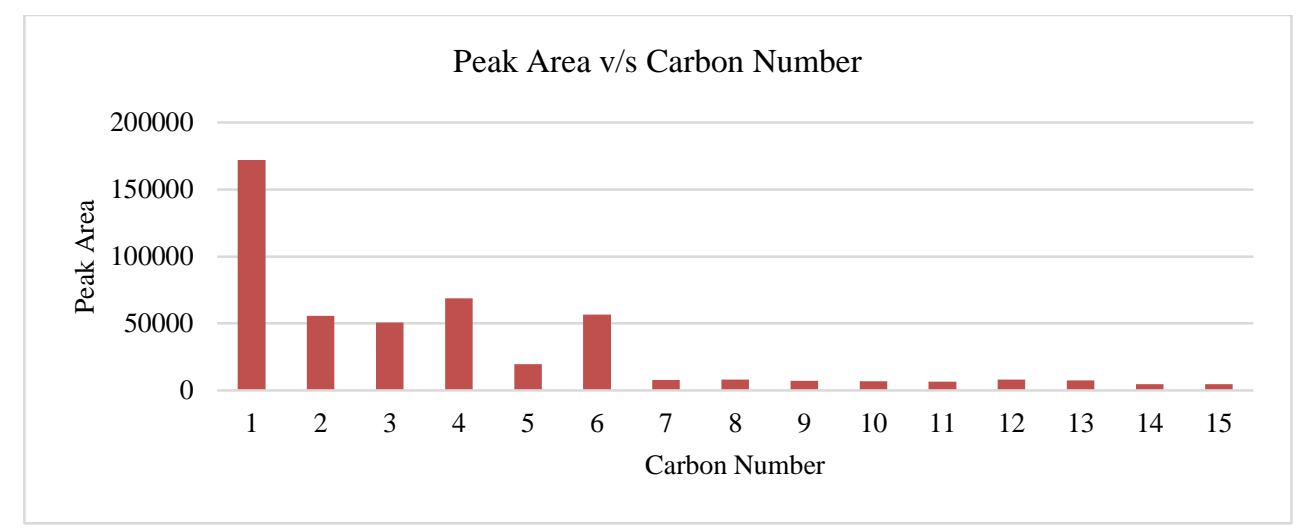



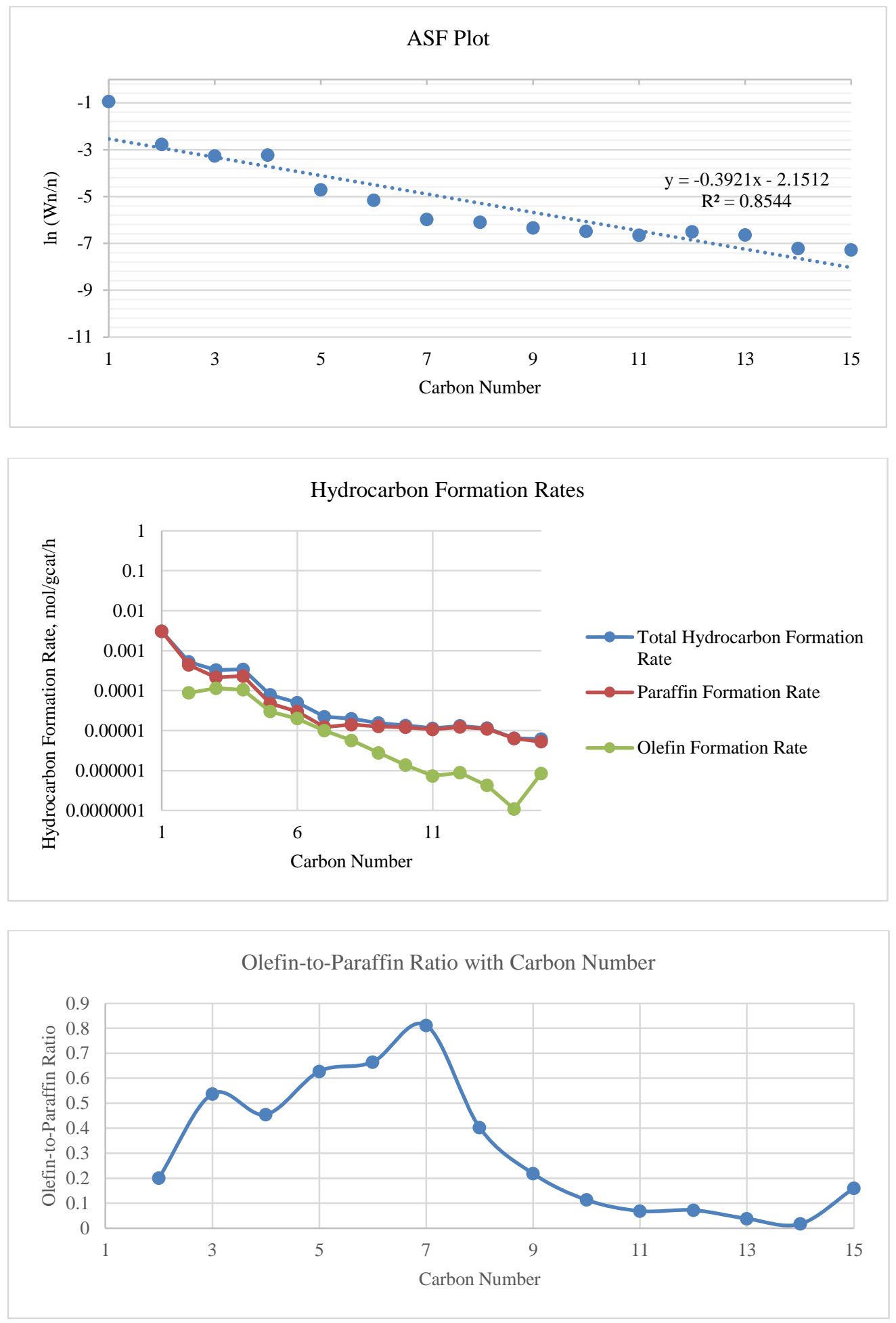


\section{Run No. 2}

Syngas Flow $50 \mathrm{NmL} / \mathrm{min}, \mathrm{H}_{2} / \mathrm{CO}$ ratio $2: 1$, Bed Temperature $210{ }^{\circ} \mathrm{C}$, CO Conversion $5.42 \%$
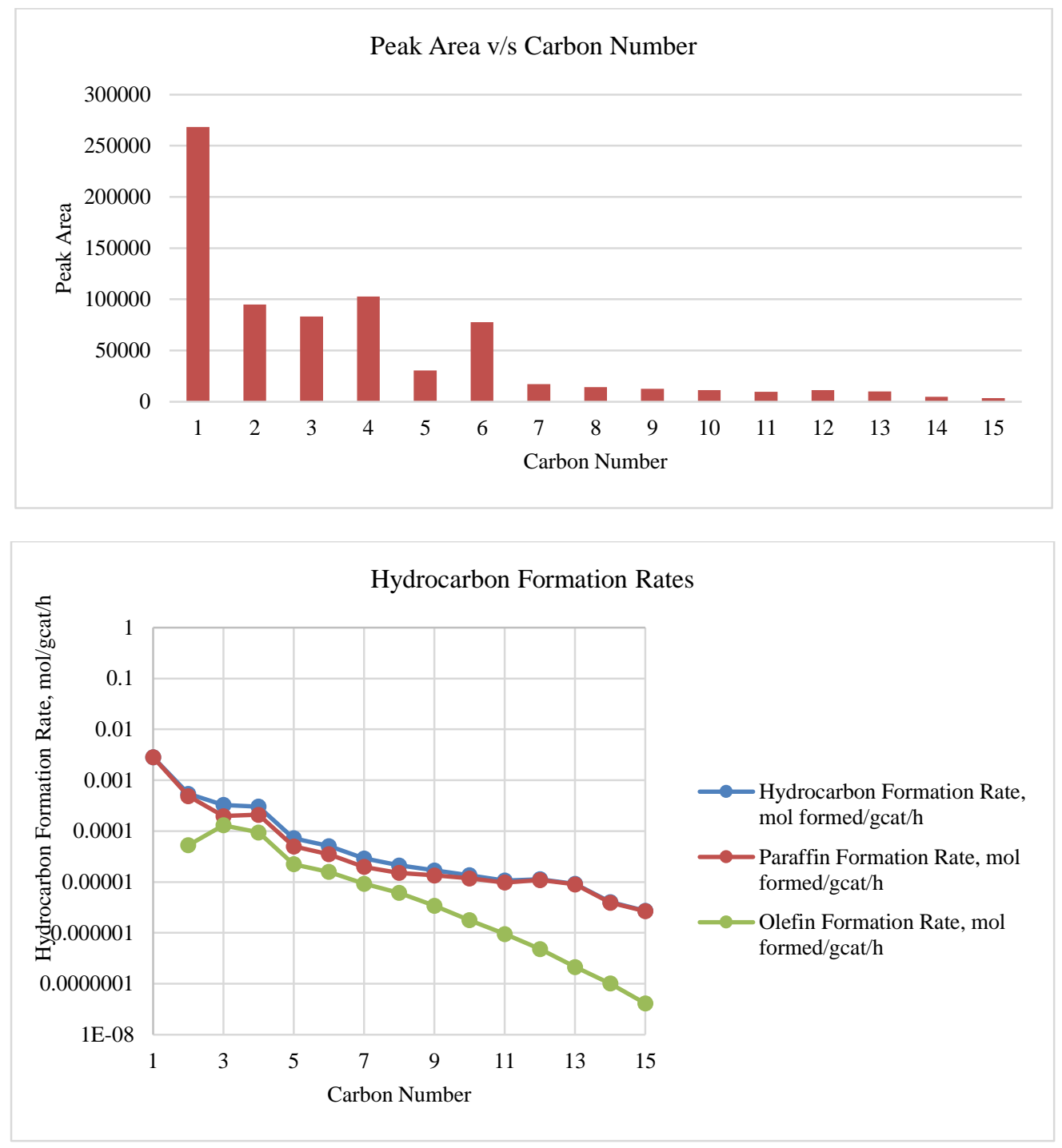

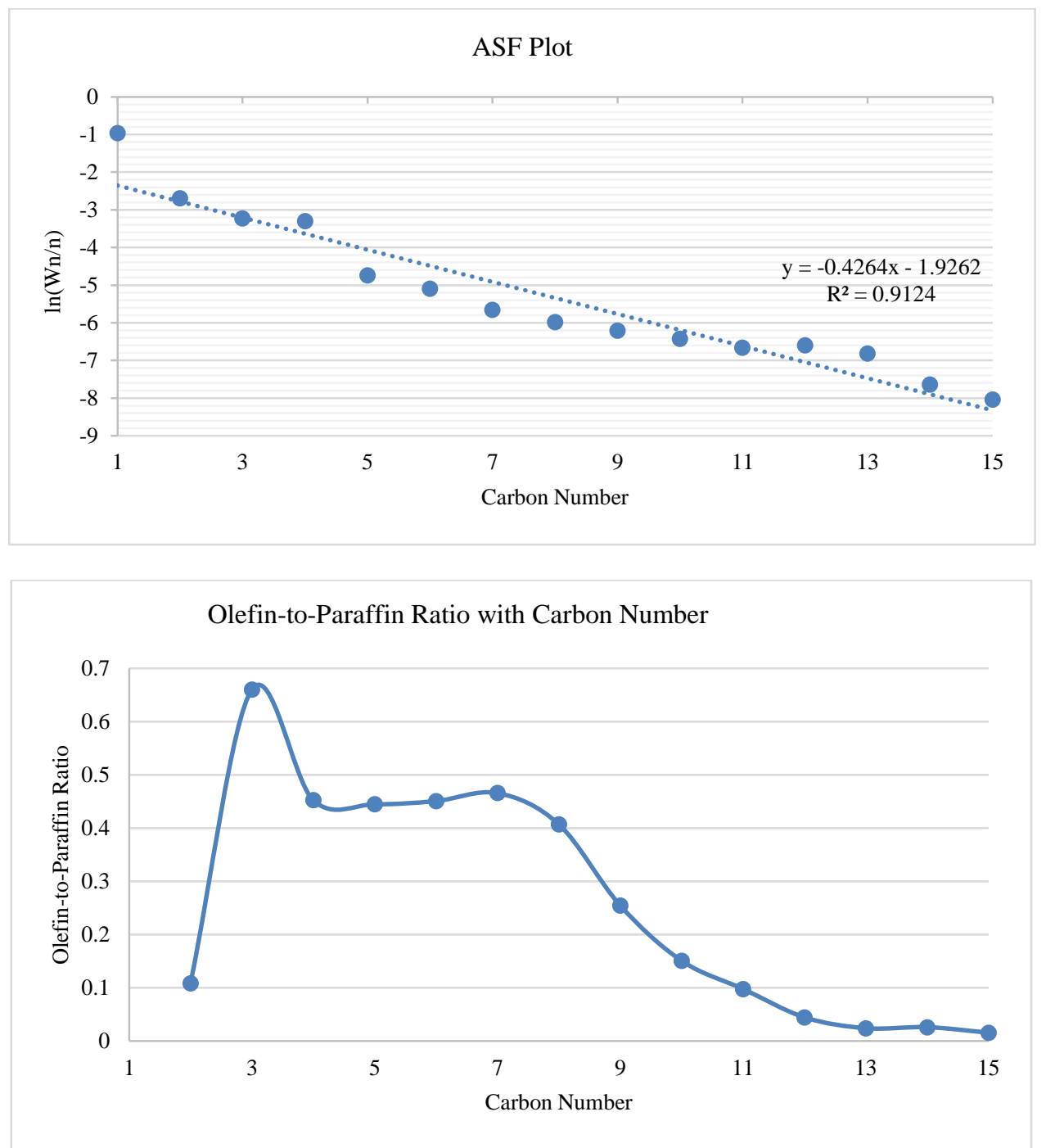


\section{$\underline{\text { Run No. } 3}$}

Syngas Flow $50 \mathrm{NmL} / \mathrm{min}, \mathrm{H}_{2} / \mathrm{CO}$ ratio $2: 1$, Bed Temperature $220{ }^{\circ} \mathrm{C}$, CO Conversion $7.97 \%$
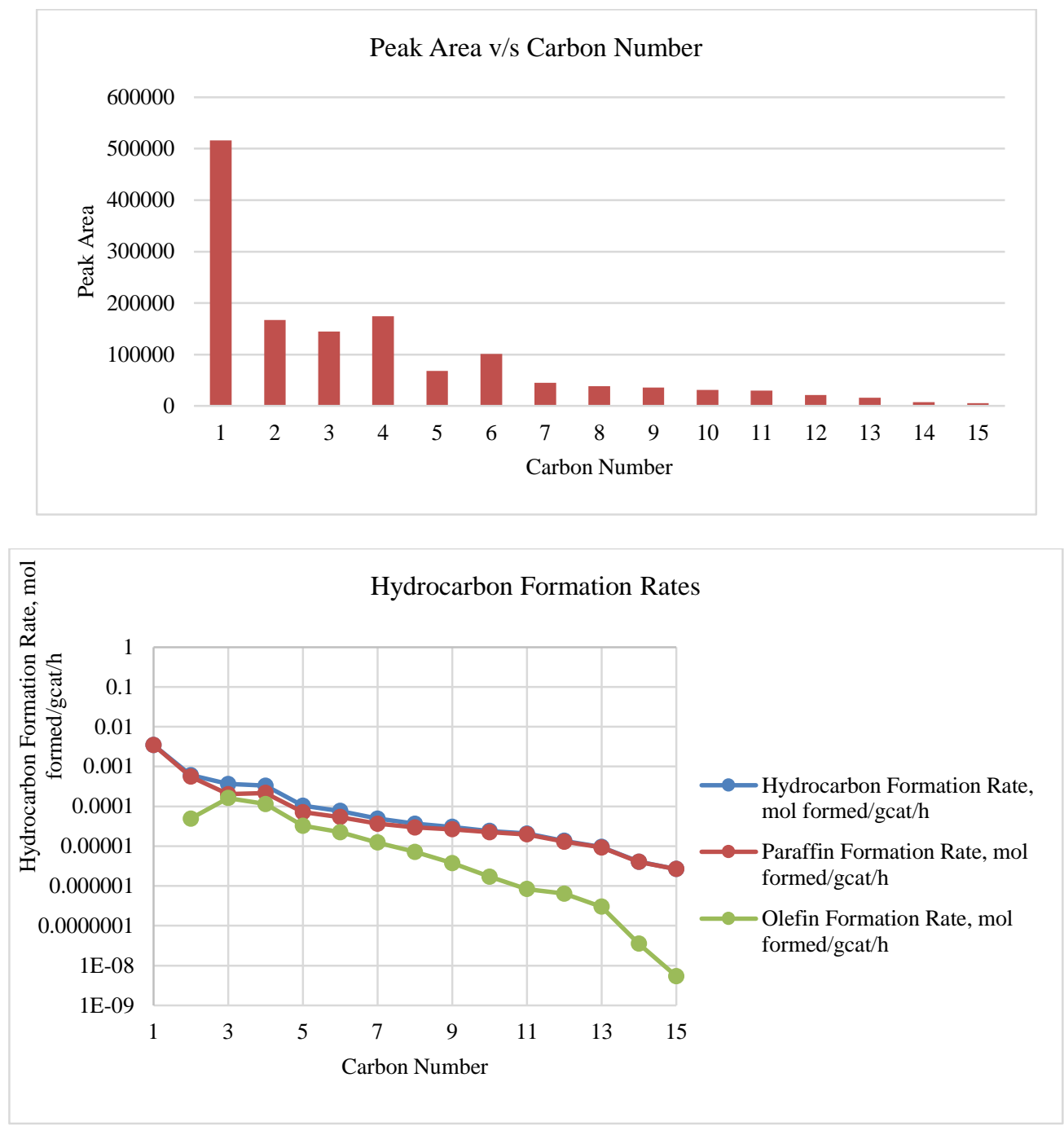

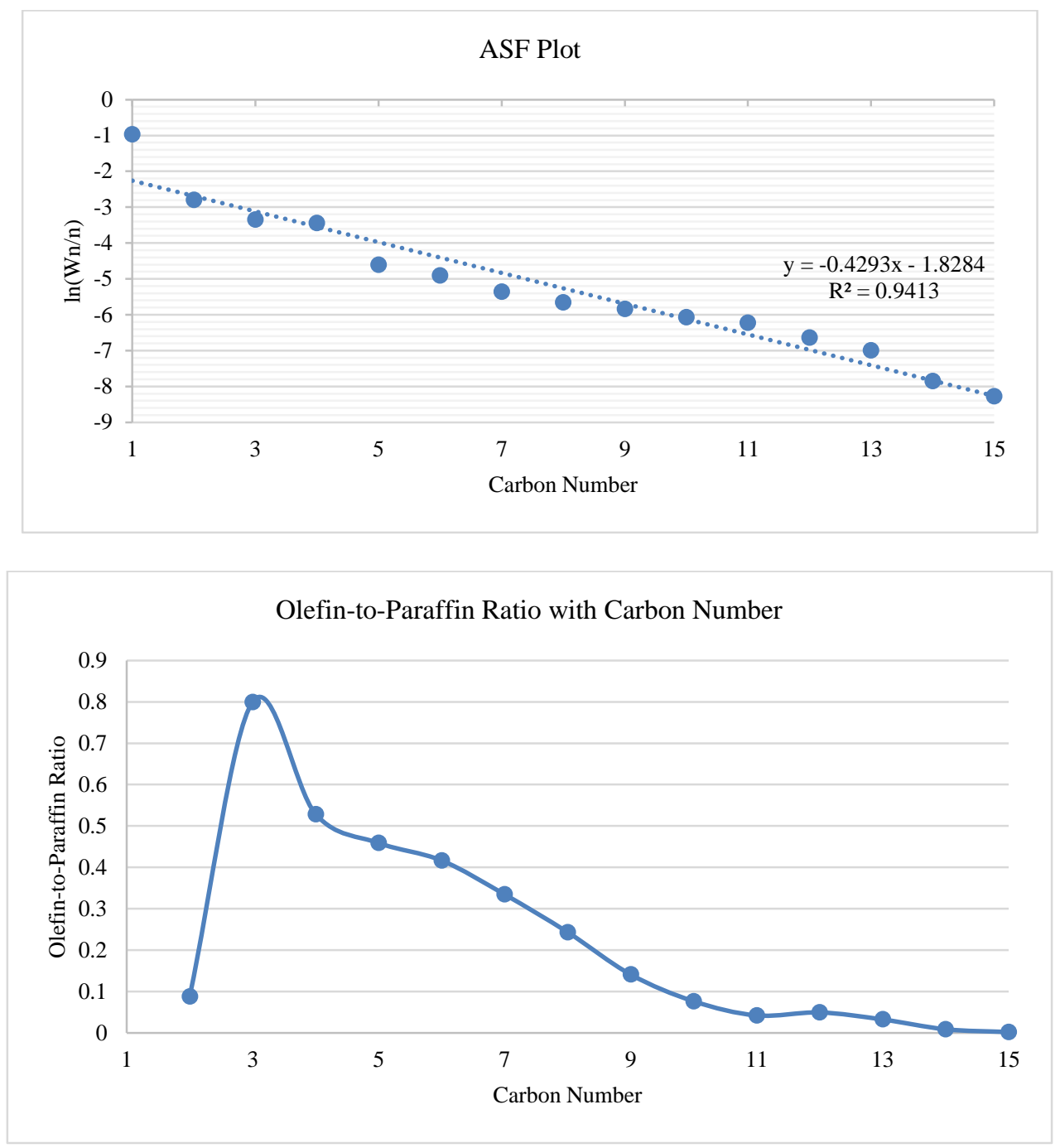


\section{$\underline{\text { Run No. } 4}$}

\section{Syngas Flow $56.85 \mathrm{NmL} / \mathrm{min}, \mathrm{H}_{2} / \mathrm{CO}$ ratio $1.28: 1$, Bed Temperature $220{ }^{\circ} \mathrm{C}$, CO Conversion}

$2.76 \%$
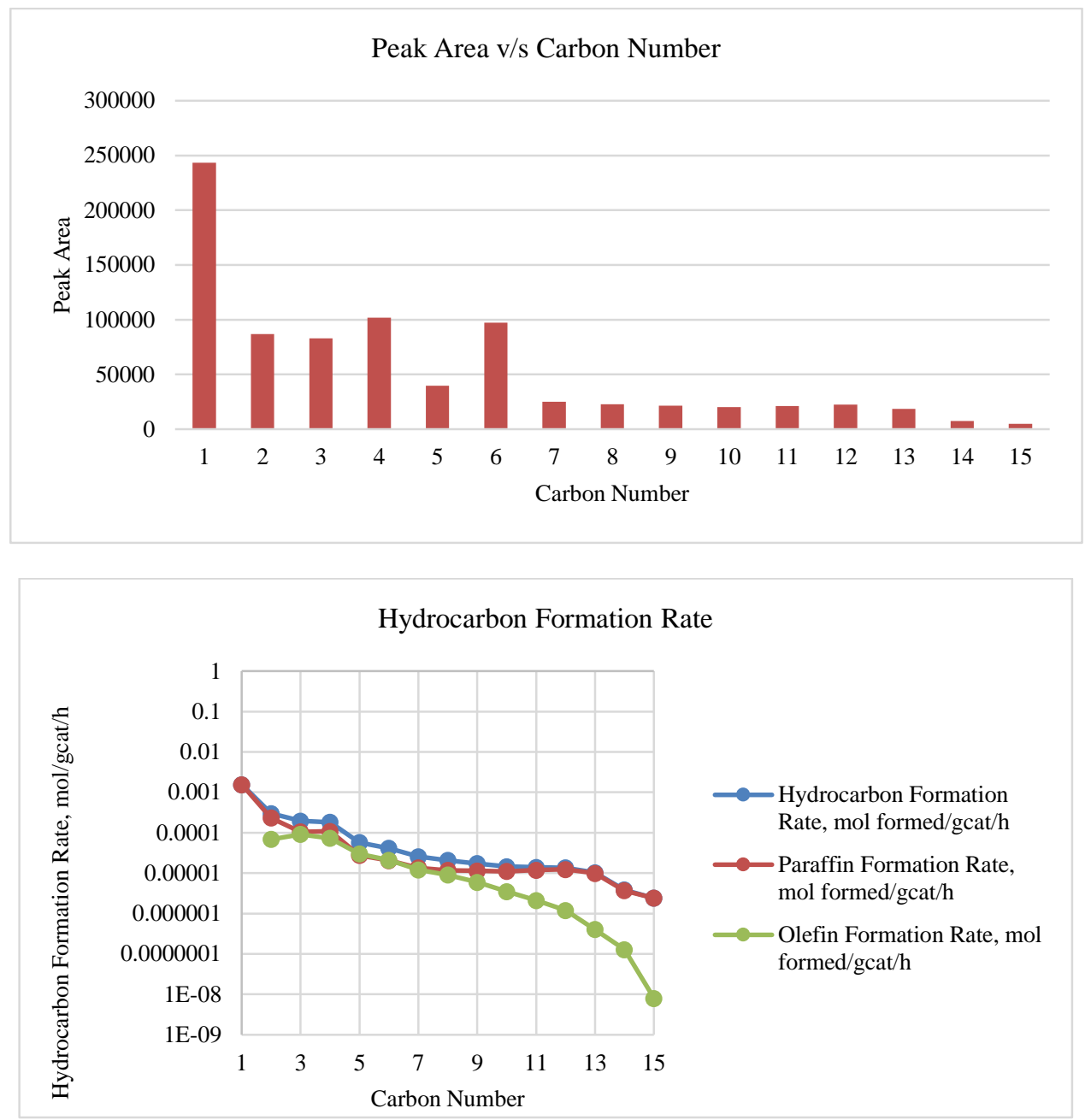

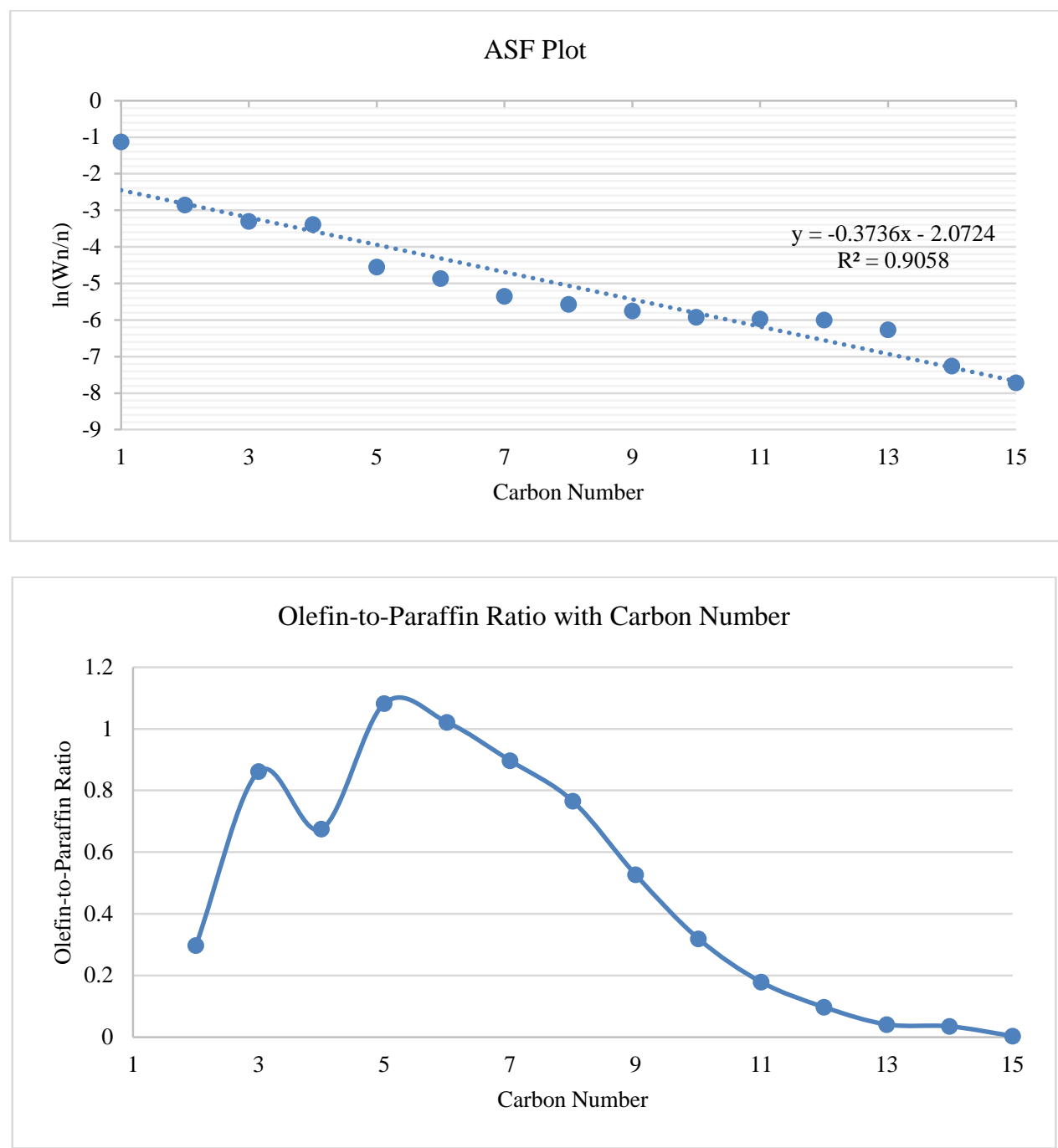


\section{Run No. 5}

Syngas Flow $36.84 \mathrm{NmL} / \mathrm{min}, \mathrm{H}_{2} / \mathrm{CO}$ ratio $0.65: 1$, Bed Temperature $220^{\circ} \mathrm{C}$, CO Conversion $5.25 \%$
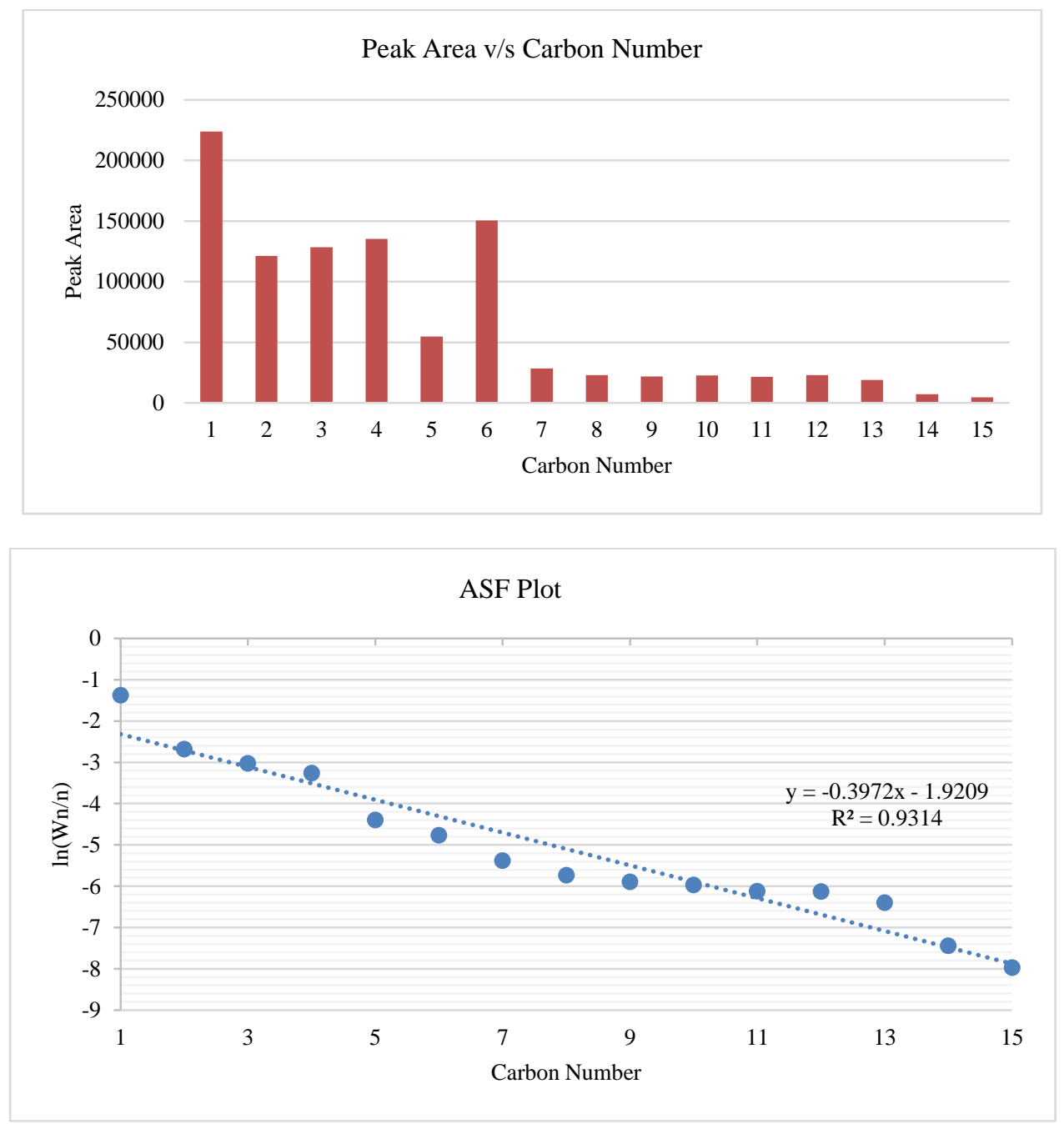

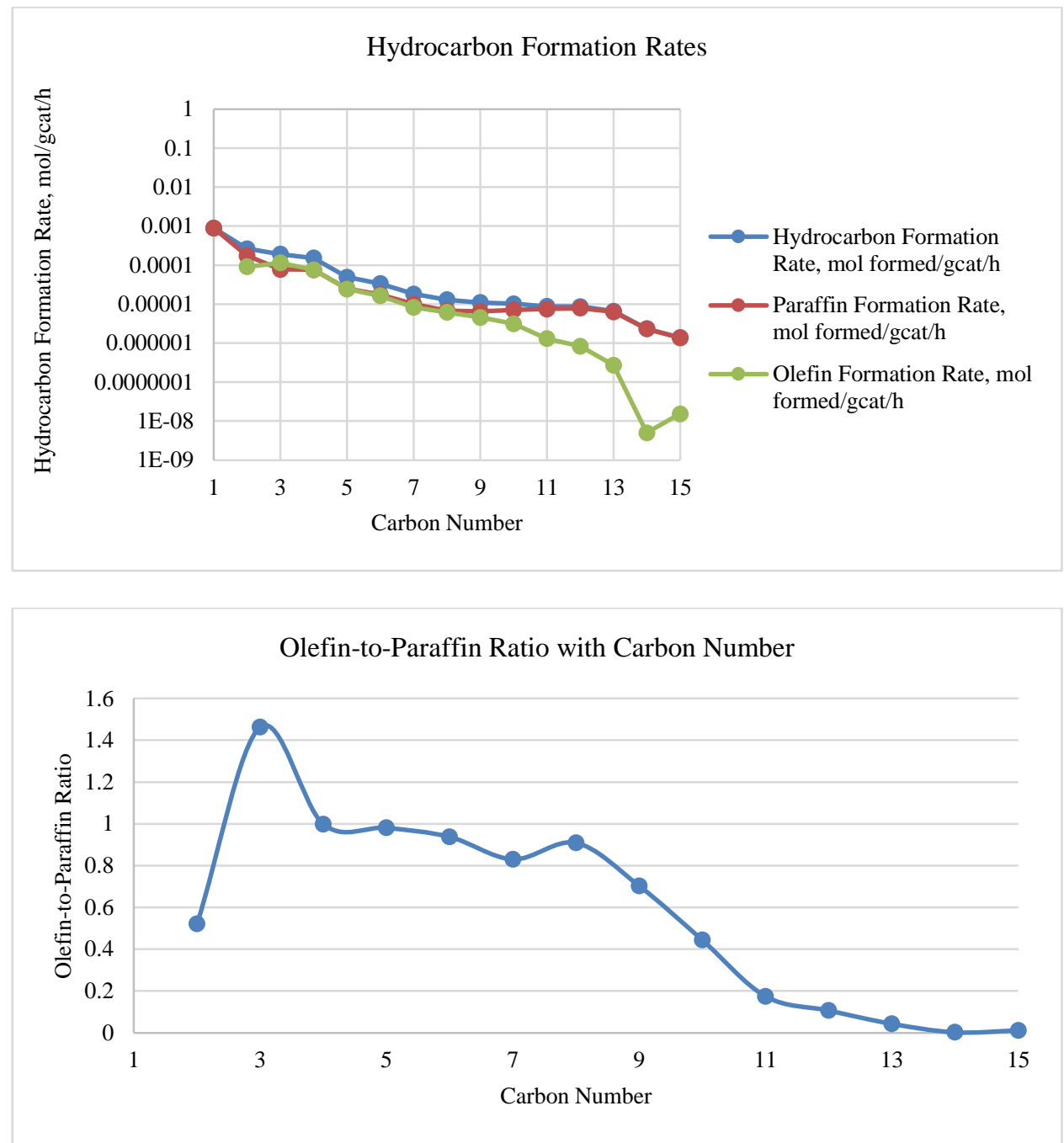


\section{$\underline{\text { Run No. } 6}$}

\section{Syngas Flow $54.43 \mathrm{NmL} / \mathrm{min}, \mathrm{H}_{2} / \mathrm{CO}$ ratio $0.63: 1$, Bed Temperature $220^{\circ} \mathrm{C}$, CO Conversion}

$2.57 \%$
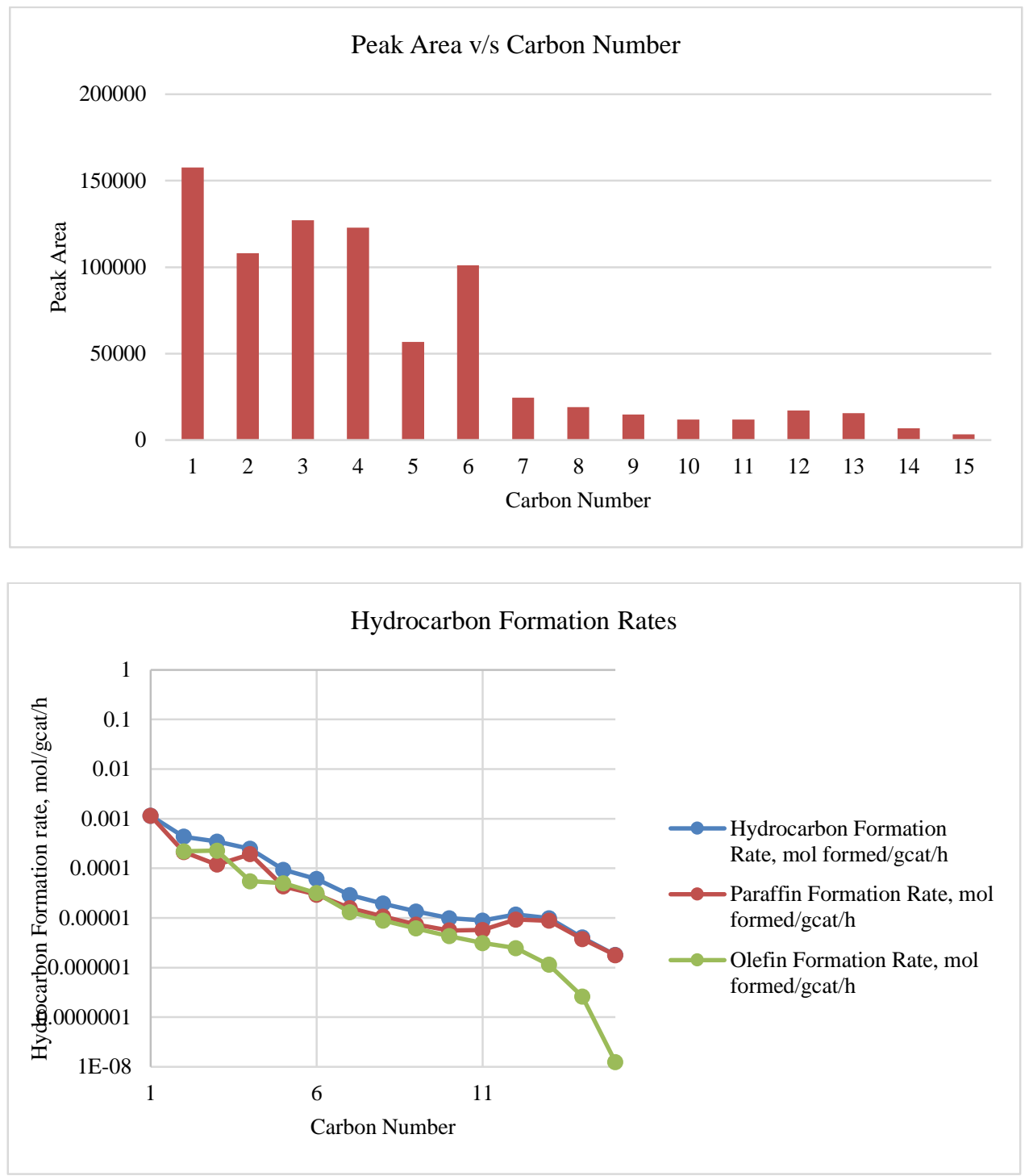

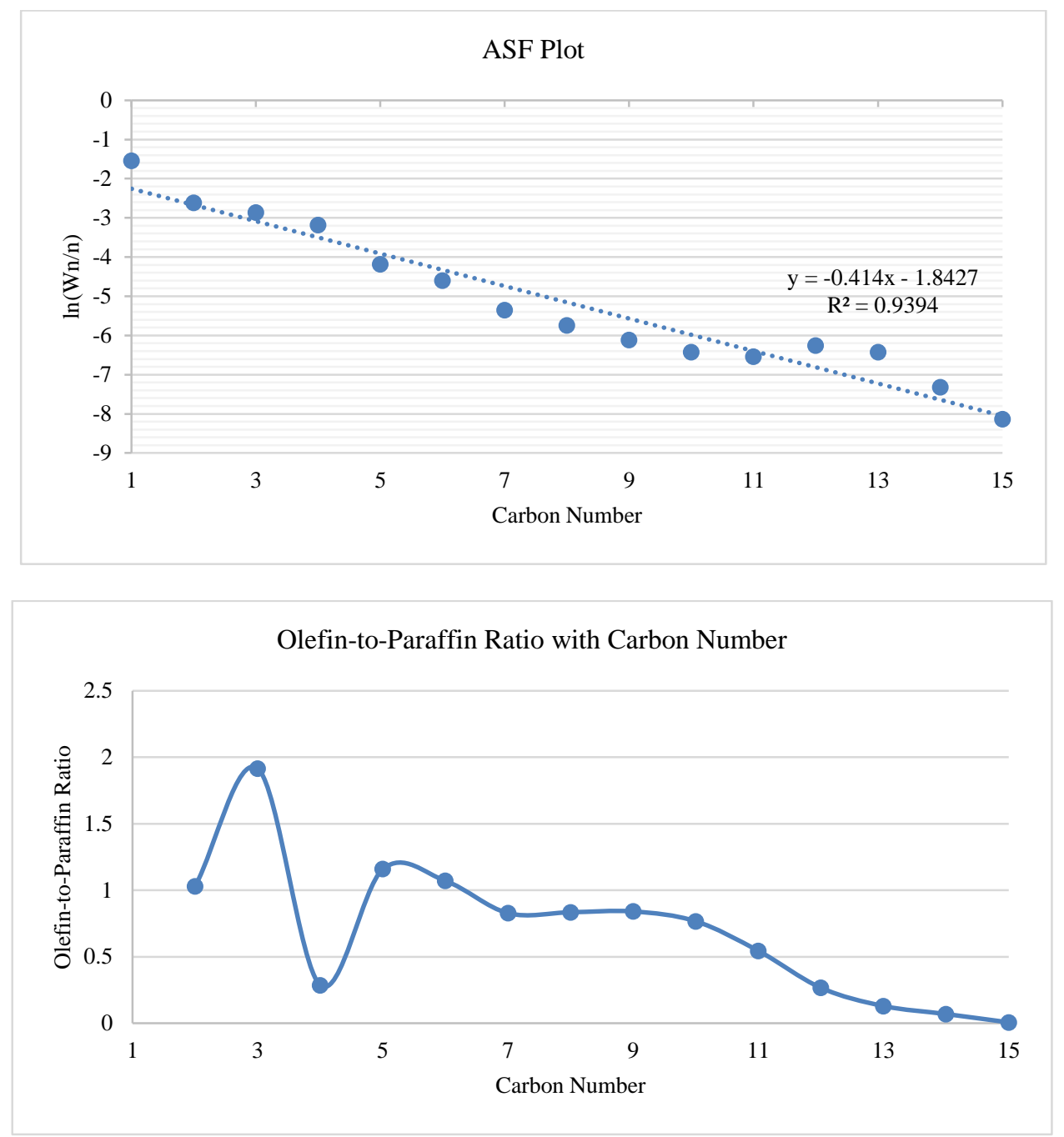


\section{Run No. 7}

Syngas Flow $50 \mathrm{NmL} / \mathrm{min}, \mathrm{H}_{2} / \mathrm{CO}$ ratio $2: 1$, Bed Temperature $230{ }^{\circ} \mathrm{C}$, CO Conversion $10.99 \%$
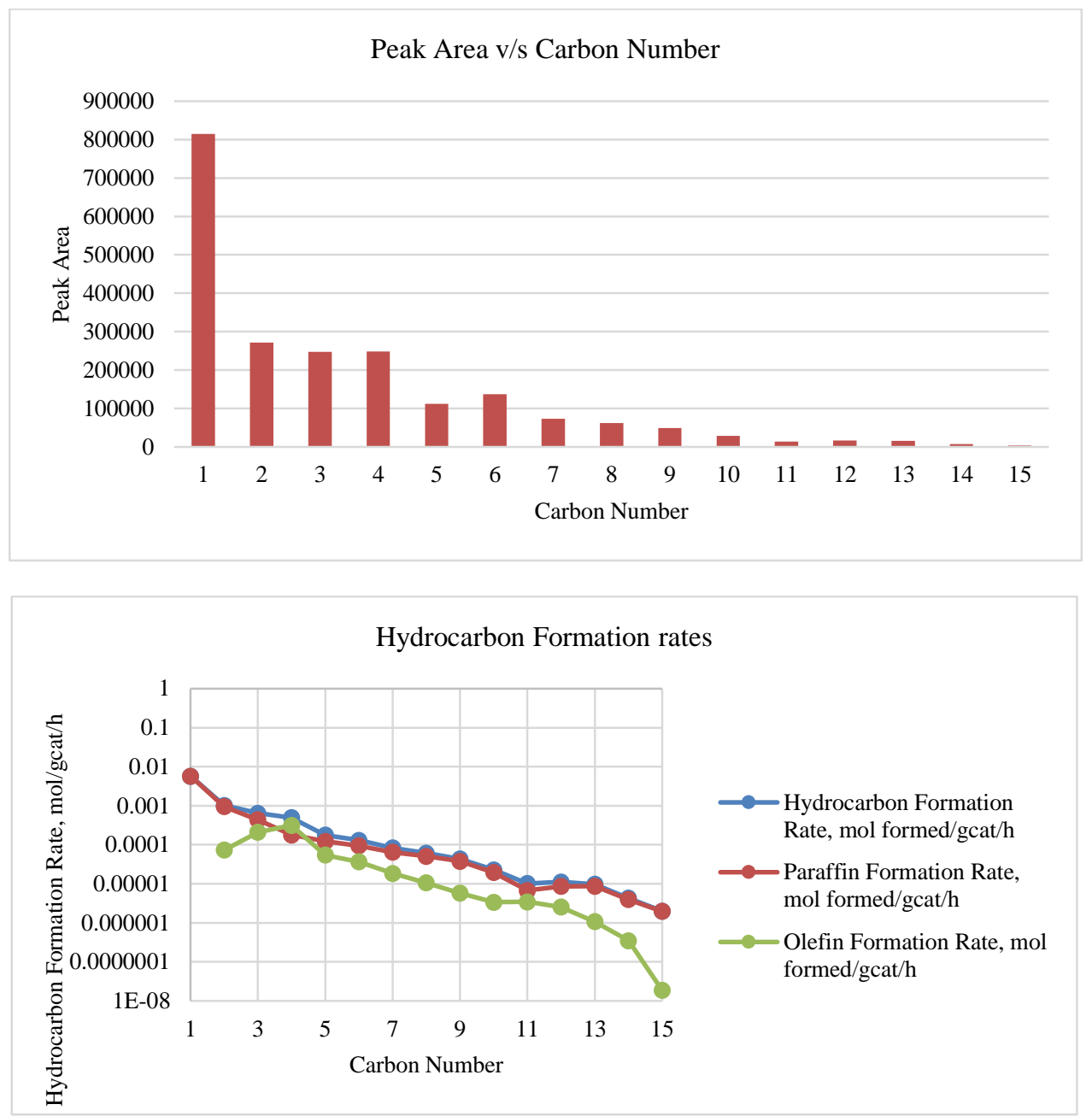

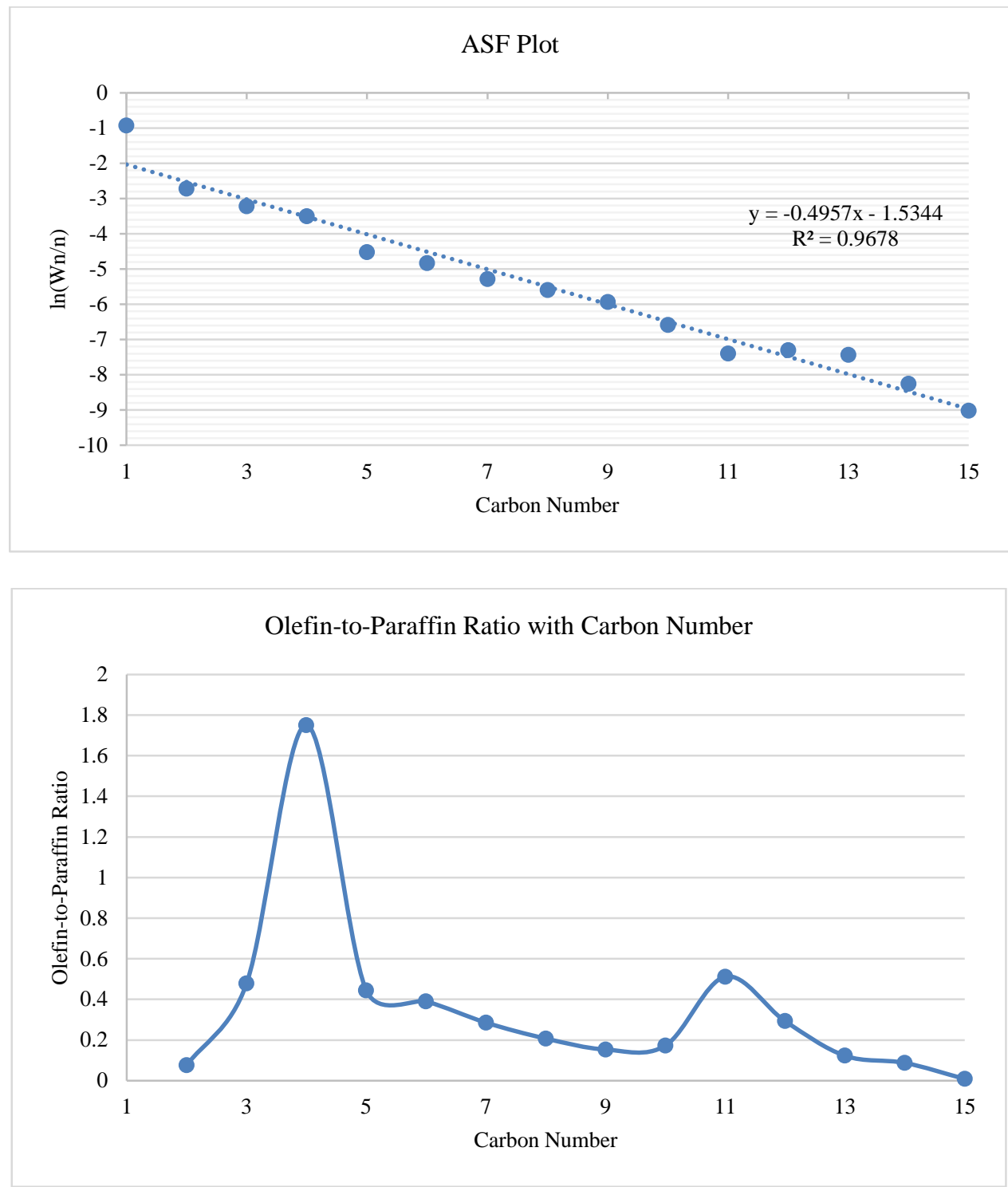